\title{
Assessing the Local Wind Field at Sierra Grande Mountain in New Mexico with Instrumentation
}

K. M. Barnett

R. D. Reynolds

Physical Science Laboratory New Mexico State University

Box 3-PSL, Las Cruces, New Mexico 88003

May 1981

Prepared for

Pacific Northwest Laboratory

Under Agreement B-23453-A-H

Pacific Northwest Laboratory

Operated for the U.S. Department of Energy

by Battelle Memorial Institute 


\title{
NOTICE
}

This report was prepared as an account of work sponsored by the United States Government. Neither the United States nor the Department of Energy, nor any of their employees, nor any of their contractors, subcontractors, or the,r employees, makes any warranty, express or implied, or assumes any legal liability or responsibility for the accuracy, completeness or usefulness of any information, apparatus, product or process disclosed, or represents that its use would not infringe privately owned rights.

The views, opinions and conclusions contained in this report are those of the contractor and do not necessarily represent those of the United States Government or the United States Department of Energy.

\author{
PACIFIC NORTHWEST LABORATORY \\ operated by \\ BATTELLE \\ for the \\ UNITED STATES DEPARTMENT OF ENERGY \\ Under Contract DE-AC06-76RLO 1830
}

\author{
Printed in the United States of America \\ Available from \\ National Technical Information Service \\ United States Department of Commerce \\ 5285 Port Royal Road \\ Springfield, Virginia 22151
}

Price: Printed Copy \$ * Microtiche $\$ 3.00$

$\begin{array}{lr}\text { •Pages } & \text { Selling Price } \\ 001-025 & \$ 4.00 \\ 026-050 & \$ 4.50 \\ 051-075 & \$ 5.25 \\ 076-100 & \$ 6.00 \\ 101-125 & \$ 6.50 \\ 126-150 & \$ 7.25 \\ 151-175 & \$ 8.00 \\ 176-200 & \$ 9.00 \\ 201-225 & \$ 9.25 \\ 226-250 & \$ 9.50 \\ 251-275 & \$ 10.75 \\ 276-300 & \$ 11.00\end{array}$




\section{1}

ASSESSING THE LOCAL WIND FIELD AT SIERRA GRANDE MOUNTAIN IN NEW MEXICO WITH INSTRUMENTATION

K. M. Barnett

R. D. Reynolds

Physical Science Laboratory New Mexico State University

Box 3-PSL, Las Cruces, New Mexico 88003

May 1981

Prepared for Pacific Northwest Laboratory Under Agreement B-23453-A-H

Pacific Northwest Laboratory Richland, Washington 99352 


\section{ACKNOWLEDGEMENTS}

Tom Hiester, Pacific Northwest Laboratory, for his close cooperation and constructive criticism.

Harold Connell, Manager, Instrumentation Division, Physical Science Laboratory (PSI), for his assistance in administration and management of the project.

Naomi Crum, PSL Contract Administrator, for assistance in negotiating the contract and keeping fiscal information.

George Fugate, PSL, Meteorological Technician, for his ceaseless efforts in data gathering and problem solving.

Eddie Ferguson, PSL Mechanical Technician, for his design and fabrication of the field support equipment, and for his work in installing them.

Robert Wagner and Harold Shaw, PSL, Electronic Engineers, for their design and fabrication of the moduprinter and computer buffer.

James Basler, PSL Programmer, for his excellent programming work and helpful suggestions.

Dick Kennedy, Rancher, Des Moines, N.M., for his cooperation and help in obtaining the land use of the sites on Sierra Grande.

D. E. Carter, Manager, Southwestern Electric Coop., Inc., Clayton, N.M., for his help in installing and removing the four 10-m telephone poles on Sierra Grande.

William Engle and Arved Placks, Boeing Engineering and Construction Company, Seattle, WA, for their help in calculations concerning the new MOD-2 wind generator system. 


\section{EXECUTIVE SUMMARY}

The primary audience intended for this report is electric utility engineers and meteorologists who wish to find the best location for large wind energy conversion systems (WECS) at mountainous sites where the wind energy potential is already considered good by vegetation indications, preliminary wind measurements, physical modeling, numerical modeling, or by other indications. It is assumed that the sites would be ranked by the amount of their mean annual wind power density and that velocity variability characteristics would be an important secondary factor. No account is taken here of the important non-wind factors of accessibility, installation costs, nearness to existing power lines, etc.

An assessment was made of the concept to directly measure wind speed and direction at several spots on a mountain to obtain data for deciding on a WECS location. An evaluation was made of the methodology by operating a specific type of wind measuring system for 6 months.

Six systems were installed on top of Sierra Grande, a nearly symmetrical mountain in New Mexico about halfway between Raton and Clayton, with a peak of $2659 \mathrm{~m}$ (8720 ft msl) standing over a wide mesa of approximately $1829 \mathrm{~m}$ (6000 ft ms 1 ). See Figure 1. Two systems were on the peak, one at $10 \mathrm{~m}$ (33 ft) above the surface and the other at $20 \mathrm{~m}(66 \mathrm{ft})$ because the peak is often the most probable spot for the greatest wind energy. The two levels were needed to measure variations of speed with height. Four other systems with instruments at $10-\mathrm{m}$ (33 ft) were located roughly north, east, south, and west from the center on secondary ridge lines to measure certain horizontal variations of the wind. These four were within 110 to $230 \mathrm{~m}$ of the center to encompass a radius of 1 to 2.5 diameters of a large WECS - a minimum area to be dedicated to a single large WECS. The wind direction and speed were measured every 6 minutes, a time interval considerably shorter than the traditional 1 hour but long enough so that all WECS power outputs are expected to respond to these wind speed variations. All six systems were operated for a period of six months between 6 June 1979 - 5 December 1979. 
: "in toms

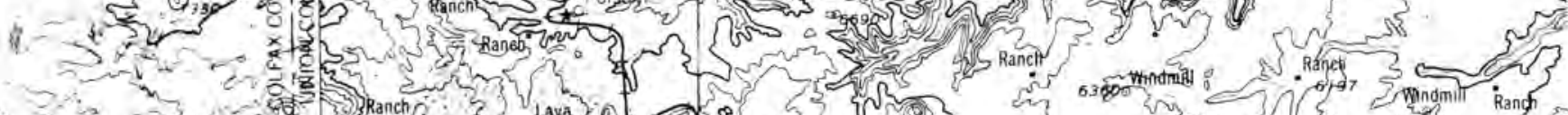
25

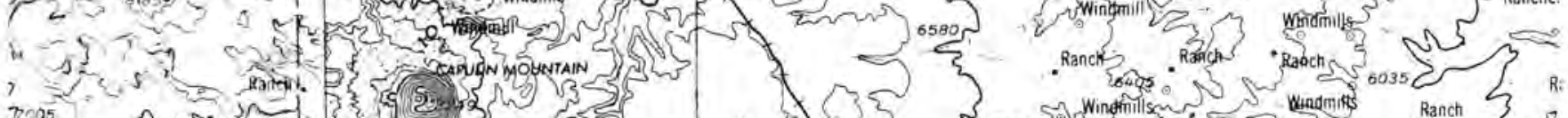

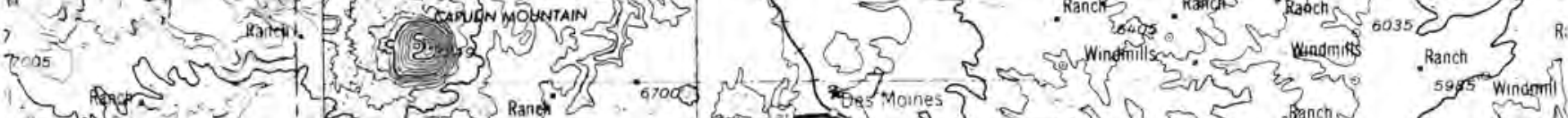
cunster

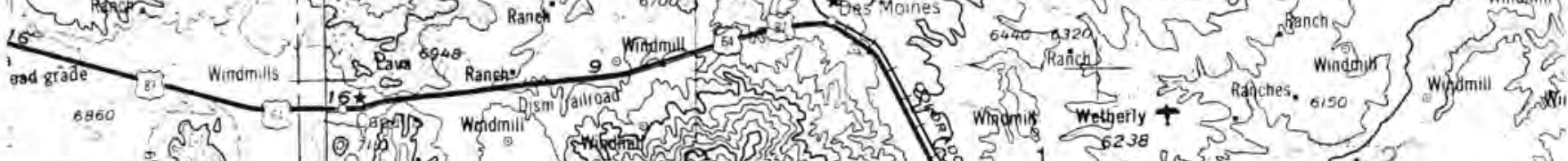
C.

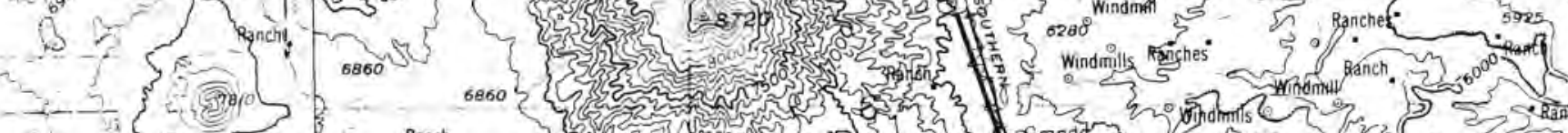

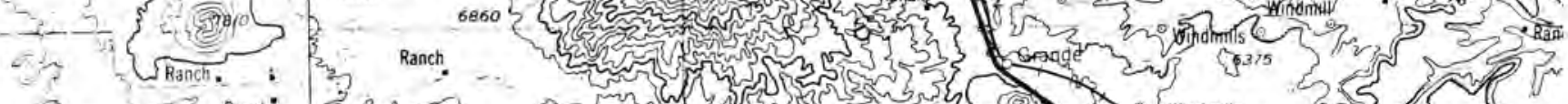

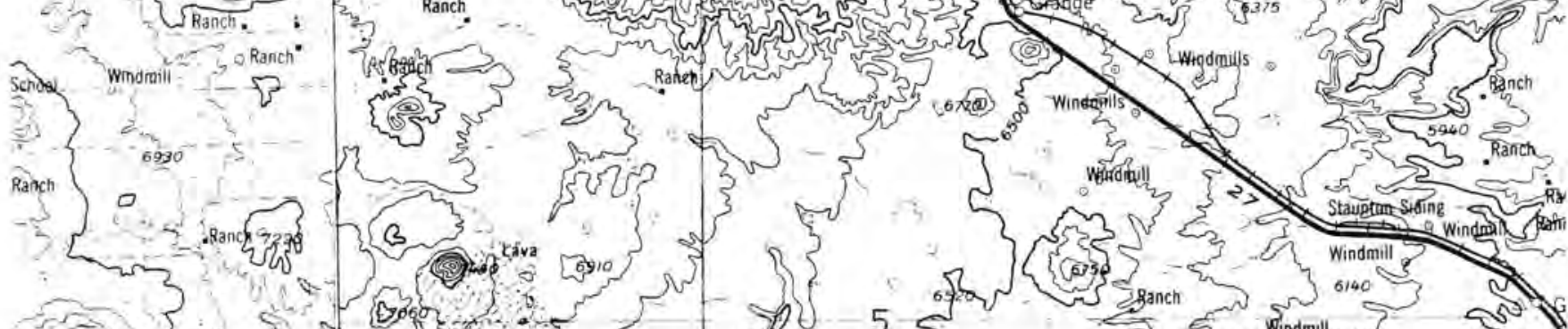
(3)

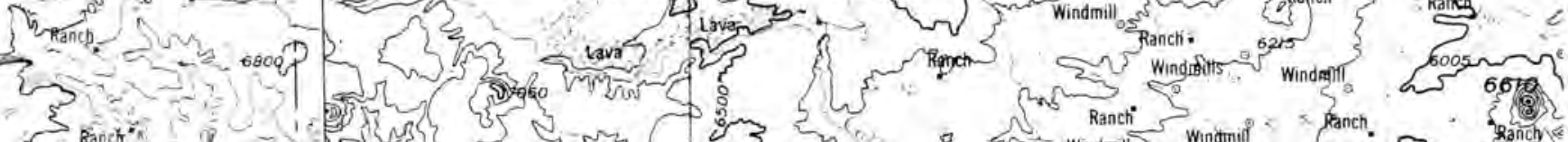
5 . 5 anct

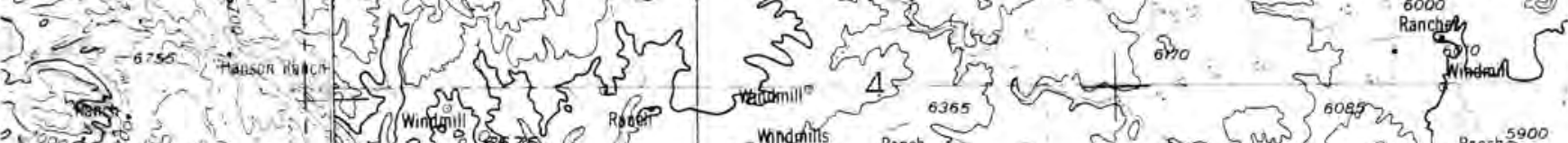

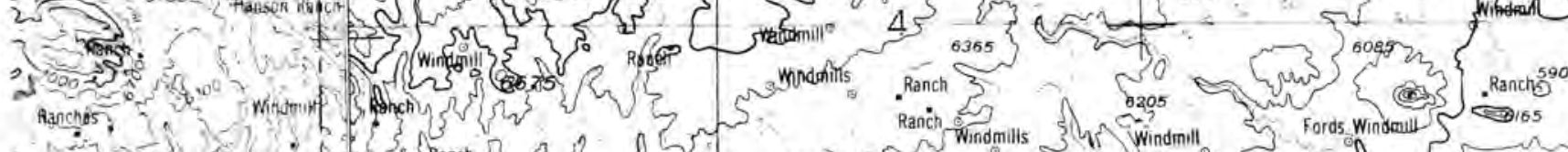
Wingmit Scale $1: 250,000$

10

$10 \quad 15$ 20 Statute Miles

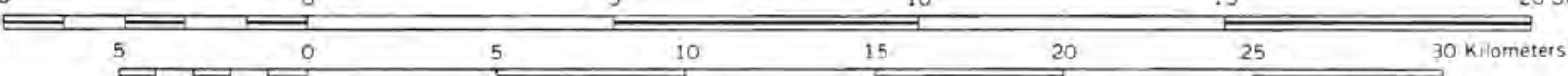

0

CONTOUR INTERVAL 100 FEET

WITH SUPPLEMENTARY CONTOURS AT 50 FOOT INTERVALS

Figure 1. Genera1 Area of Sierra Grande 
The wind-observing and recording system used was the Wind Data Logger, Model A60, built by the Natural Power, Inc. (a) with a Memodyne ${ }^{(b)}$ Reader Model 3122 BV. The mean wind speed and the instantaneous wind direction was measured every 6 minutes and recorded on a cassette magnetic tape. The entire system operated on small batteries. The batteries and tapes were replaced monthly. The tapes were brought to the Physical Science Laboratory (PSL) for computer processing of the data. Data loggers with timing capability are required to analyze the temporal flow over a mountain and to depict the diurnal flow.

The major problems encountered were:

1. Obtaining accurate wind data at hub heights of large WECS, 30 to $60 \mathrm{~m}$ above the ground was the most difficult problem. Towers of that height are very expensive. The extrapolation of wind speeds from anemometers on available towers, near $10 \mathrm{~m}$, upward to 30 or $60 \mathrm{~m}$ is likely to be inaccurate in mountainous areas. No practical, inexpensive solution is apparent.

2. The cassette tape data reader was not compatible with our IBM 370 computer used to reduce the data; a dedicated computer or minicomputer is required or else data cassette conversion to 9-track computer should be available from the manufacturer at a nominal cost.

3. Calibration checks of the system were difficult both in a wind tunnel and in the field. The field difficulties were mostly overcome by Natural Power's development of new field test units.

4. Direction data were difficult to record due to direction head malfunctions; speed data were recorded easily. More detailed direction measurements, to approximately every 10 degrees, are needed to calculate WECS yaw control limits which would automatically stop the WECS operation.

5. The three-cup anemometers were not sturdy enough under some icing and wind conditions. They should be redesigned for more structural integrity.

(a) Natural Power, Inc., Francestown Turnpike, New Boston, NH 03070

(b) Memodyne, 220-T Reservoir St., Needham, MA 02194 
6. The wind vanes were not rugged enough and should have a much slower response to damp gusty wind directions.

7. The timing on taped data was not consistent between the six systems. This problem was not successfully isolated - it may be in the realtime clock, in the cassette recorder's recording mechanism, or due to thunderstorm's influence on the electrical circuits in the data logger.

8. The long distance between the investigators and the site, 450 miles, created significant personnel scheduling problems, over and above the travel costs.

The major results were:

1. The wind speed change with height from the 10- to 20-m levels on the central tower varied considerably and appeared to be a function of speed magnitude, direction, and time of day.

2. For $10-m$ towers, the use of wooden poles was the least expensive, about one order of magnitude cheaper than the erection of $10-\mathrm{m}$ metal towers on cement bases. Taller towers become much more expensive to install. The expense of erecting towers to hub heights of $30 \mathrm{~m}$ to $60 \mathrm{~m}$ in remote mountain locations may be very large.

3. The methodology of instrumenting an isolated peak and leaving the equipment unattended for a month at a time proved feasible.

4. The wind-measuring equipment, after recommended improvements, should prove to be a cost-effective way to obtain wind data for proposed WECS sites, except for the uncertainties of extrapolating wind conditions to a higher altitude in mountainous areas.

5. This type of equipment manufacturing is a very competitive field so better equipment and even a relative decrease in cost should be expected. 
6. Difficulties with direction sensors and timing devices did not allow any significant use of the time series capabilities of the four sensors surrounding the peak to study WECS stoppage due to yaw error, wind shear or convergence.

7. The maximum mean wind speed for six months (6 June - 5 December) was $18.8 \mathrm{mph}$ at $10 \mathrm{~m}$ with a mean power density of $542 \mathrm{~W} / \mathrm{m}^{2}$. The estimated annual values are $19.7 \mathrm{mph}$ and $680 \mathrm{~W} / \mathrm{m}^{2}$, respectively.

8. During this six-month investigation the peak of the mountain did not provide the greatest wind energy. A slightly greater maximum, about $11 \%$ more, was east of the peak.

9. The winds over Sierra Grande had a diurnal maximum at night, usually between 2 and 4 a.m.

10. The estimated energy output of a MOD-2, if installed at the peak, for 6 months ( 6 June - 5 Dec) was calculated to be $4.5 \times 10^{6} \mathrm{kwh}$. This assumed that the wind increased above $20 \mathrm{~m}$ by the $1 / 7$ power law.

Recommendations to proposed users of this methodology or equipment:

1. Wind measurements every two minutes with direction to the nearest 10 degrees are needed at hub height for a year to calculate an accurate estimate of the annual energy output to be expected from a large WECS in mountainous areas. These data are needed to calculate outages due to speed and direction variations.

2. The distance between the investigator and the site should be minimized as much as possible to decrease personnel scheduling problems and travel expenses.

3. The instrumentation should have a reader that will put data from the cassette tape directly into any standard computer; the anemometers 
need to be stronger; the wind vanes need to be stronger and with a much slower response time.

4. Exact synchronization of two or more observations on one tower should be manditory so that calculations of $k$ are possible and realistic.

5. Sierra Grande should be seriously considered as a location for a large WECS. Some locations slightly further from the peak should be investigated.

6. A study to find less expensive ways to put up 30-m or taller towers in remote areas is recommended.

7. It is recommended for any future operation that a dedicated minicomputer for field tests be mated to the reader if a simple reduction and associated program is needed. In the event that a more sophisticated program is desired, a reader mated to a Universal Asynchronous Receiver Transmitter (UART) would allow data from the RS 232 port to be fed into a large computer.

8. Towers $10 \mathrm{~m}$ high are much easier to install and should be used to compare the wind power density at different sites. 
ACKNOWLEDGEMENTS . . . . . . . . . . . . . . . . . . . . ii

EXECUTIVE SUMMARY . . . . . . . . . . . . . . . . . . . . . . . iii

INTRODUCTION . . . . . . . . . . . . . . . . . . . . . . . . 1

DISCUSSION . . . . . . . . . . . . . . . . . . 6

Site Selection . . . . . . . . . . . . . . . . . . 6

System Description . . . . . . . . . . . . . . . . . . 10

Equipment Tests and Problems . . . . . . . . . . . . . . . 13

Installation Techniques . . . . . . . . . . . . . . . 22

Data Collection . . . . . . . . . . . . . . . . . 26

Estimated Cost of Application . . . . . . . . . . . . . 36

Data Analysis . . . . . . . . . . . . . . . . . 37

Data Results . . . . . . . . . . . . . . . . . . 38

Estimate of a Large WECS Energy Output on Sierra Grande . . . . . 41

CONCLUSIONS . . . . . . . . . . . . . . . . . . . . . 42

RECOMMENDATIONS .......................... . . . 44

REFERENCES . . . . . . . . . . . . . . . . . . . . . . . 45

APPENDICES

A Buffer Interface ... . . . . . . . . . . . . . 47

B Letter From Natural Power . . . . . . . . . . . . . . . 51

C Tabulated Results of Wind, Power and Energy Measurements. . . . 54

D Moduprinter . . . . . . . . . . . . . . . . 78

E Error Analysis of Data Loggers . . . . . . . . . . . . 83

F Calculation of MOD-2 Energy . . . . . . . . . . . . . . 87

G Analysis of Selected Wind Conditions . . . . . . . . . . . . 95 
1. Contours of general area . . . . . . . . . . . . . . . iv

2. Contours of Sierra Grande and environs . . . . . . . . . . . . 2

3. Contours of Sierra Grande showing site locations. . . . . . . . . 3

4. Location of Stations . . . . . . . . . . . . . . . . . 4

5. View of Sierra Grande from the highway looking south. . . . . . . 7

6. The peak viewed from the north . . . . . . . . . . . . . 8

7. Closeup of a data logger .................. 11

8. Data logger in cold test chamber. . . . . . . . . . . . . . . 14

9. Natural Power's field reader . . . . . . . . . . . . 17

10. The sensor checker . . . . . . . . . . . . . . . . . . 18

11. Installing the wind equipment at the 10-m level on the peak of Sierra Grande....................... . 20

12. A power auger from the Southwestern Electric Coop, Inc. of Clayton was used to install four 10-m poles near the peak . . . . 21

13. A one-meter cross arm was bolted to the top of each 10-m pole. .......................... . . 23

14. An extra heavy lock clasp was welded on the Hoffman boxes for security of the data loggers. . . . . . . . . . . . . . . . . . 24

15. Special brackets were welded to the back of the Hoffman boxes for mounting on the four telephone poles. . . . . . . . . . 25

16. The minimoduprinter was fabricated in-house at PSL to be used with the reader for field testing the data tapes. . . . . . . . 29

17. Closeup of a wind direction sensor showing where the vane was broken off......................... 30

18. A second wind vane was broken almost in two by a combination of ice and wind. . . . . . . . . . . . . . . . . . 31

19. A regular speed head configuration is shown behind three anemometers that lost their heads in the October blizzard of 1979. . 33

20. The speed heads all popped off at the nipple where it was epoxied to the shaft. . . . . . . . . . . . . . . . . . . . 34

21. A cup head that had earlier blown off intact shows the hollow area around the nipple. . . . . . . . . . . . . . . 35 
Al. Logic Diagram of Buffer Interface • • • • • • • • • . 49

A2. Circuit Diagram of Buffer Interface . • • • • • • • . 50

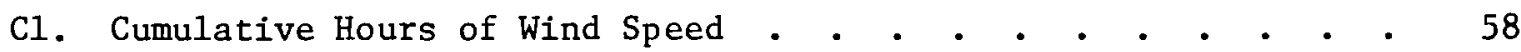

C2. Diurnal Wind Speed Variations at Station A (Center, $20 \mathrm{~m}$ ) . . 67

C3. Diurnal Wind Speed Variations at Station B (Center, $10 \mathrm{~m}$ ) . 68

C4. Diurnal Wind Speed Variations at Station C (North, $10 \mathrm{~m}$ ) . 69

C5. Diurnal Wind Speed Variations at Station D (West, $10 \mathrm{~m}$ ) • • 70

C6. Diurnal Wind Speed Variations at Station E (South, $10 \mathrm{~m}$ ) . . 71

C7. Diurnal Wind Speed Variations at Station F (East, $10 \mathrm{~m}$ ) . . 72

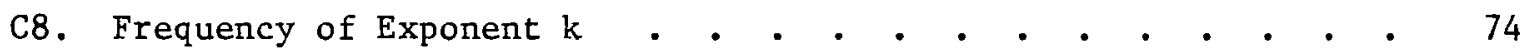

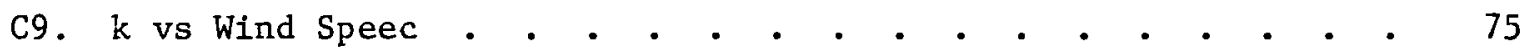

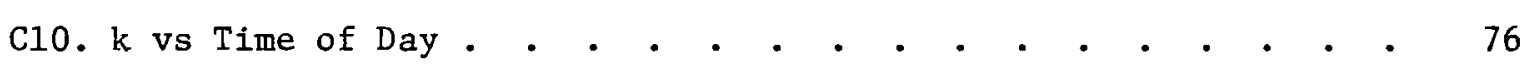

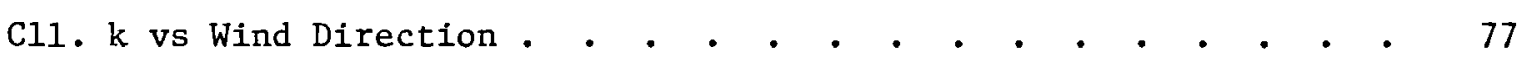

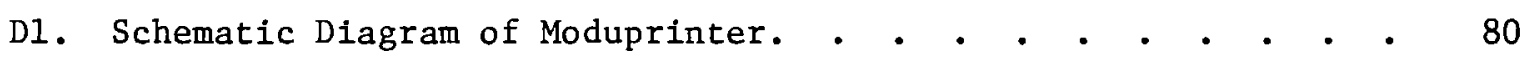

D2. Wiring List of Moduprinter. . . • . • • • • . . 81

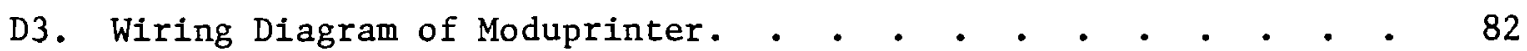

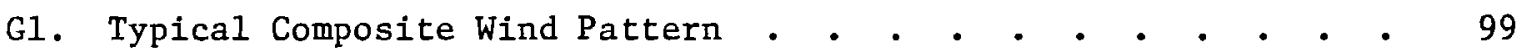




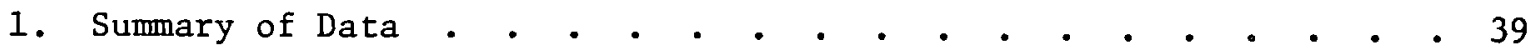

Cl. Sample Tabulation of Six Minute Observation . • • • • • • 56

C2. Summary of Wind Data, Power and Energy Calculations • • • • 57

C3. Wind Summary for Station A (Center, $20 \mathrm{~m}$ ) . . . . . . . . 60

C4. Wind Summary for Station B (Center, $10 \mathrm{~m}$ ). . . . . . . . . 61

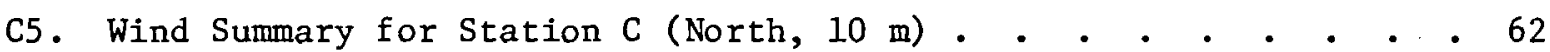

C6. Wind Summary for Station D (West, $10 \mathrm{~m}$ ) . . . . . . . . 63

C7. Wind Summary for Station E (South, $10 \mathrm{~m}$ ) . . . . . . . 64

C8. Wind Summary for Station F (East, $10 \mathrm{~m}$ ) . . . . . . . • . 65

E1. Logger Error Analysis • • • • • • • • • • • • • • 87 


\section{INTRODUCTION}

The selection of a site is an important decision when installing a wind energy conversion system (WECS). This is especially so in irregular or mountainous areas where the wind velocity and variability can be strongly influenced by terrain and ground cover. Concepts and methodologies are needed for assessing the wind characteristics in such areas. Several concepts are possible: observing wind effects on vegetation; remote sensing of wind conditions over the area; numerical or physical modeling of terrain effects; and direct measurements of the wind field. Each concept requires different methodologies and related equipment.

The concept of direct measurements of the wind field was investigated in this project. The equipment recorded wind speed and direction on magnetic tapes. Six sets of wind speed and direction sensors were installed on a mountain top, Sierra Grande, in northeastern New Mexico. Contours to different scales are shown in Figures 2 and 3. The mean wind speed and the instantaneous wind direction were recorded every 6 minutes on magnetic tape. Two sets of sensors were installed, one at $10-\mathrm{m}$ and one at $20-\mathrm{m}$ height on a tower at the top of Sierra Grande, $2659 \mathrm{~m}$ (8720 feet) msl. The other four were on wooden, electrical utility poles approximately $224 \mathrm{~m}$ (800 feet) horizontally in the north, east, south, and west directions. These four systems were all exposed at $10 \mathrm{~m}$ above the ground. The relative locations of the six systems are shown in Figure 4.

The recorded data were read into a computer and analyzed to give values of $\bar{v}$, the horizontal wind velocity (direction and speed), at each of the six locations. The systems were synchronized manually when tapes were replaced by starting each tape at increments of $6,12,18, \ldots$ etc. minutes apart. Therefore, each system recorded its wind velocity at the same time as the others. Wind speed was observed to the nearest $0.22 \mathrm{~m} / \mathrm{s}\left(\frac{1}{2} \mathrm{mph}\right)$ and the direction to eight points of the compass.

Values of wind speed at each of the locations can be used to calculate the accumulated wind energy over a period of days, weeks, or months to determine 


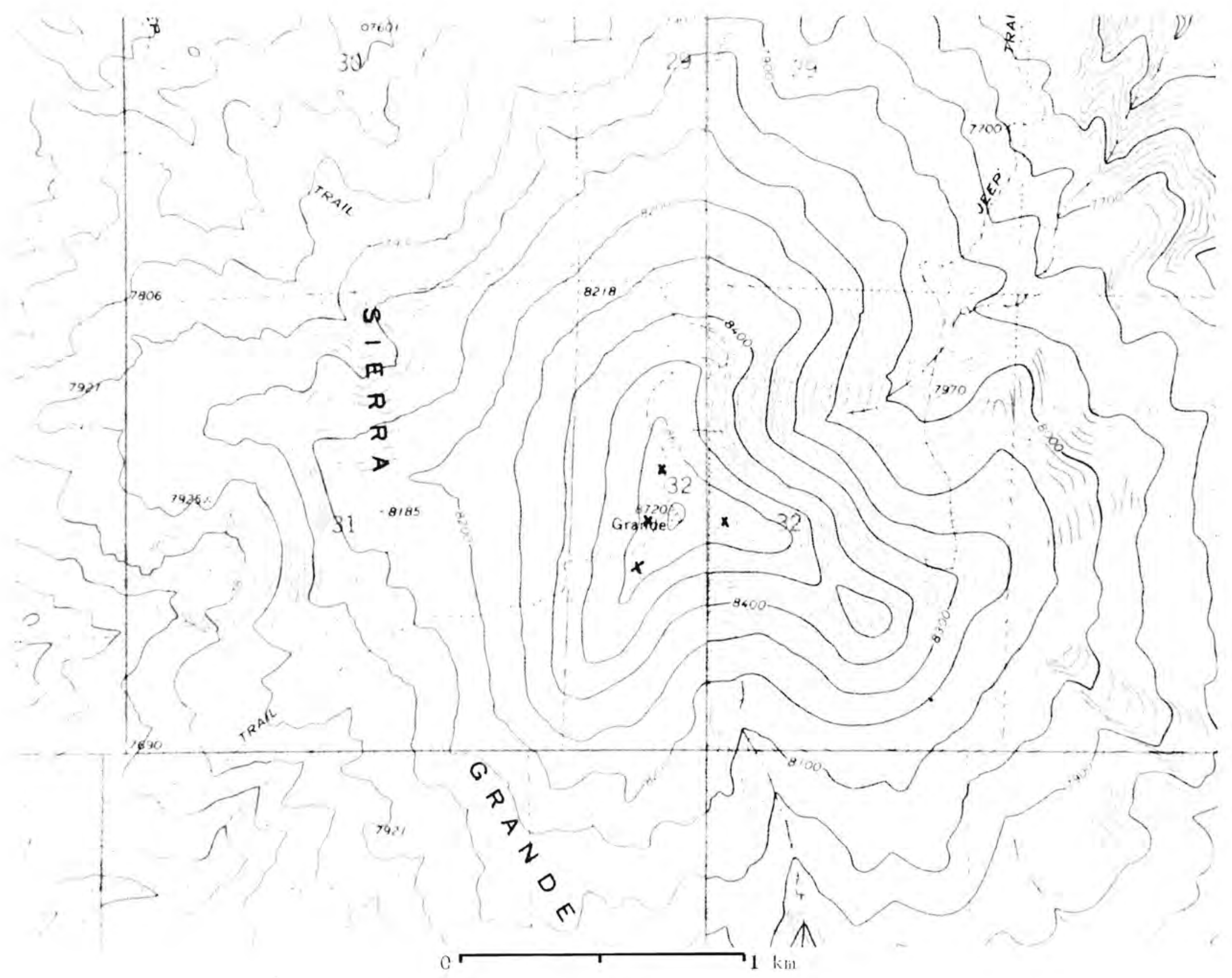

Figure 2. Contours of Sierra Grande and environs. 


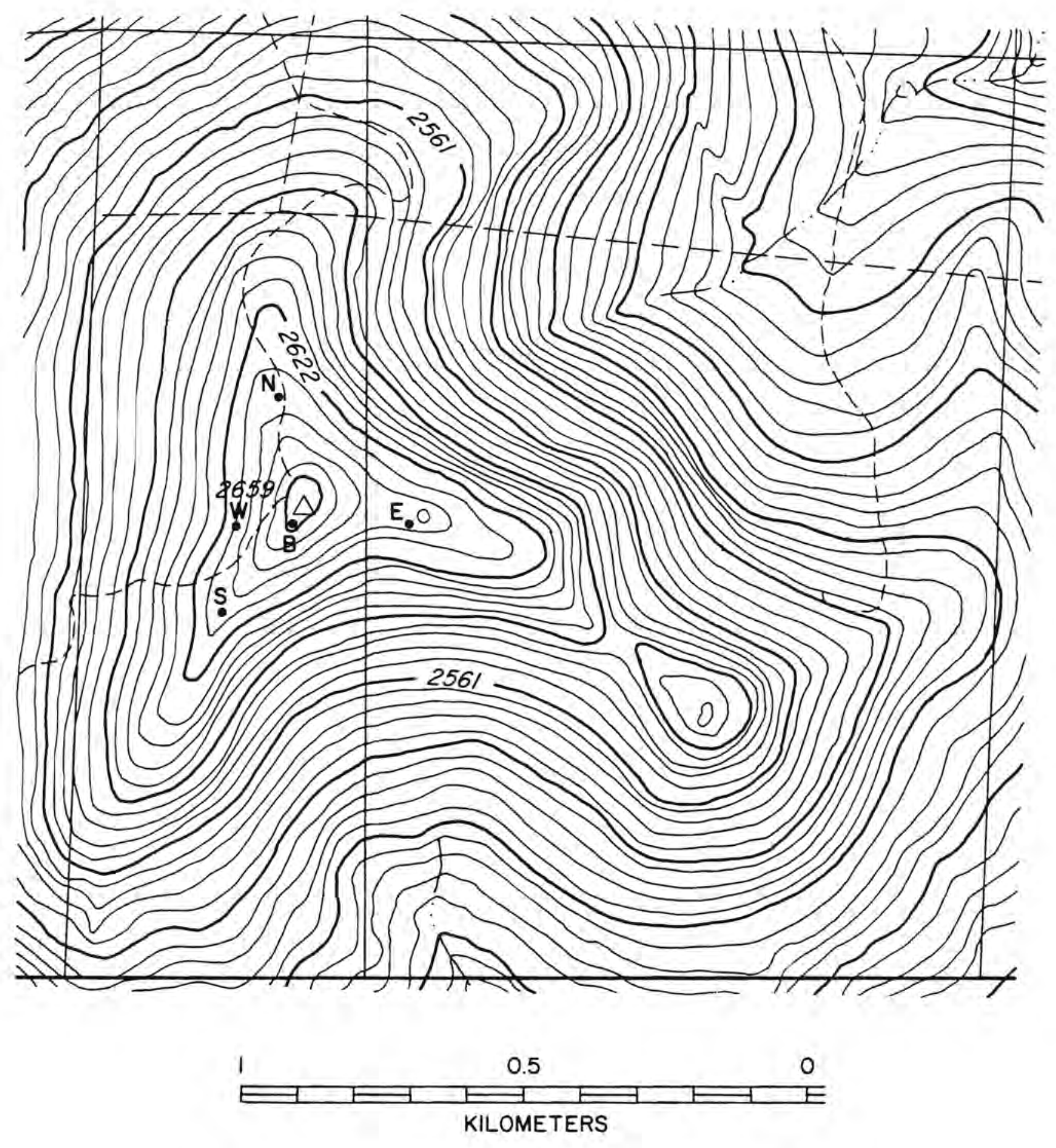

20 foot $(6.1 \mathrm{~m})$ Contours

Figure 3. Contours of Sierra Grande showing site locations. 
Figure 4. Location of Stations Relative to Central, Lower Station "B"

\begin{tabular}{|c|c|c|c|c|c|c|}
\hline \multicolumn{2}{|c|}{$\begin{array}{c}\text { Station } \\
\text { Designation }\end{array}$} & $\begin{array}{c}\text { Location } \\
X(E-W)\end{array}$ & $\mathrm{Y}(\mathrm{N}-\mathrm{S})$ & $\begin{array}{c}\text { Surface } \\
\mathrm{z}(\mathrm{a} l \mathrm{t}, \mathrm{ms} 1)\end{array}$ & $\begin{array}{l}\text { Azimuth } \\
\text { Deg from B }\end{array}$ & $\begin{array}{c}\text { Distance } \\
\text { from B }\end{array}$ \\
\hline$\overline{\mathrm{A}}$ & $\begin{array}{l}\text { Center } \\
20 \mathrm{~m} .\end{array}$ & $\frac{\mathrm{m} .}{0}$ & $\frac{\mathrm{m} .}{3 \mathrm{~N}}$ & $\frac{\mathrm{m} .}{2655}$ & $\overline{360^{\circ}}$ & $\frac{\mathrm{m} .}{3}$ \\
\hline B & $\begin{array}{l}\text { Center } \\
10 \mathrm{~m} .\end{array}$ & 0 & 0 & 2655 & 0 & 0 \\
\hline C & $\begin{array}{l}\text { North } \\
10 \mathrm{~m} .\end{array}$ & $-24 W$ & $+235 \mathrm{~N}$ & 2634 & $354^{\circ}$ & 236 \\
\hline D & $\begin{array}{l}\text { West } \\
10 \mathrm{~m} \text {. }\end{array}$ & $-110 \mathrm{~W}$ & $+2 \mathrm{~N}$ & 2631 & $271^{\circ}$ & 110 \\
\hline $\mathrm{E}$ & $\begin{array}{l}\text { South } \\
10 \mathrm{~m} .\end{array}$ & $-133 W$ & $-162 \mathrm{~S}$ & 2634 & $219^{\circ}$ & 210 \\
\hline$F$ & $\begin{array}{l}\text { East } \\
10 \mathrm{~m} .\end{array}$ & $+209 \mathrm{E}$ & $-2 \mathrm{~s}$ & 2640 & $091^{\circ}$ & 209 \\
\hline
\end{tabular}

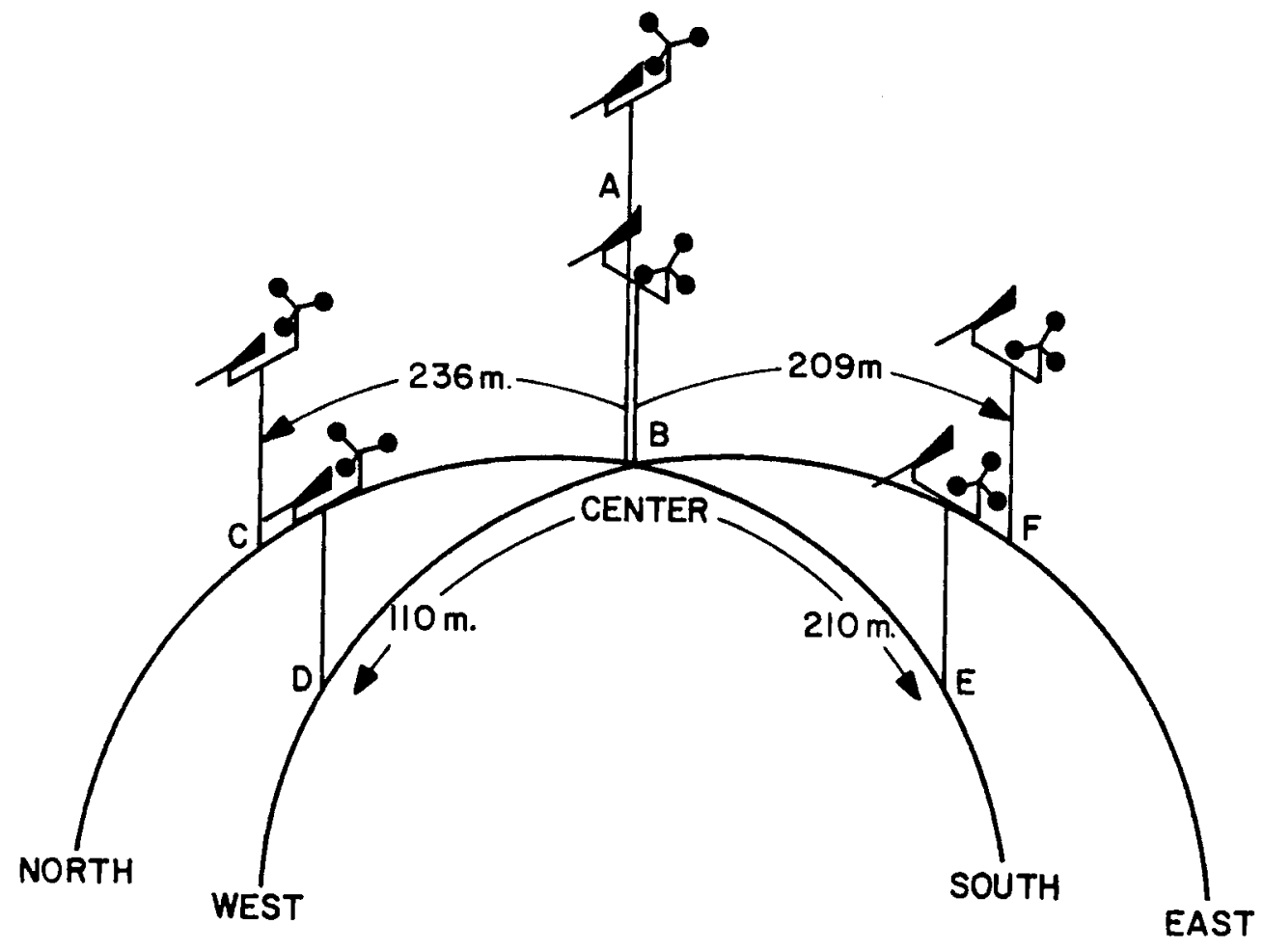


which location had the most wind energy and the most acceptable variabilities. In calculating these comparative rankings, the inclusion of density is not needed but it is important that each wind speed be cubed individually and multiplied by its time interval before being accumulated. For absolute values of energy, values of air density must be included. Density can be estimated by using mean temperature and pressure values from synoptic weather maps for each day, week or month and should be reasonably accurate. A review of the daily rawinsonde data at Albuquerque, Amarillo, and Denver for July 1978 and January 1979 showed that the estimated density variations for Sierra Grande should be within $\pm 2.2 \%$ of the monthly mean during July and $\pm 5.1 \%$ during January. The density variations are of the order of magnitude of the uncertainties in anemometer measurements. Pressure and temperature observations could be added and each individual density calculated, but at an increased cost and complexity of the system.

This system of several recording wind sensors represents a concept that can be used to assess the wind field in a mountainous area. The methodology of using this type of sensor and recorder was evaluated by actually installing and operating them for a period of approximately 6 months. All six systems were installed and put into operation between the period of 17 May to 6 June, 1979 . Data were collected until 5 December 1979.

Although in this assessment the systems were operated for only 6 months, we believe that in using this concept to pick a WECS location, the wind data should be collected for at least one whole year. 


\section{DISCUSSION}

\section{SITE SELECTION}

Sierra Grande, in northeast New Mexico (Figure 5, Figure 6) was chosen as the site for this study for several reasons: It is an isolated peak; Sierra Grande is a nearly symmetrical mountain that juts some $800 \mathrm{~m}$ (2625 ft) above the New Mexico plains. It is the easternmost dominant mountain in the foothills of the New Mexico Rocky Mountains, only 64 kilometers (40 miles) northwest of Clayton; the mountain is strongly influenced by the major wind maximum near the center of the nation located over the Texas Panhandle and its quintuplet of adjoining states. Sierra Grande has very little vegetation near its top, mostly weeds and low scrub brush less than $1 \mathrm{~m}$ high. The nearest mountain to the prevailing windward, or west, side of Sierra Grande is 30 kilometers away, and only 30 meters taller, thus giving Sierra Grande an essentially unobstructed wind flow.

A previous wind energy survey sponsored by the Energy and Minerals Department of the State of New Mexico showed a mean wind speed, measured at $28 \mathrm{~m}$ (and adjusted to $10 \mathrm{~m}$ ) above the peak, of $19.8 \mathrm{mph}$ in the late summer and fall of 1978. This established the area as a good candidate site. A tower already existed on the peak and belonged to the State of New Mexico.

The goal of applying this concept and methodology was to find the best location, at or near the peak, for one large WECS. This assumption indicated a radius of a few rotor diameters about the peak be used as the general area or "candidate site". If several WECS were to be located on the site an appropriately larger area would have to be considered. (Since the project started, the Program Opportunity Notice for Candidate Sites concerning the MOD-2 has recommended that distances of $2100 \mathrm{ft}$ along the prevailing wind and $1500 \mathrm{ft}$ laterally be kept between two MOD-2 WECS, or seven and five rotor diameters, respectively.)

With "a few rotor diameters" giving a first estimate of the area to be investigated, the terrain must then be considered. See Figures 2 and 3 for large scale contour maps. The peak was chosen for installing one wind measuring 


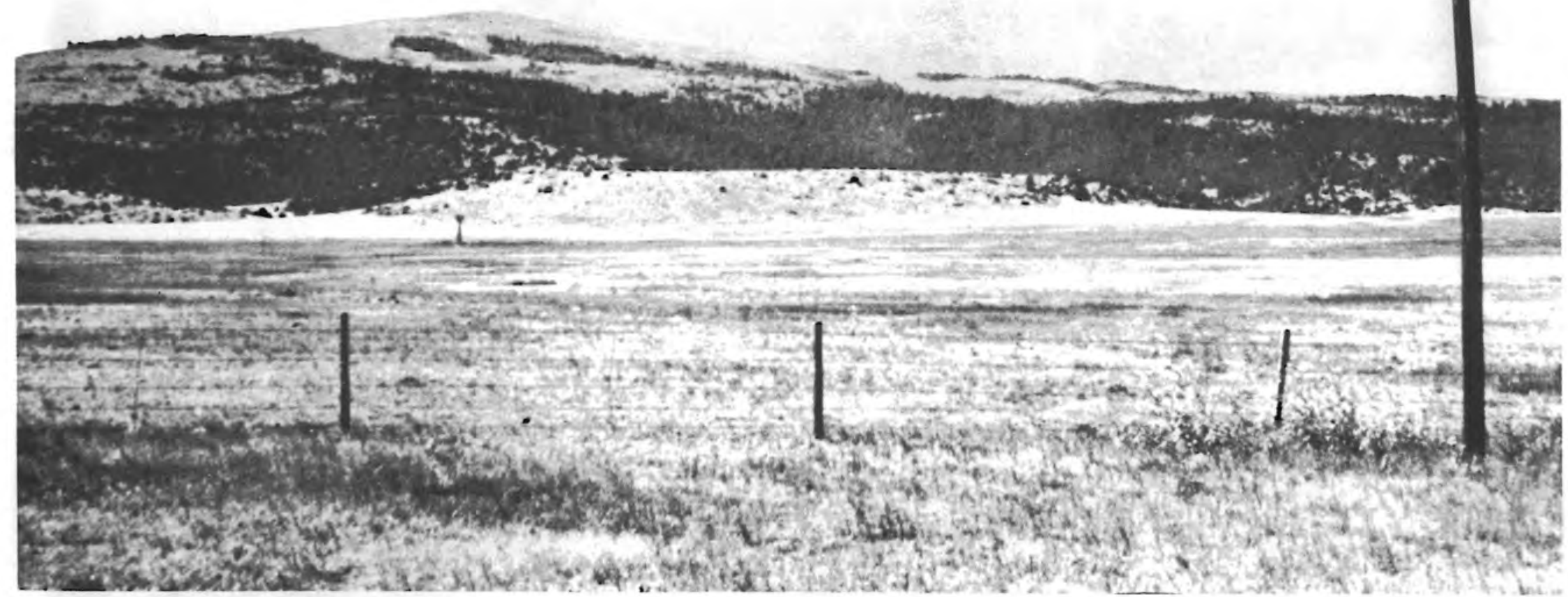




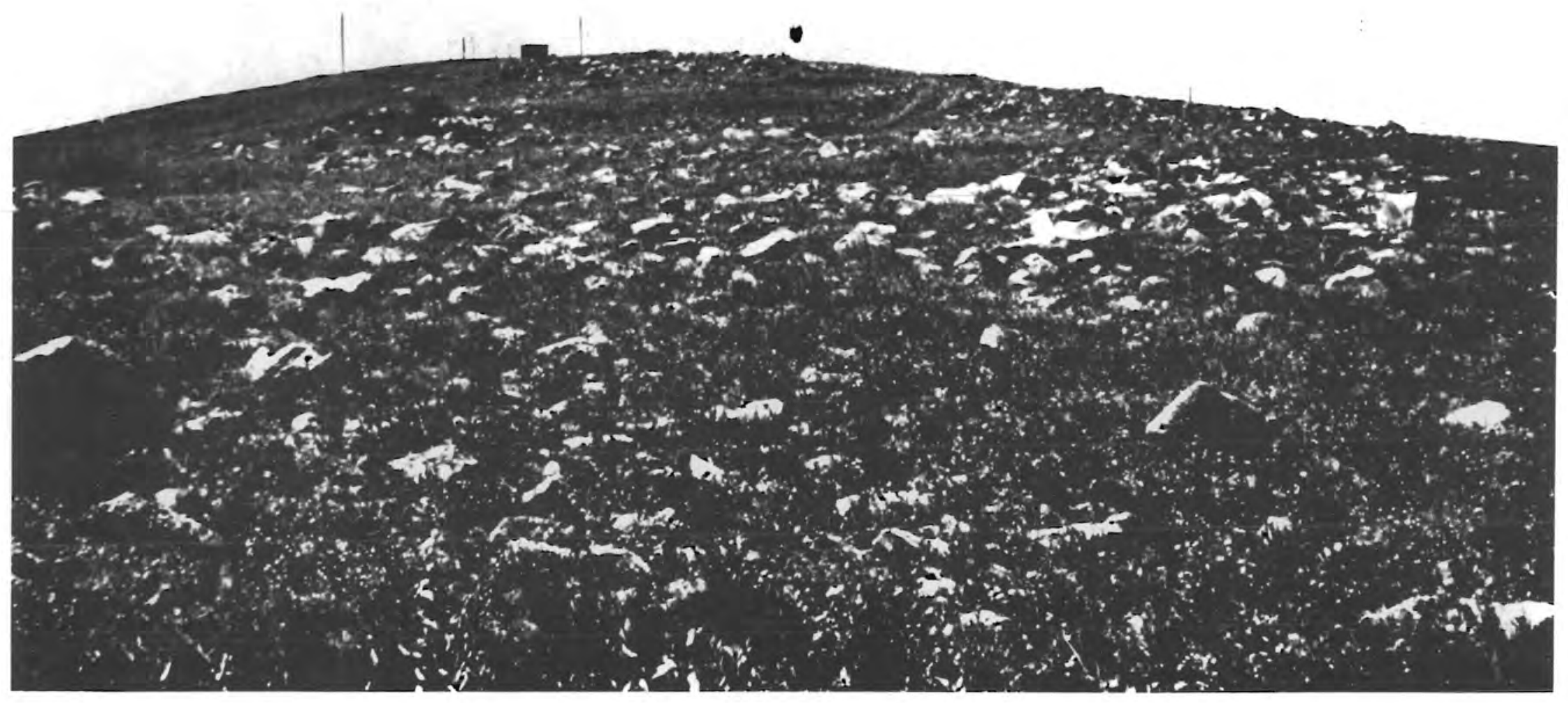

Figure 6. The peak viewed from the north. The Radio Communications Department of the State of New Mexico $28 \mathrm{~m}$. tower dominates the peak. 
system because a summit is often the location of strongest wind speed. A height of $10 \mathrm{~m}(33 \mathrm{ft}$ ) was used; first because $10 \mathrm{~m}$ is a recommended standard height, and second because $10 \mathrm{~m}$ is about the maximum height at which a tower can be installed without incurring rapidly increasing installation costs.

Although Sierra Grande is relatively symmetrical as an isolated peak, Figures 2 and 3 show that there are modest ridges, saddles and valleys near the peak. Hence, there are likely to be areas of speed enhancement which could not be measured at the peak. Figures 5.5 and 5.8 of the small WECS siting handbook (Wegley et al. 1980) are directly applicable to the area near the peak. According to Wegley the areas of maximum flow around an isolated mountain is "the upper half where the prevailing wind is tangent." We decided to test this hypothesis by placing two instruments on the peak with the other four sites orthogonal and at the cardinal points. We thought of using only wind data accumulators at the four outer sites but discarded that idea because of two reasons; we wanted to analyze the temporal flow of the wind over the peak, and the diurnal variation of the flow over the peak would be very important to a power company.

To determine the wind climatology for Sierra Grande, the best available information came from interpolations of mean monthly rawinsonde observations between Albuquerque, Amarillo and Denver at 750 and $700 \mathrm{mb}$ published by the National Oceanic and Atmospheric Administration (NOAA) in the monthly Climatological Data - National Summary. Sierra Grande has a mean air pressure of $738 \mathrm{mb}$, a mean density of $0.918 \mathrm{~kg} \mathrm{~m}^{-3}$, and is close to the middle of the triangle formed by the three cities. The following prevailing winds were estimated from mean monthly rawinsonde data tabulations:

$\begin{array}{lll}\text { Spring } & - & \text { west-southwest } \\ \text { Summer } & - & \text { southwest } \\ \text { Autumn } & - & \text { west } \\ \text { Winter } & - & \text { west-northwest }\end{array}$

In order to get some measurement of wind speed variation with height, a system was chosen to place two anemometers vertically on the peak. A 28-m permanent tower was already there. The feasibility of mounting this system at $28 \mathrm{~m}$ was 
abandoned as not being typical (due to tower costs) of what might be used subsequently on a peak with no tower. In retrospect, we believe we should have used this higher altitude, to be closer to the hub height of a large WECS.

Some of the actual system locations had to be varied because the wooden poles were put in place by a power auger on a utility truck. Because of the location of some rock formations, the auger could not operate at some selected sites, but they were placed as near as possible to the chosen points. The final locations were within 110 to $236 \mathrm{~m}$ of the peak, as shown in Figures 3 and 4 .

If more than one WECS location is needed, a repeat of the above rationale is recommended. The flatter the terrain the fewer measuring systems are needed and the further apart they can be. In more complicated terrain, more instruments closer together may be required.

The ideal arrangement would be to have all towers to WECS hub height and each tower with two or three wind measuring systems. However, such a project would be expensive. The frequency of observations should ideally be about every two minutes (the time a MOD-2 can go from no rotation to full rotational speed in winds dropping to $45 \mathrm{mph}$ ) and every $10^{\circ}$ of direction (because if the MOD-2 yaw error exceeds $20^{\circ}$ in 2 minutes, the machine is automatically shut down (Boeing 1979).

\section{SYSTEM DESCRIPTION}

The Natural Power A60 Wind Measurement Systems "data logger" employs stateof-the-art sensing, processing and recording techniques. Powered by lithium cells, the systems (Figure 7) are capable of unattended operation for several months in ambient temperatures ranging from $-20^{\circ} \mathrm{C}$ to $+70^{\circ} \mathrm{C}$. Long-term operational reliability is achieved in part through the use of low power, zero drift, digital circuits for sensing, processing and recording.

The data logger records wind speed, direction, time and header information once every 6 minutes on a standard Philips-type cassette. Figure 7 is a picture of the recorder part of the system. The logger can store up to 2 megabits of data on a standard $300-\mathrm{ft}$ cassette tape. Operating time between 


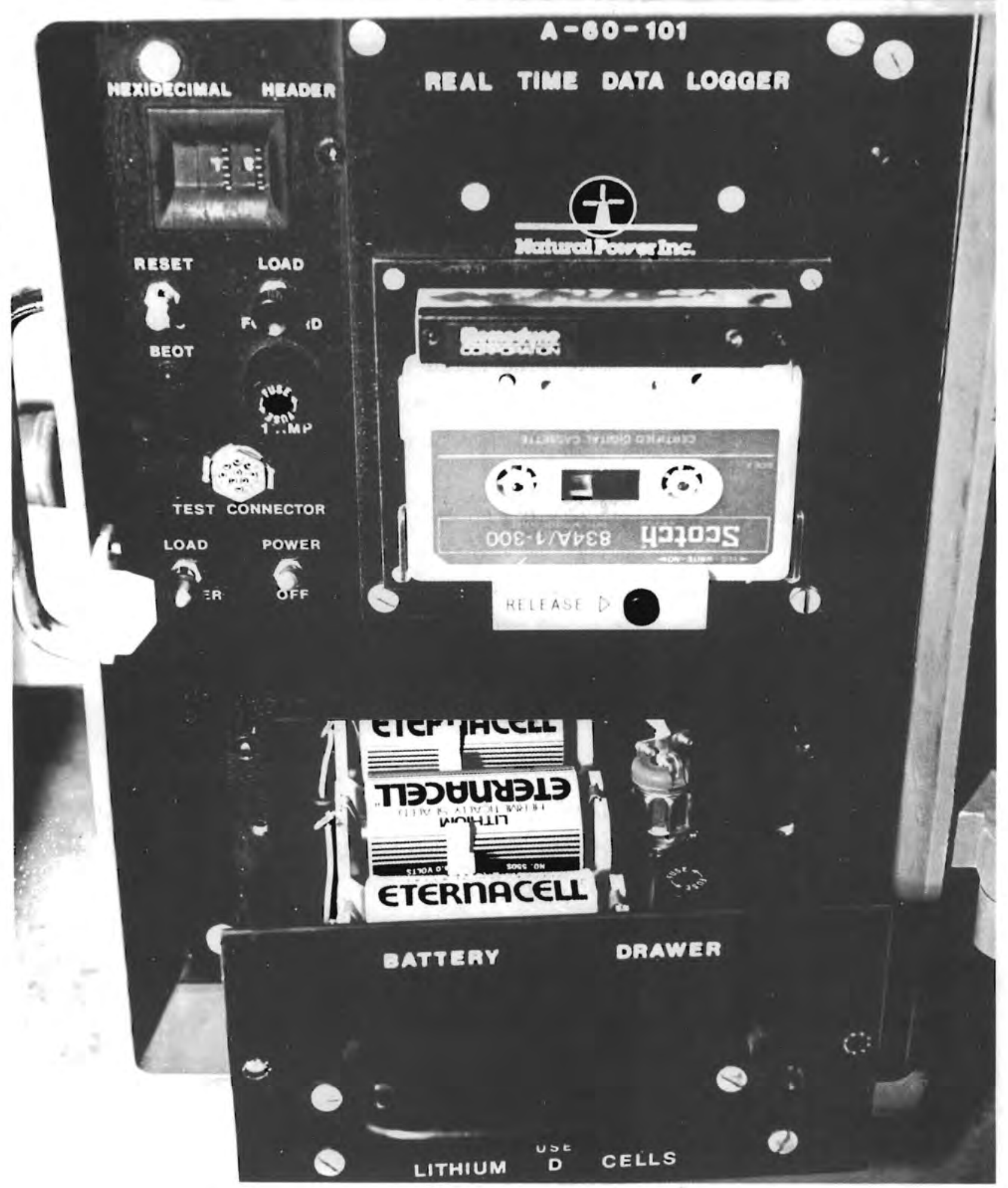

Figure 7. Closeup of a Data Logger. The hexidecimal header shows that this was logger $\mathrm{C}$ and the first tape to be run. The battery drawer is open, disclosing three of the five lithium D cells; two batteries are on the underside of the battery drawer. Note the test connector outlet. 
tape changes was 110 days at a collection rate of one data point each 6 minutes. This rate was chosen so that more than one month of data could be collected in case the mountain peak was inaccessible in a winter situation. The time interval of recording is adjustable on the $\mathrm{A} 60$ Data Logger. The lithium cells are capable of continuous operation for 6 months at $0^{\circ} \mathrm{C}$. We changed tapes and batteries at 1-month intervals to be conservative, to check for unusual problems, and to expedite the data processing and interpretation.

Wind speed was measured by accumulating pulses every second over a 6-minute interval, dividing the total number of pulses by a constant, and recording on tape a value twice the average wind speed in mph. This technique provides speed resolution to the nearest one-half $\mathrm{mph}$. Wind speed was related to the output pulse rate from the sensor and was not dependent upon the voltage level of the sensor.

Wind direction was sampled instantaneously and recorded at 6-minute intervals concurrently with wind speed summations. The direction sensor, using optical shaft encoding, produces a coded output as follows:

\begin{tabular}{rrrrrrrr} 
SE & E & NE & N & NW & W & SW & S \\
\hline 0 & 1 & 2 & 3 & 4 & 5 & 6 & 7
\end{tabular}

The codes shown above are derived from a three-bit Grey Code generated by the direction sensor. The Grey code is a 3-bit reflected binary code used in electronics; one and only one digit of the code changes in proceeding to or from the next higher or next lower number.

In addition to speed and direction data, the value of a real-time clock, a code related to battery condition, and a switch selectable header used for identification were recorded every 6 minutes. Time was recorded as elapsed time in seconds from the last clock reset. The clock in each recorder was reset at approximately 1 -month intervals when tapes and batteries were changed. The clock accuracy is rated at $10 \mathrm{ppm} / \mathrm{year}$.

The Memodyne 3122 Reader was used to read the field data tapes. We planned to have the RS232 port on the reader read the cassette data directly into the IBM 
370 computer, but the output (serial, binary) was not compatible with the New Mexico State computer terminals without some type of computer instructions and control. Natural Power developed their own solution to this problem. They have made arrangements with Memodyne so that cassette tapes may be mailed in to Memodyne who will in turn transfer the cassette data to 9-track computer tape for processing, or Natural Power has an assembly program for those who wish to decipher the data through a minicomputer.

At New Mexico State University, the Memodyne 3122 reader was mated to a PDP-11 computer through an in-house-developed buffer interface (see Appendix A). The PDP-11 generates a 9-track computer tape that is processed through several programs on the IBM 370 computer to provide data and calculations in final form.

\section{EQUIPMENT TESTS AND PROBLEMS}

The data loggers were received on 30 April and 17 May 1979. They were first tested in a cold chamber to their design temperature of $-20^{\circ} \mathrm{C}$. The second day they were successfully run at $-30^{\circ} \mathrm{C}$ for 24 hours (Figure 8 ). The wind vane and anemometer were connected to each logger in the cold chamber, and data were recorded during the cold tests.

The anemometers were claimed to be accurate to within $\pm 3 \%$ from $1.3 \mathrm{~m} / \mathrm{s}$ to $46.0 \mathrm{~m} / \mathrm{s}$, based upon their catalog descriptions and calibration tests in the M.I.T. low-turbulence wind tunnel. At the Physical Science Laboratory, the anemometer calibrations were spot checked by comparison in a small wind tunnel. Due to difficulties in reading the magnetic tapes, these checks were not conclusive. However, speed readings of the new wind speed heads were also compared in the wind tunnel with speed data from a second anemometer connected to a Natural Power 1/60-mile Accumulator, and were found consistent with the accumulator and each other to within an estimated $\pm 5 \%$.

To be more certain of the calibration, a two-part process for field calibration was devised and put into action; this utilized an excellent wind tunnel (closed circuit with 1.2-m $\times 1.2-\mathrm{m} \times 2.4-\mathrm{m}$ test section) at the U.S. Army White Sands Missile Range. 


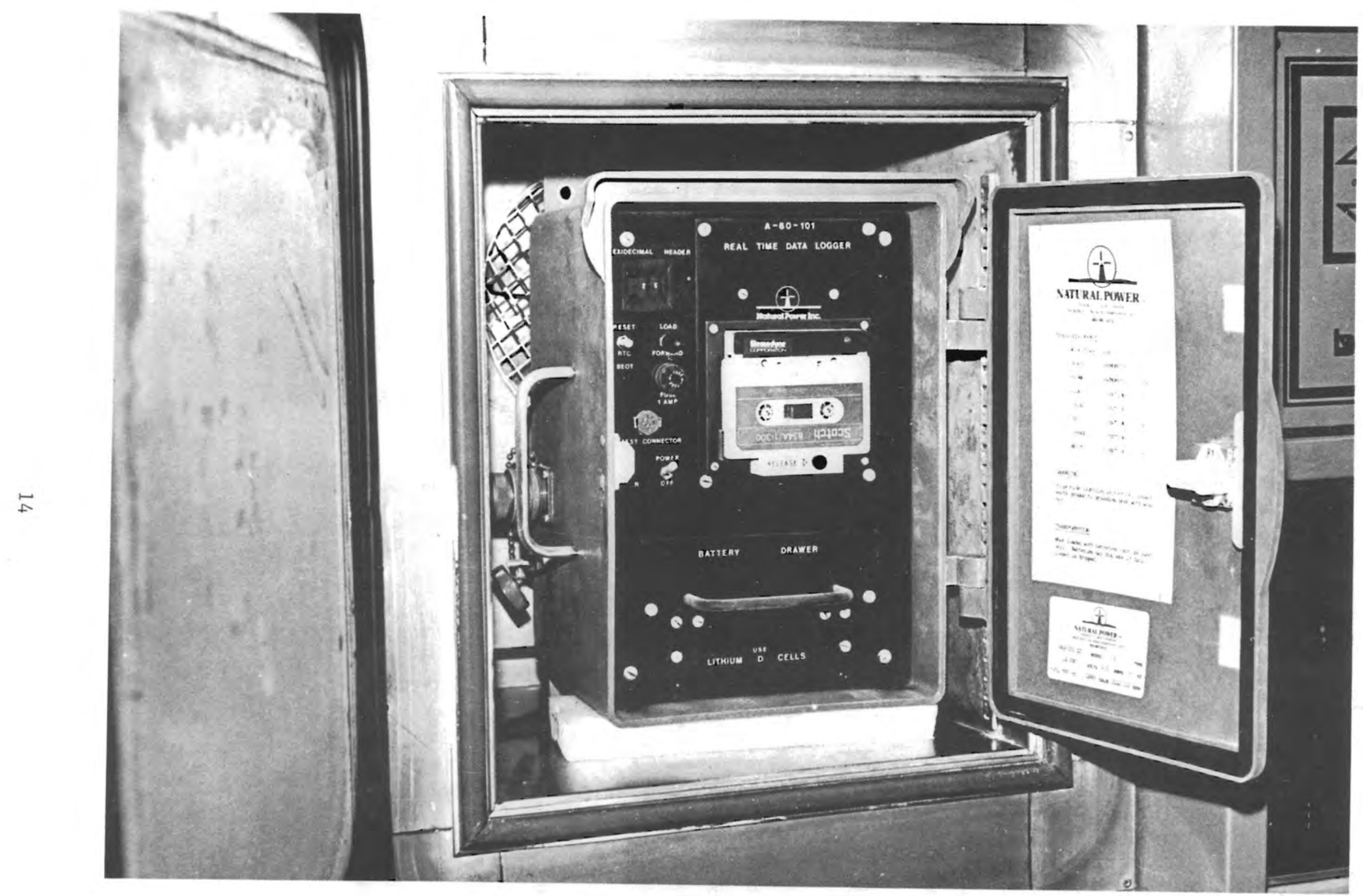

Figure 8. Data logger in cold test chamber. 
The first part of the process was to check the calibration of the anemometer heads ( 3 cup maximum supplied by Natural Power) using the wind tunnel and a calibrated Natural Power Accumulator. These heads were found to be accurate to within $+4.4 \%$ or closer. The new calibrated heads were placed on all six of the systems at Sierra Grande on 7 August.

The second part was to take a separate, calibrated anemometer head and physically place it, on each tower or post, very closely to the operating anemometer head. This separate speed was read for slightly over 6 minutes on a Natural Power Accumulator. During the same time, speed was measured by the installed system, and its wind vane was manually moved $180^{\circ}$ from the prevailing wind direction. This changed wind direction helped to identify the data sample on the tape. The tape was then removed and taken back for processing. A comparison of the 6-minute wind speed and direction from the tape was then compared with the wind speed on the Accumulator and the taped direction with the manually set direction. This process was performed on 13 September. Comparison of the two sets of data showed good accuracy $( \pm 4 \%)$ of speed data but showed errors in much of the direction data. This result led to a special field test with the assistance of a Natural Power engineer.

A comprehensive calibration of all six wind speed and direction sensor sets, each with its own recorder, is a considerable task, even in a large and wellequipped wind tunnel. Each direction has to be indicated on the direction head for a full 6 minutes while the wind speed is held constant at a specified speed. Between each 6-minute recording period, a new direction needs to be selected and the wind tunnel air speed changed. This sequence would require a minimum of 90 minutes for each set, assuming that the wind tunnel air speed could be changed and stabilized in 6 minutes. Set-up time for changing sets in the tunnel needs to be considered. If this change time is 30 minutes, then a total of at least 720 minutes ( 12 hours) is needed. After this, the six sets of tapes must be reduced and the results compared with wind tunnel results. A faster, basic equipment calibration procedure would be desirable for something such as annual checks. The field checks should be satisfactory at something such as three-month intervals, or at signs of damage.

The analysis of the field data gathered in August disclosed that the wind 
direction data at most locations indicated only west winds. When the field calibration was performed it was determined that only the wind direction from the east site (F) was working properly.

The wind velocity heads used with the Natural Power equipment are from Maximum, Inc.; the wind direction head, shell and vane are from Maximum; the internal electronics are Natural Power's design. Of the six original wind direction heads, only one worked. Of the two spares on hand only one worked properly. A Natural Power engineer was requested to make a field trip to Sierra Grande. of the six new sensors he brought with him that were specially fabricated to correct the problem, four were dropping one out of three bits; this was a $71 \%$ failure rate. Natural Power has since found the cause of this problem and cured it. A letter from Natural Power concerning these factors and all other equipment problems is included in Appendix B. Natural Power personnel discussed the problems thoroughly with Memodyne representatives before sending the letter.

The reason that the wind direction problem was not discovered before mid-summer was this: On previous trips when the tapes were printed out on the miniprinter to validate the data in the field, the winds were always from the west, the prevailing direction. On the August data trip, it was noted that the winds were mostly southeasterly, yet the logger data showed westerly except for one site. The three Grey Code bits used in the direction head are engineered such that if one bit is dropped, wind directions are reported incorrectly, but one may be able to evaluate and determine the wind direction knowing the idiosyncrasies of the system. However, if two bits are dropped, the wind head will show only winds from the west regardless of the correct wind direction.

The "Test Connector" plug on the front panel of the loggers (Figure 7) was not useable until 28 October 1979, when a Natural Power engineer brought down their first newly completed field test units. If these two test units (Figures 9 and 10) had been available at the beginning of the project, many problems with the use of the loggers in the field would have been eliminated.

The Field Reader shown in Figure 9 allows the data to be displayed in two sections: one, the MSD (Most Significant Digits) switch shows the hexadecimal header (2 digits), two unused digits, wind direction (2 digits) and the wind 


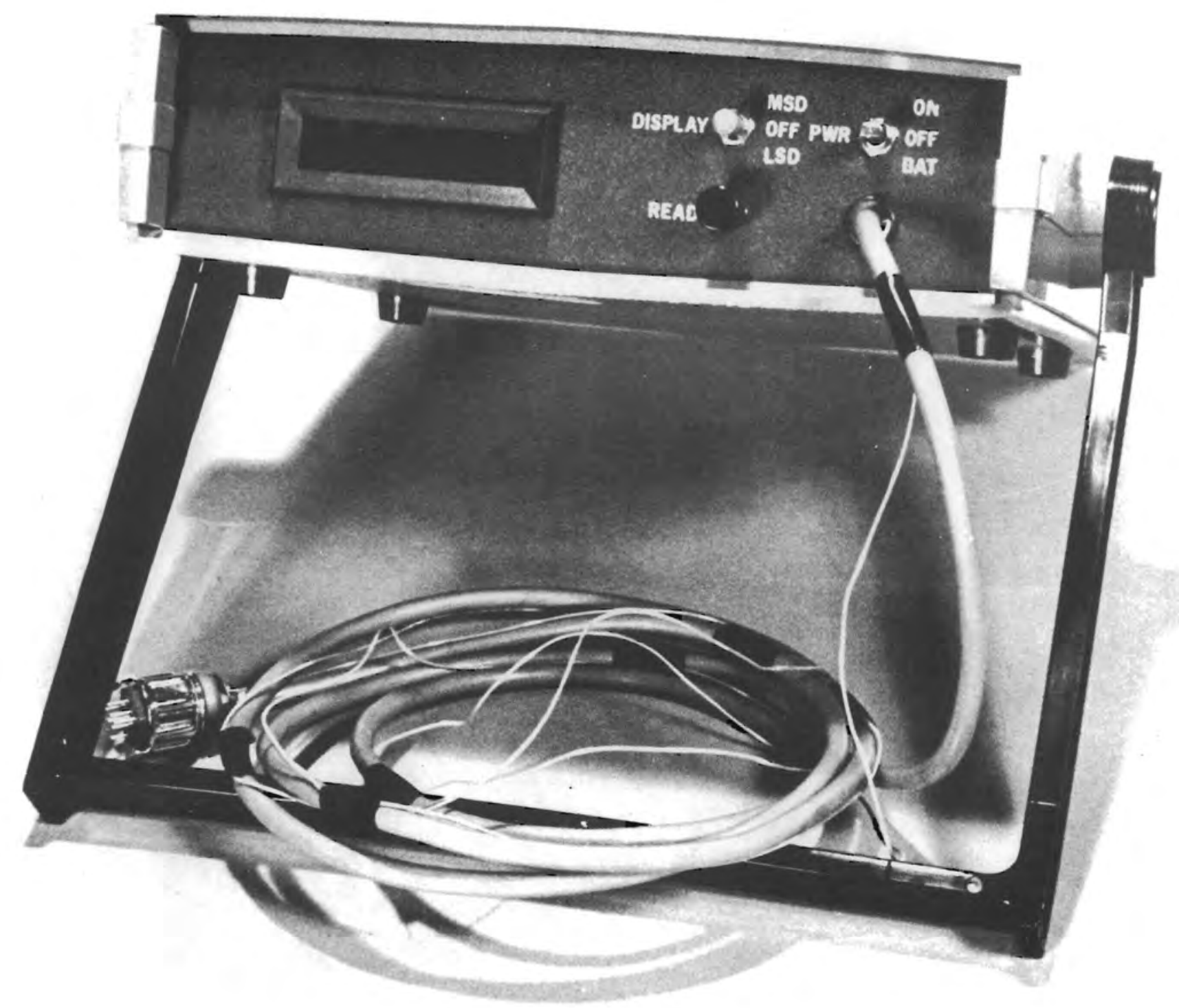

Figure 9. Natural Power's Field Reader which by use of the MSD and LSD switch allows one to read the data that is ready to be recorded on the cassette tape of the logger. 


$$
E
$$


velocity (2 digits); two, in the down position, the LSD (Least Significant Digits) displayed the real-time clock in eight hex digits.

In reading the wind velocity, the logger must be allowed to accumulate pulses for 6 minutes to read what wind velocity the logic circuit had accumulated. To read wind direction more often than once every 6 minutes, the wind direction head (negative terminal post $\#_{4}$ ) had to be jumped to the anemometer BLACK lead.

The "Read" button on the front of the Field Reader causes the data to be read directly onto the cassette tape when depressed.

The use of the Sensor Checker (Figure 10) is threefold: one, it reads out direction of the wind vane; two, it simulates any direction and two speeds, $25.5 \mathrm{mph}$ and $51 \mathrm{mph}$, for input into the data logger; three, it is a direction head continuity tester.

The most useful test on the Sensor Checker was performed by the three lights on the bottom center of the front panel. The lights from the left are, respectively, for Grey Code column C, B, and A. With the use of the engineering code from Natural Power posted on the top of the Sensor Checker, the direction being transmitted by the direction vane could be verified. This checker was used to test for shorts and circuit continuity through the cable from the instruments to the logger. 


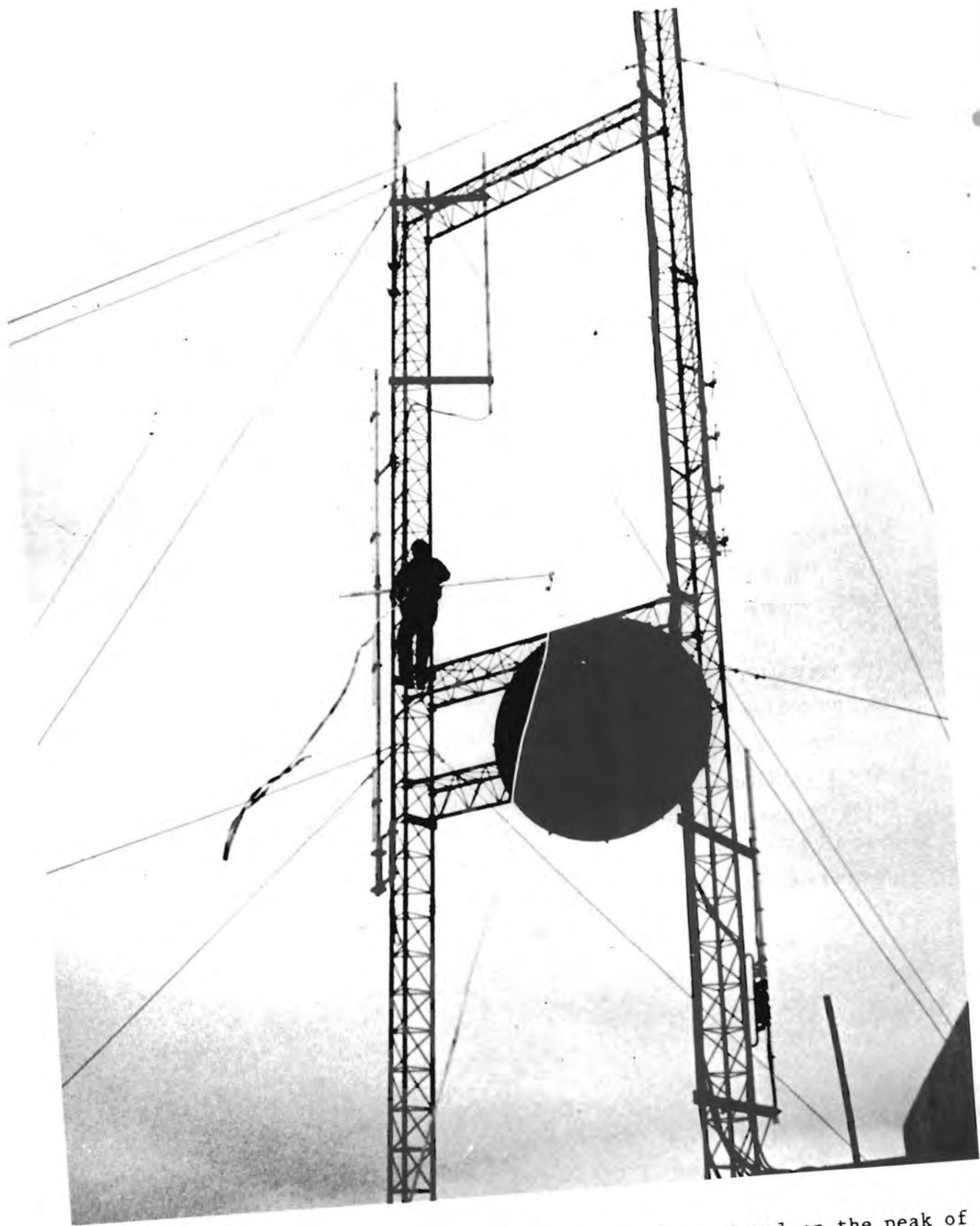

Figure 11. Installing the wind equipment at the $10 \mathrm{~m}$. level on the peak of Sierra Grande.

20 


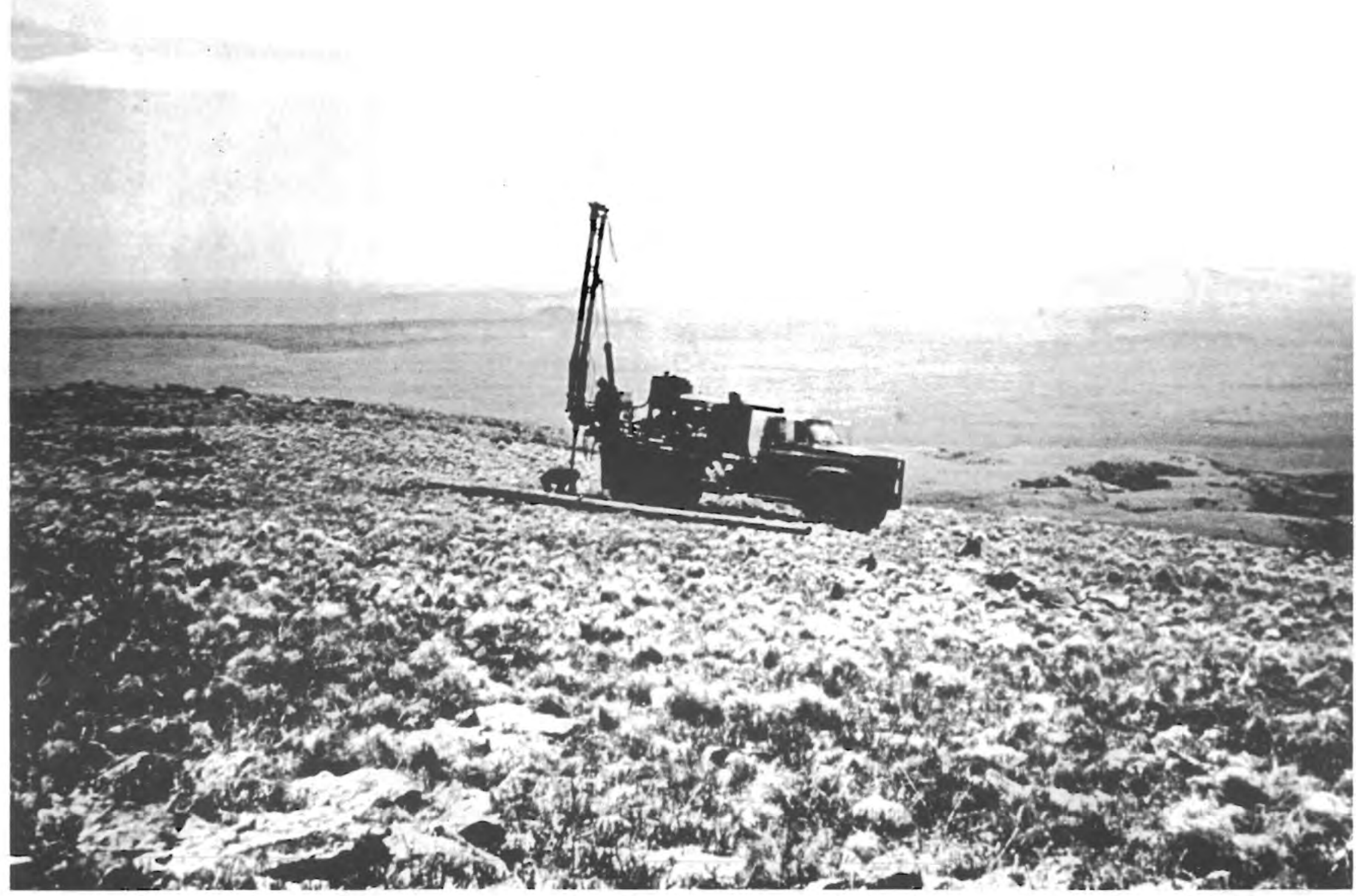

Figure 12. A power auger from the Southwestern Electric Coop, Inc. of Clayton was used to install four $10 \mathrm{~m}$. poles near the peak. 


\section{INSTALLATION TECHNIQUES}

The first two sets, Site $A, 20 \mathrm{~m}$, and Site $B, 10 \mathrm{~m}$, were installed at the peak on 16 May 1979. (See Figure 11.) They were installed on the existing Rohn towers belonging to the New Mexico State Department of Radio Communications. The outlying four poles were set $10 \mathrm{~m}$ above the group at the four chosen sites. The poles were standard 12.2-m wooden poles and were put 2.2-m deep in holes dug by a power auger. A large electrical utility truck transported the poles, dug the holes, and installed them, as shown in Figure 12.

Anemometers and wind vanes were mounted atop the poles on a $1-\mathrm{m}$ cross arm, as depicted in Figure 13.

Weatherproof Hoffman boxes were purchased to house each of the six loggers. A Hoffman box was placed near the base of each tower or pole. The boxes were modified by welding a strong hasp on the outside (Figure 14) and by welding special brackets to the four boxes that were mounted on poles (Figure 15).

The four boxes on the poles were held in place by four 15-cm lag bolts. It was found that driving the lag bolts in with a three-pound maul was much faster than screwing them in with a ratchet wrench. Then the inside of each box was lined with $5 \mathrm{~cm}$ of styrofoam. All cracks were filled with glass wool. Three one-gallon bottles of water with anti-freeze were placed inside each box for more thermal mass. A maximum-minimum thermometer was placed inside the box at Site $B$. The results of these tests showed temperature variations of as much as $45^{\circ} \mathrm{F}$ in a month. This is more than was expected inside a well insulated box with a large heat mass inside. Adding a simple, ventilated shield to keep the box from direct sunlight and nighttime radiation might help to reduce the temperature variations.

The Hoffman boxes were $41 \mathrm{~cm} \times 61 \mathrm{~cm} \times 61 \mathrm{~cm}$ inside and allowed plenty of room, even after the loggers were mounted inside the back center by four bolts. Any excess cable between the logger and the heads was coiled and taped on the bottom inside a Hoffman box. Each box was locked by a Best lock; all the locks were ordered with one common key. 


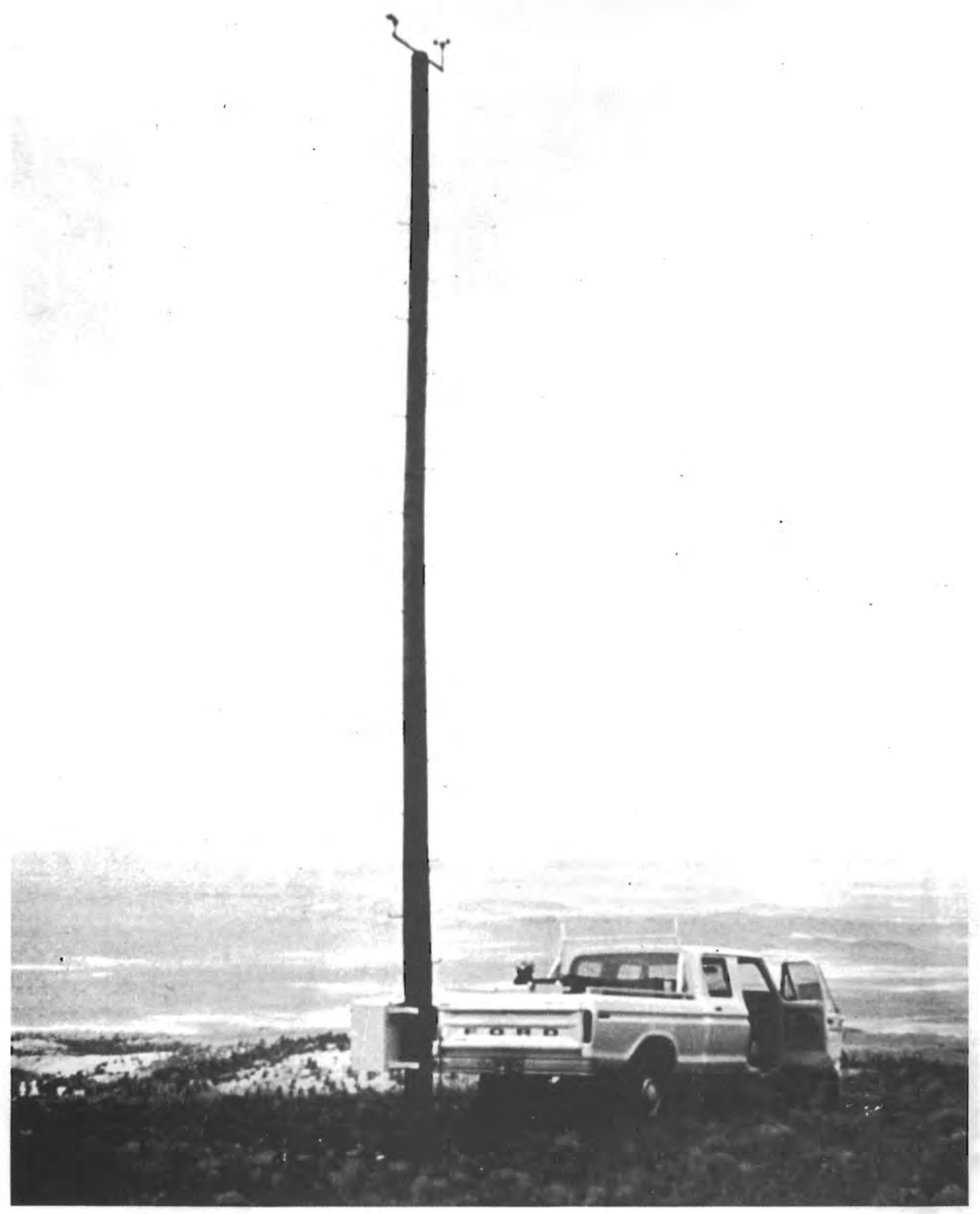

Figure 13. A one meter cross arm was bolted to the top of each $10 \mathrm{~m}$. pole. The Hoffman box housing the data logger was mounted at the bottom of each pole. 


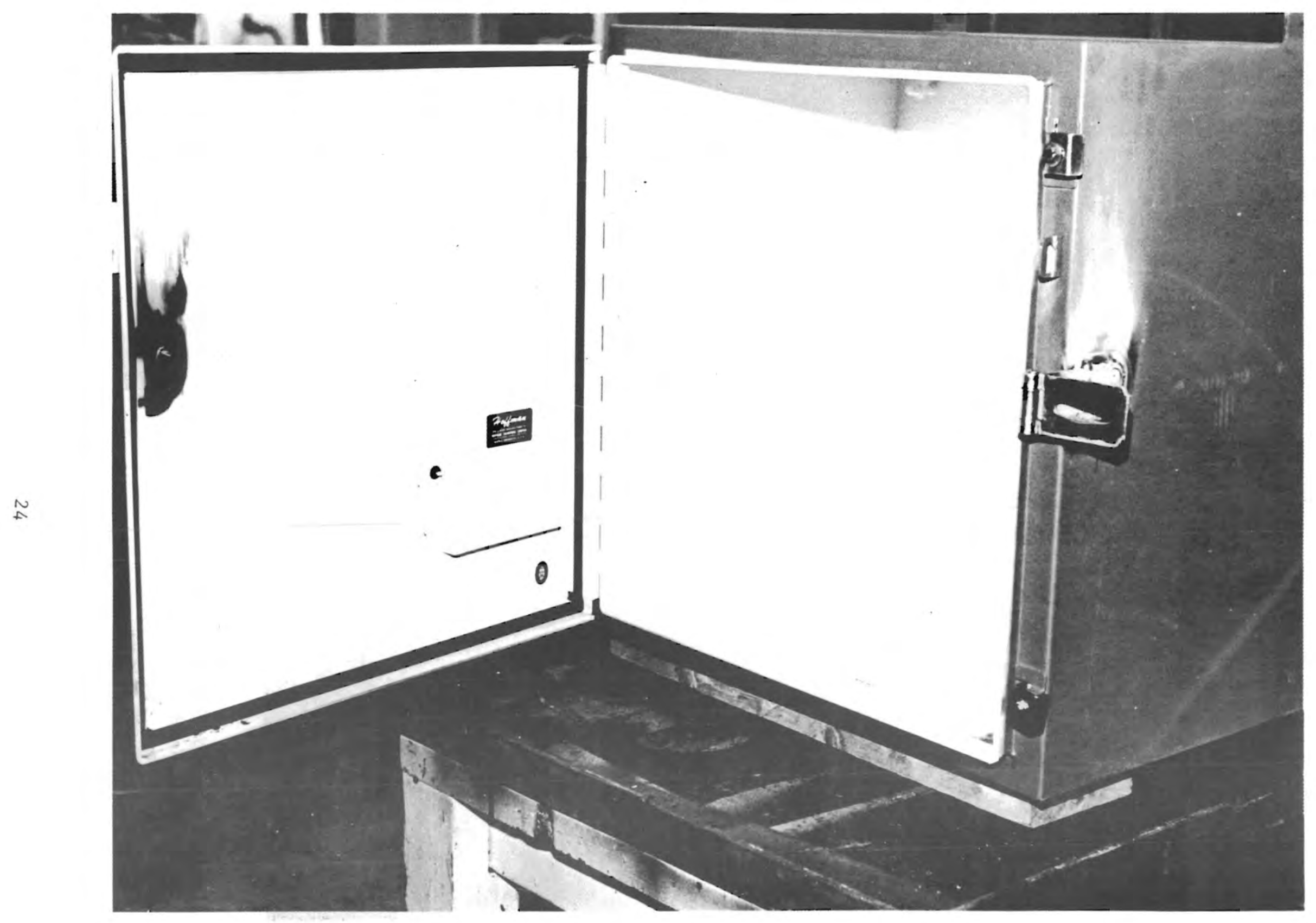

Figure 14. An extra heavy lock clasp was welded on the Hoffman boxes for security of the Data Loggers.

○

0

0

○

0

'0

Q 


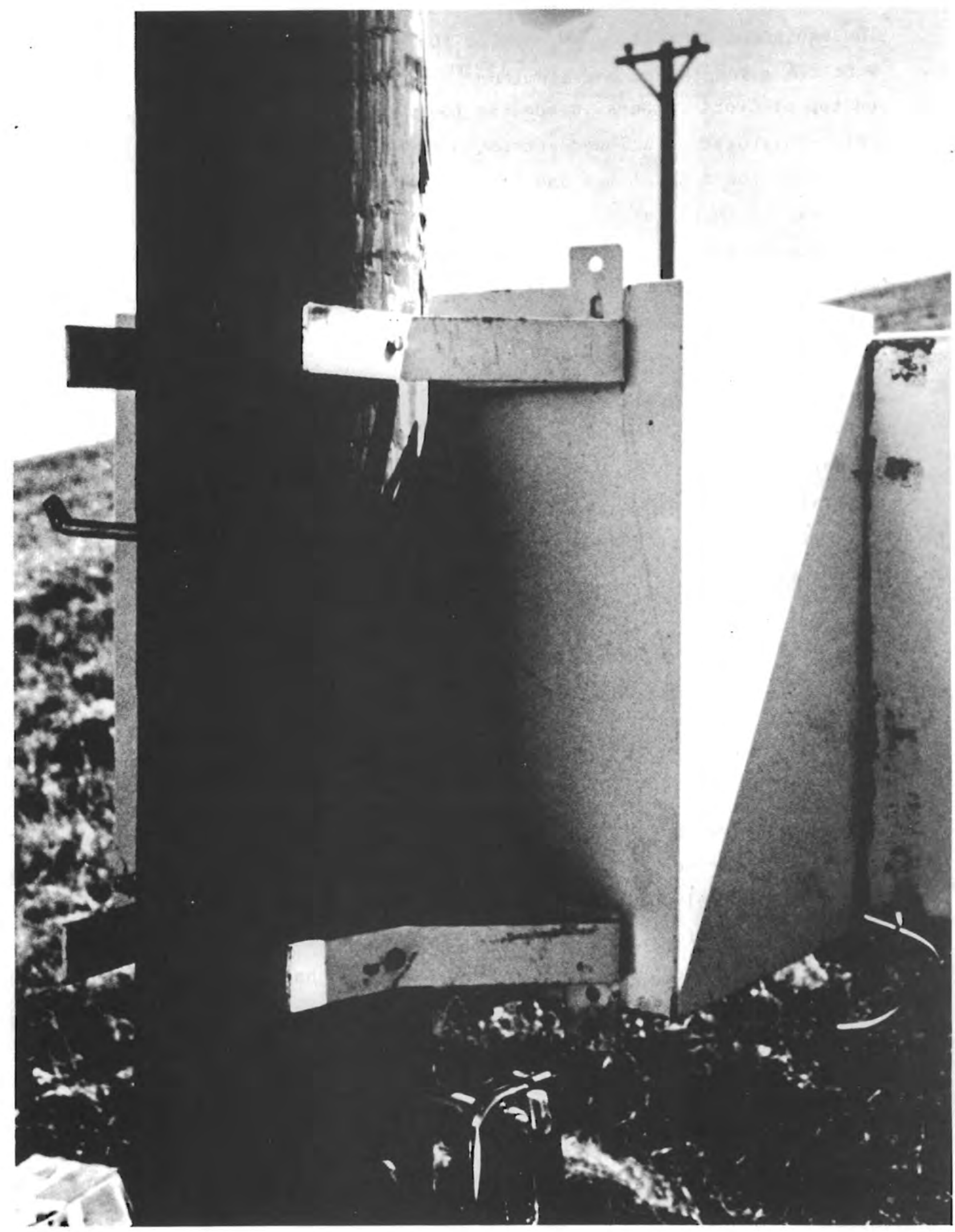

Figure 15. Special brackets were welded to the back of the Hoffman boxes for mounting on the four telephone poles. 
The equipment support booms used at $10 \mathrm{~m}$ and $20 \mathrm{~m}$ on the tower at the peak were $2.4 \mathrm{~m}$ lengths of box aluminum $5 \mathrm{~cm} \times 10 \mathrm{~cm}$. The booms were laid parallel on top of cross members inside the tower and held in place by four hose clamps. This configuration allowed access to the wind equipment on the boom simply by loosening the hose clamps and sliding the boom in to the technician. During the initial installation, several loops of the cable were coiled and taped to the boom at the tower, which provided enough slack to allow the booms to be moved as needed. It was still necessary to remove and replace several of the cable ties when moving the boom.

A record $\log$ was kept at each site and updated each time the tapes were changed; this was necessary to convert the real-time clock data to actual time. A master $\log$ was also kept and returned to the office from the field. A quartz digital chronograph was used to start each real-time clock exactly on an even 6-minute interval; that way each of the six sites could record data at the same instant.

This site was quite remote and isolated, therefore no vandalism was experienced during the tests.

If a large truck can reach an installation site such as Sierra Grande, and if the ground is suitable for a power auger to dig a hole, then the installation of wooden poles appears to be the cheapest installation method. It is believed that the next most practical method is to haul in four 3-m lengths of telescoping steel poles, use rocks to hold the base of the pole and to hold down "dead men" for guy wires; the instrument can be mounted on a pole in the horizontal position and raised. This technique has been used by Baker and Wade (1978) in oregon. For a 20-m or taller tower, it may be necessary to put in concrete bases and "dead men", and then install heavy duty triangular towers in 3-m lengths; this method could become very expensive and indicates that tower installation may be the major limitation in this methodology.

\section{DATA COLLECTION}

Data tapes were collected from 17 May through 5 December 1979. These tapes were collected on a monthly basis. Table $\mathrm{C} 1$ in Appendix $\mathrm{C}$ is a sample of 
6-minute data printed out by the computer. Copies of these data, on standard nine-track tape can be obtained from PSL for reproduction costs.

The road from the highway to the top of the mountain was $4 \frac{2}{2}$ miles long and so rough and often muddy that the usual driving time to the top was one hour. For safety considerations in this isolated travel spot, two people were always sent on data-gathering trips. The usual procedure was to drive in one day from the New Mexico State campus in Las Cruces to Raton, a distance of 415 miles, in a university staff car.

In Raton, a 4 wheel-drive vehicle was leased. Raton is 40 miles from the Sierra Grande peak. The next day the crew usually left Raton by 7 a.m. (though in case of severe weather, it would be necessary to wait before going up) and after a full day of servicing the equipment and changing the data tapes, the crew returned to Raton by $5 \mathrm{p} . \mathrm{m}$. On the third day, the crew drove back to Las Cruces. So, each data expedition took at least a full three days by two persons. The time and expense of these trips became a significant factor. In this case, at least, we do not believe local persons could have been found who could have diagnosed these complicated electronics and internal computer programming problems. Closeness of operational, maintenance and computer processing personnel to the site is important.

The Natural Power Data Loggers have a tape advance button on the face of the logger labeled "Load Forward". Initially, once a new tape was inserted, the load forward button would have to be depressed from $1 \frac{1}{2}$ to 2 minutes before the Before End of Tape (BEOT) light would come on. The BEOT is also used as a BOT (Beginning of Tape) light. This light is to insure that the beginning of tape hole had successfully been passed before the logger was turned on to begin taking data. The Data Logger lights were difficult to see in sunlight. It was found to be more expedient to manually advance the tape in the cassette past the Beginning of Tape hole. A hexagonal BIC pen fits in the capstan perfectly to facilitate a fast manual advance. It is strongly recommended that tape without BEOT or BOT holes be used with these loggers.

Memodyne recommends only the use of their low-temperature-range tape where the instrumentation will be exposed to ambient temperatures below $0^{\circ} \mathrm{C}$. Their tape is more expensive, by about a factor of two, than the $3 M$ digital cassette tape 
that was used in this study. In telephone discussions with $3 M$ engineers in Minneapolis they said their tape should be all right to slightly below $0^{\circ} \mathrm{C}$.

The batteries used were five D-size lithium cells, 3 volts each. Figure 7 shows the logger with the battery drawer open. Two of the batteries are on the bottom side of the drawer. Two short screws have to be removed each time the batteries are replaced. A quick disconnect aircraft-type screw would be very beneficial here to speed up time in changing batteries and to protect hands against frostbite.

The hexidecimal headers worked satisfactorily on these loggers. Each site had an alphabetical designation and the number was changed each time to identify each tape.

One major problem with the data logger in the field before the two new test sets were available was the inability to validate that data were being recorded properly and that the data were good. To solve this problem, a digital, portable moduprinter was fabricated at PSL to be mated to the cassette reader (Figure 16) (Also Appendix D). The miniprinter and reader were taken to the field for data gathering. The Radio Communications Department of New Mexico had $110 \mathrm{~V}$ power in their radio equipment shack on top of the peak. The cassette data would be brought in from the six sites; the last few data records for each site would be printed out and verified. The miniprinter was a good end-to-end check on the logger system because it also showed what was actually printed on the cassette, whereas the two Natural Power test units could not show what was actually recorded on the cassette tape.

The Natural Power Data Logger in our opinion was marketed prematurely. This experiment turned out largely to be a field test of their system. Their two field test units available now will enable one to avoid a lot of the field problems that were encountered on Sierra Grande; the field test units used were not a true end-to-end test of what was observed and what was recorded in the cassette, it did show what was available in the data to go on the tape, but a miniprinter or other similar technique will fill this need. An error analysis of the Data Loggers is in Appendix E. 


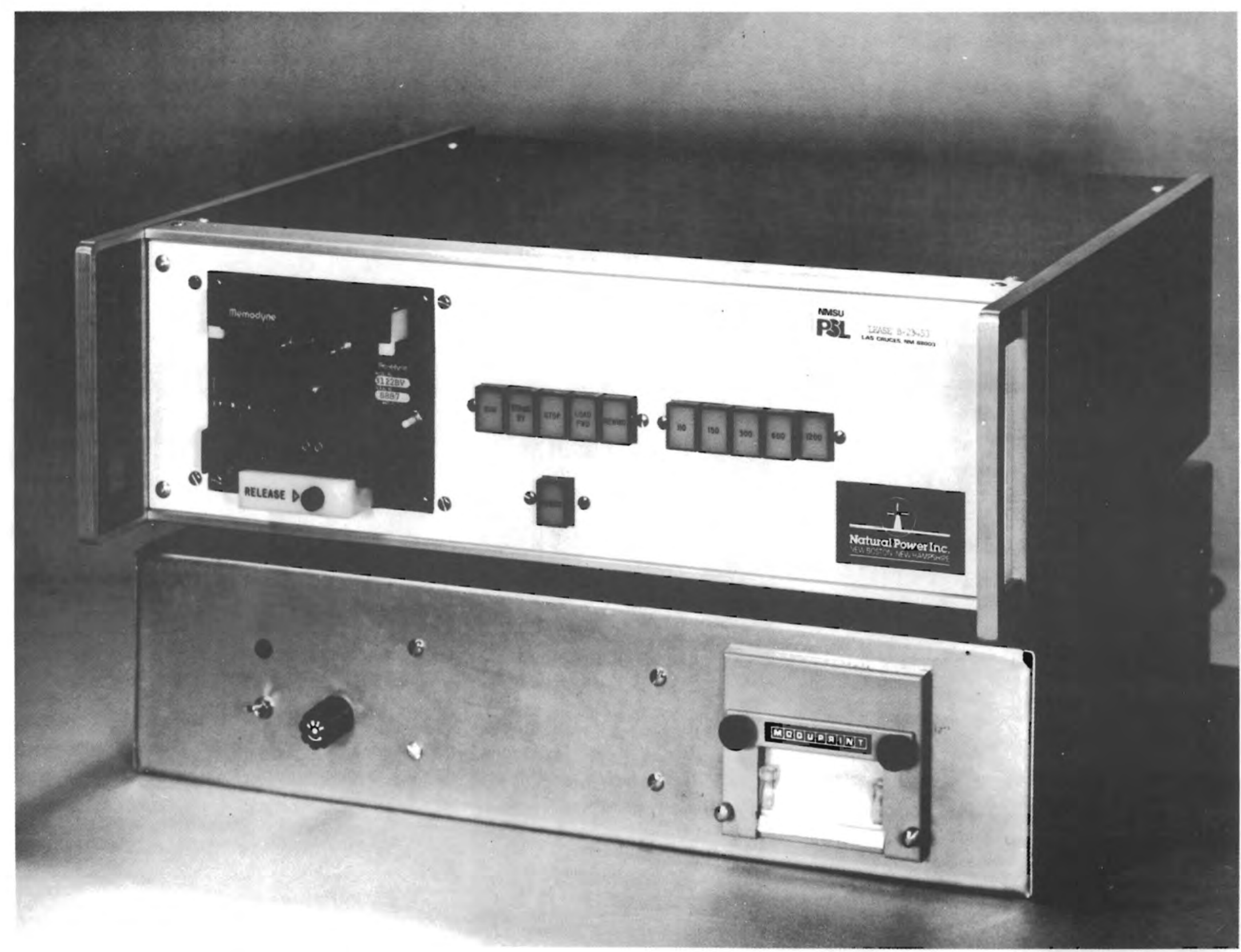

Figure 16. The minimoduprinter was fabricated in-house at PSL to be used with the Reader for field testing the data tapes. 


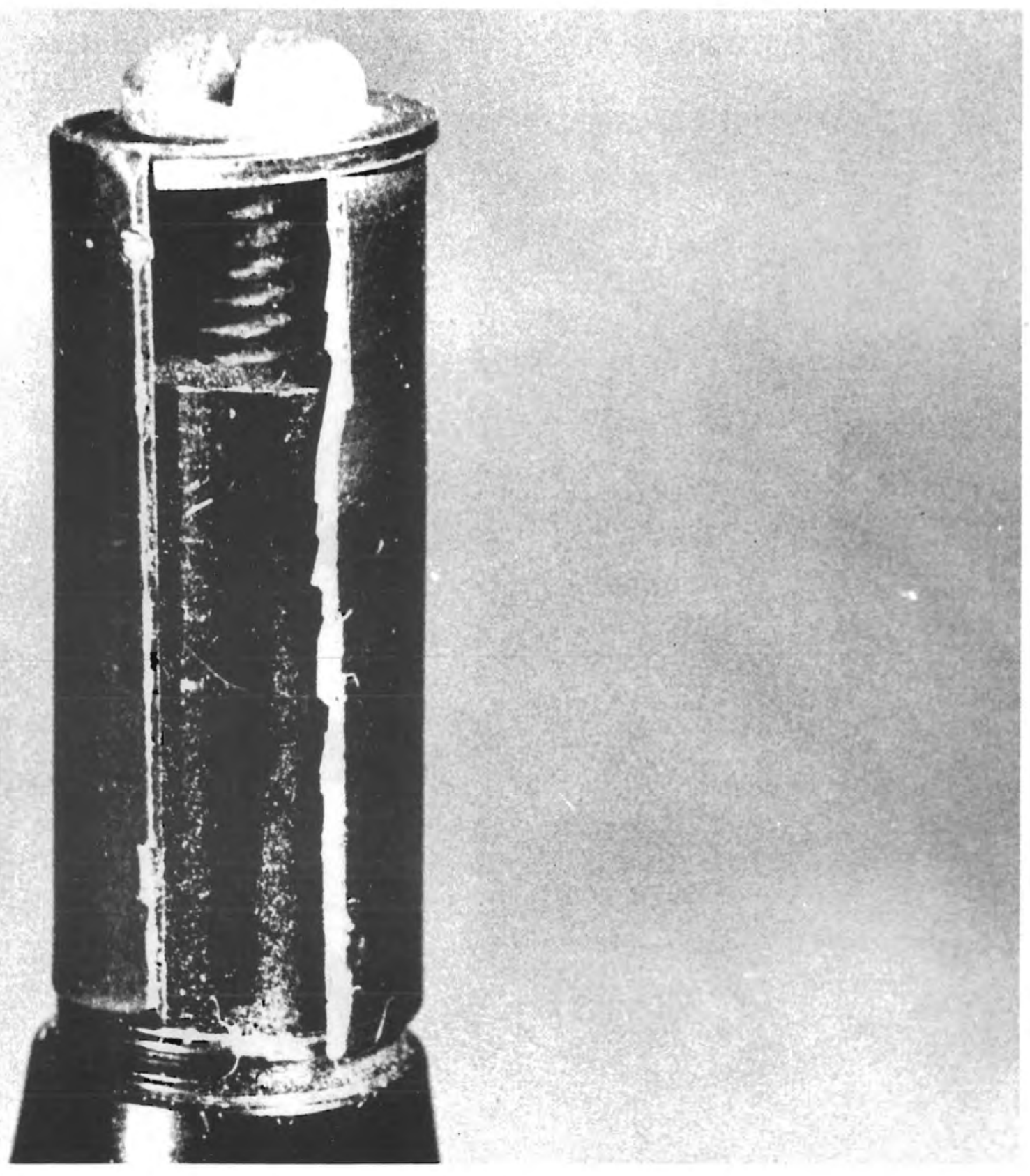

Figure 17. Closeup of a wind direction sensor showing where the vane was broken off. 


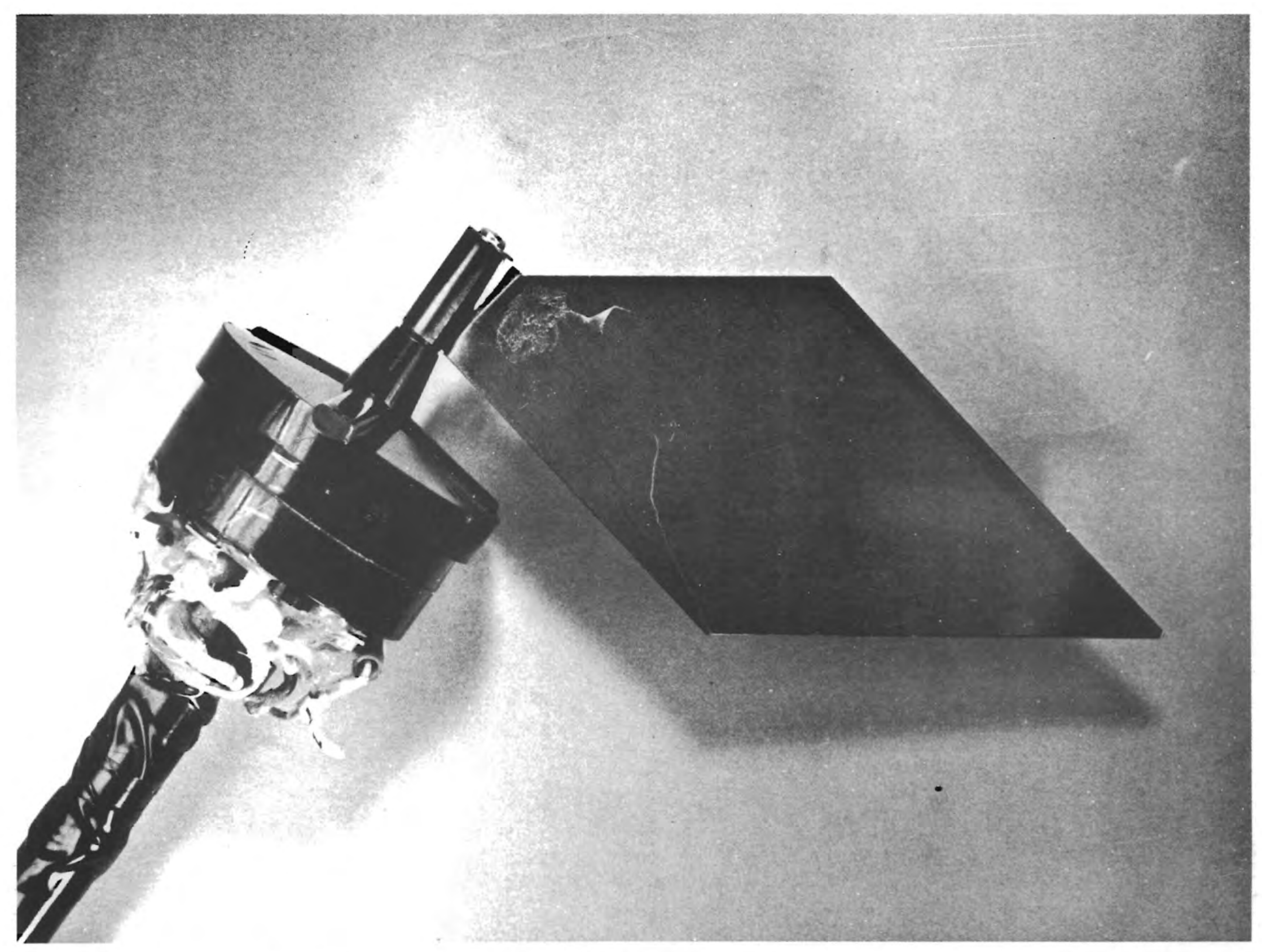

Figure 18. A second wind vane was broken almost in two by a combination of ice and wind. 
The flaw in the wind direction heads electronics has now been corrected. The wind vanes as now structured are not suitable for rugged field use. One vane sheared off in use - it was conjectured that the head iced up to prevent the wind vane from turning but the gusty side winds kept whipping the metal blade back and forth until the metal fatigued and broke off (Figure 17). A second vane was broken partially in two (Figure 18). We suggest that the heads should be redesigned for better structural integrity; a longer wind vane to damp response time should also prove beneficial.

The wind speed cups presented a problem under icing conditions on the mountain; they broke off. Figure 19 shows a normal anemometer behind three that lost their heads in the October blizzard of 1979. As shown in the close-up in Figure 20, the cups popped off the shaft on which they are epoxied. Figure 21 shows a detail of the cup head where it is epoxied on to the shaft along with one of the speed heads (a victim to a second ice storm). The cup head has a hollow area around the nipple that is epoxied to the shaft; evidently the flexing of the cup head breaks off the nipple. It is suggested that if the cup heads were cast as a solid unit, without the hollow area, the structural integrity of the cup heads would be improved.

Natural Power claims this is the first known failure of the speed heads, including several years of exposure on Mt. Washington.

The Data Loggers invariably dropped some digits from the first data file (i.e. the first six minutes recording). After that, they performed fairly well for being left totally unattended for a month or slightly longer at a time. Their recovery rate of data was over $90 \%$ after a computer analyst reviewed the data tapes.

The original Memodyne reader started causing problems in October. Natural Power shipped in a second Memodyne reader as well as a test tape. The data using the new reader was of better quality than that of the old reader.

It is recommended for any future operation that a dedicated minicomputer for field tests be mated to the reader if a simple reduction and associated program is needed. In the event that a more sophisticated program is desired, a 


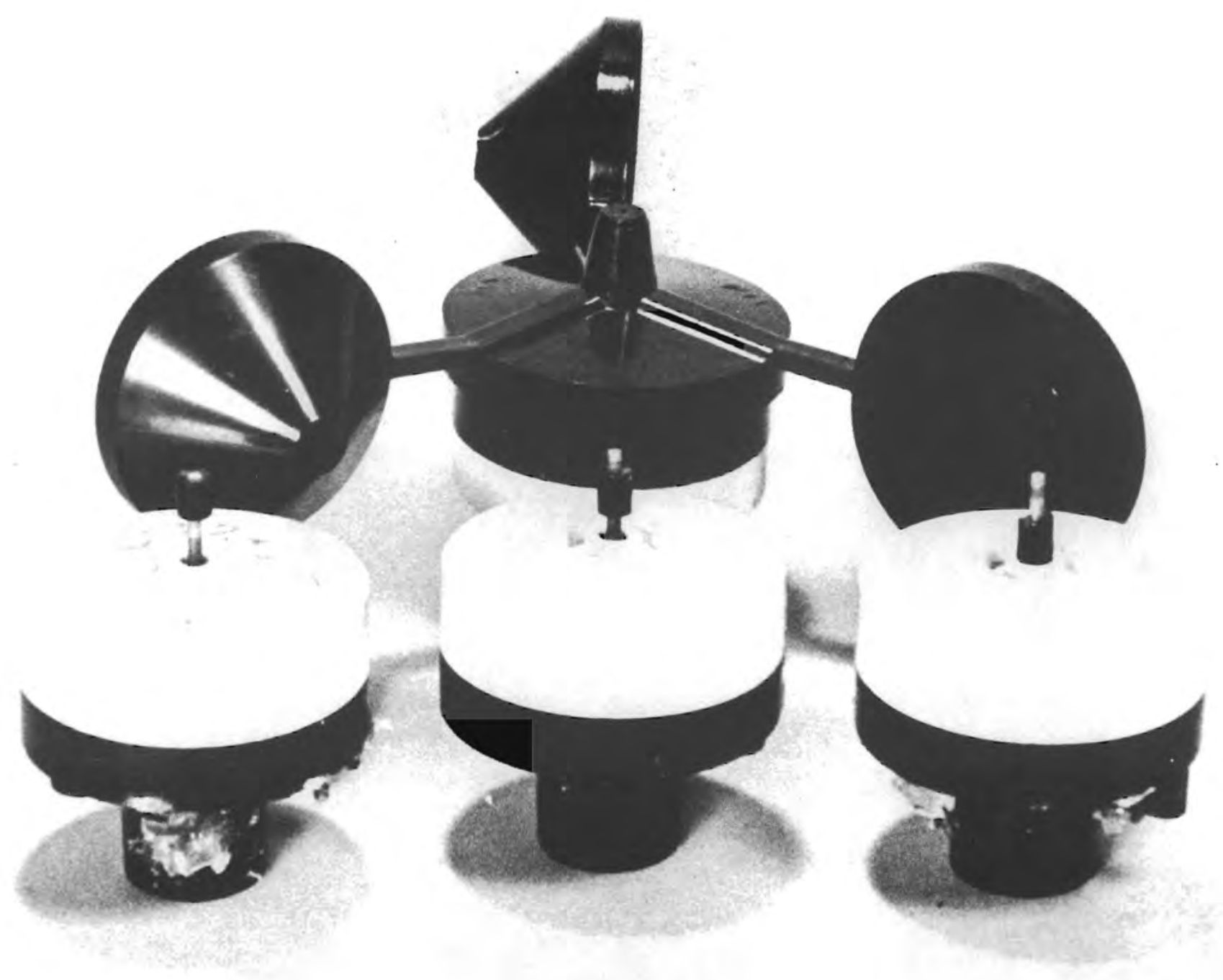

Figure 19. A regular speed head configuration is shown behind three anemometers that lost their heads in the October blizzard of 1979 . 


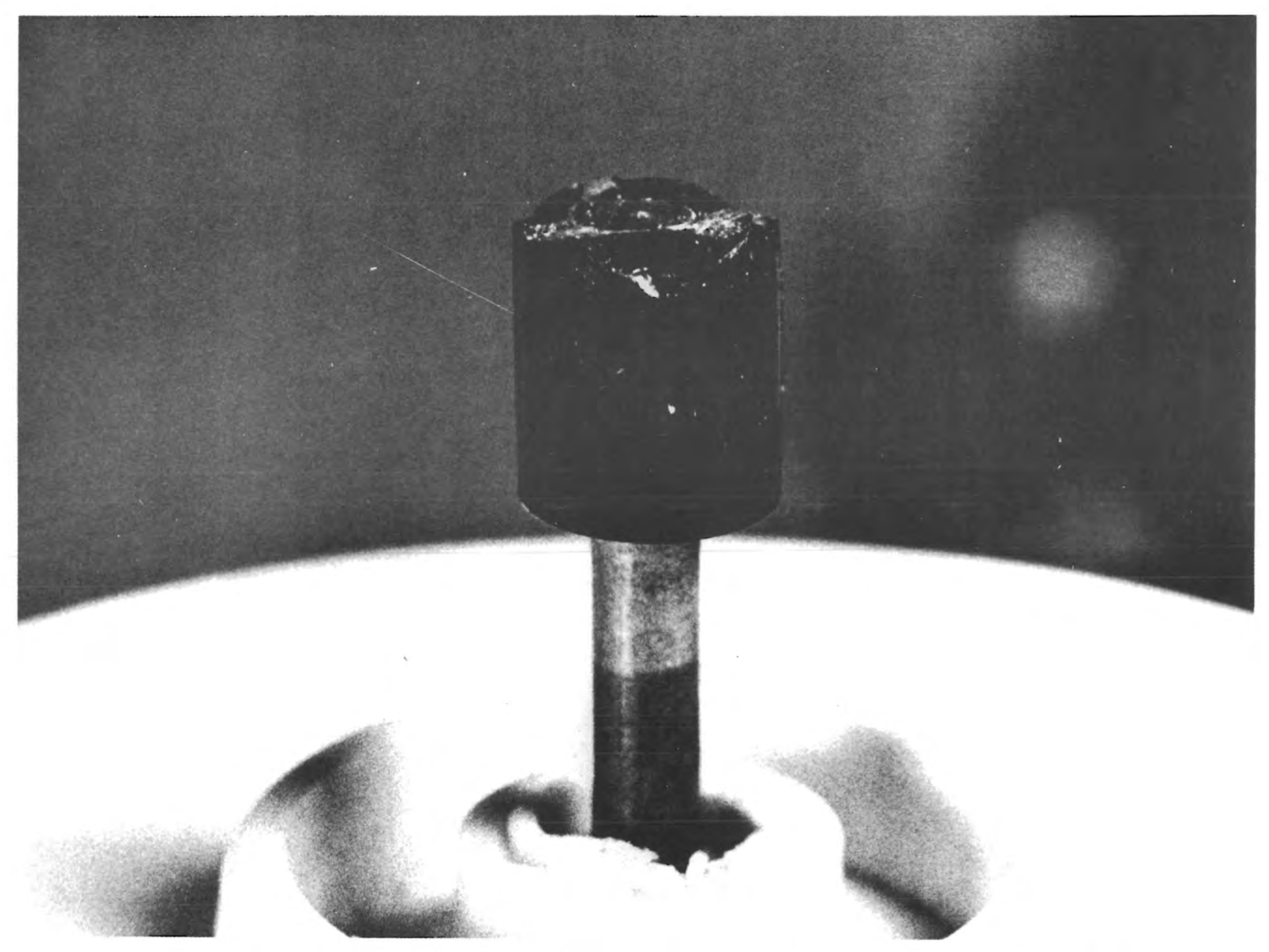

Figure 20. The speed heads all popped off at the nipple where it was expoxied to the shaft. 


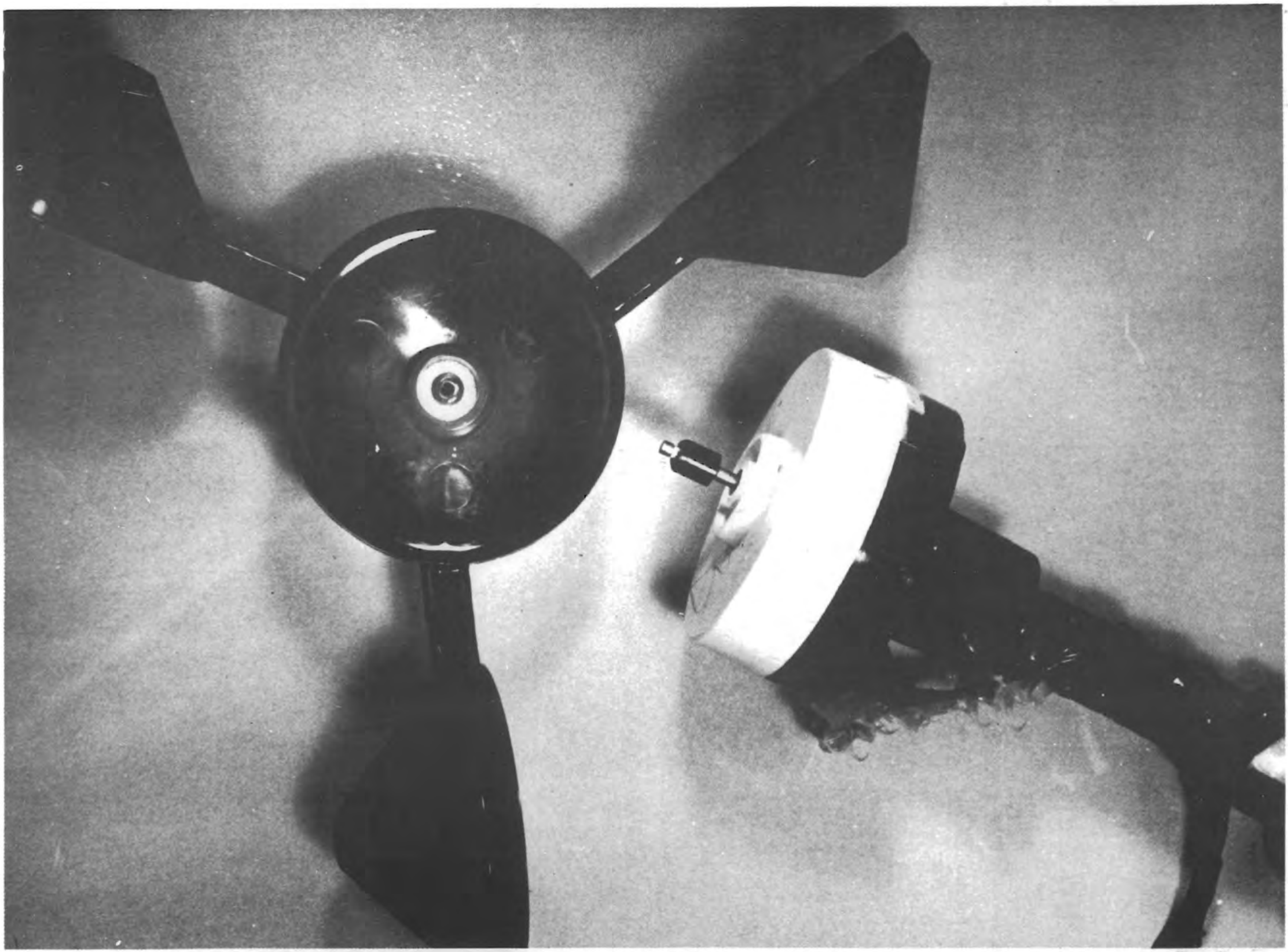

Figure 21. A cup head that had earlier blown off intact shows the hollow area around the nipple; evidently the flexing of the nipple when the cups are iced caused the nipple to break off on the shaft. 
reader mated to a Universal Asynchronous Receiver Transmitter (UART) would allow data from the RS 232 port to be fed into a large computer. As mentioned before, the problem that was found with the current system is that it spews out serial binary with no control; it would be all right if it were mated to a dedicated computer but not with time share terminals.

\section{ESTIMATED COST OF APPLICATION}

The estimated costs and manhour requirements for a typical application using this methodology are as follows:

\section{Assumptions:}

1. One year of data to be taken.

2. Data loggers to be purchased.

3. Two people to make data runs from an isolated area (for safety purposes).

4. No overnight trips and no per diem fund.

5. Distance to site 100 miles one way, or less.

Equipment \& Supplies:

Six Natural Power Data Loggers, @ $\$ 3900=$ $\$ 23,400.00$

One cassette reader

$2,650.00$

72 low-temperature-range digital cassettes a $\$ 15.60$

$5,443.00$

360 lithium 3-volt batteries (D-size) @ $\$ 7.80$

$2,808.00$

One complete tool chest $w / m u l t i m e t e r$

250.00

One 4-wheel-drive vehicle, $2400 \mathrm{miles,} \mathrm{(c)} \mathrm{40 \% /mi}$

960.00

Erection of four $10-\mathrm{m}$ aluminum towers

$5,555.00$

Erection of one 20-m aluminum tower

$3,750.00$

TOTAL $\$ 44,816.00$ 
Manhour Requirements:

$\begin{array}{lrrr}\text { Programmer time } & 250 \text { hours } & \mathrm{x} & 14.00=\$ 3,500.00 \\ \text { Two field personnel } & 1,200 \text { hours } & \mathrm{x} & 9.00=10,800.00 \\ \text { Computer time (IBM 5/370) } & 20 \text { hours } & \mathrm{x} & 196.00=\frac{3,920.00}{\$ 18,220.00}\end{array}$

TOTAL $\quad 1,470$ hours

This gives a grand total of $\$ 63,036$ plus overhead costs.

The above estimate is probably on the high side because it is based upon this one case and verbal estimates from two local contractors in one small and relatively isolated town. The DOE-sponsored program to erect approximately twenty 170-ft towers at potential MOD-2 sites with two or three wind data gathering systems was obtained by competitive bidding throughout the country. The experience of that program may be able to provide more realistic cost estimates.

Two field test units are included in the above estimate; at the time of this report, Natural Power had not established a price for them. Also, no wind tunnel tests of the anemometer heads have been priced in. The user should have the equipment manufacturer furnish calibration curves or run special tests on anemometers.

DATA ANALYSIS

Data were analyzed by the following computer programs:
a. Daily max wind speed and direction.
b. Weekly max wind speed and direction.
c. Monthly max wind speed and direction.
d. Monthly median and mean wind speed.
e. Monthly speed frequency distribution.
f. Diurnal speed frequency distribution. 
g. Monthly wind duration curve.

h. Monthly mean wind power density by speed class.

i. Standard deviation of speed.

j. Exponent $k$ for vertical change of speed.

k. Gust analysis.

1. Wind speed differences.

m. Calculation of mean wind power density.

n. Calculation of wind energy accumulated by a MOD-2 WECS.

In addition, several subjective analyses were made. The daily wind maxima were compared with daily synoptic weather maps, and 17 cases of interesting wind speed and direction were studied to compare results with Wegley's hypotheses. Cases of probable icing or thunderstorms were noted. Mean wind speed and power densities were compared with results in Reed's (1977, 1979) analyses for consistency.

\section{DATA RESULTS}

A review of data for the 6-month period, 6 June through 5 December 1979, is in Table 1 on the next page. (For more detailed information see Tables in Appendix $C$. Appendix $F$ is a subjective analysis of several interesting wind conditions.)

The Program Opportunity Notice concerning the choice of sites for installation and field testing of the MOD-2 Wind Turbine specifies that any two turbines should be at least $2100 \mathrm{ft}$ apart along the direction of the prevailing wind velocity and at least $1500 \mathrm{ft}$ apart across the mean direction. These dimensions indicate that only one MOD- 2 should be located within the area encompassed by the six wind measuring stations.

An interesting result of the data is that the greatest mean wind speeds, power density and energy density, for $10 \mathrm{~m}$, were observed at station $\mathrm{F}$ which is to the east of the peak. The peak instrument at $10 \mathrm{~m}$ had about $11 \%$ less power density. 
Table 1. Summary of Data (June - December 1979)

\begin{tabular}{|c|c|c|c|c|c|c|c|c|c|}
\hline \multirow[t]{2}{*}{ Station } & & \multicolumn{2}{|c|}{$\begin{array}{l}\text { Mean } \\
\text { Speed }\end{array}$} & \multicolumn{2}{|c|}{ Standard Dev } & \multirow{2}{*}{$\begin{array}{l}\text { Mean } \\
\text { Power } \\
\text { Density } \\
\text { watts } / \mathrm{m}^{2}\end{array}$} & \multicolumn{2}{|c|}{$\begin{array}{l}\text { Maximum } \\
\text { Speed }\end{array}$} & \multirow{2}{*}{$\begin{array}{c}\text { Accumulate } \\
\text { Energy } \\
\text { Density } \\
\mathrm{kwh} / \mathrm{m}^{2}\end{array}$} \\
\hline & & $\mathrm{mph}$ & $\mathrm{m} / \mathrm{s}$ & $\mathrm{mph}$ & $\mathrm{m} / \mathrm{s}$ & & $\mathrm{mph}$ & $\mathrm{m} / \mathrm{s}$ & \\
\hline Center (20) & A & 19.0 & 8.5 & 9.5 & 4.2 & 550 & 70 & 31 & 2286 \\
\hline Center (10) & $\mathrm{B}$ & 18.4 & 7.7 & 9.0 & 4.0 & 487 & 61 & 27 & $1960 *$ \\
\hline North & $\mathrm{C}$ & 17.2 & 7.7 & 9.6 & 4.3 & 454 & 71 & 32 & 1841 \\
\hline West & $\mathrm{D}$ & 14.1 & 6.3 & 6.9 & 3.1 & 218 & 48 & 21 & $773 * x$ \\
\hline South & $E$ & 14.4 & 6.3 & 7.4 & 3.3 & 288 & 64 & 29 & 1192 \\
\hline East & $\mathrm{F}$ & 18.8 & 8.1 & 8.6 & 3.8 & 542 & 58 & 26 & 2229 \\
\hline
\end{tabular}

*No data after 25 Nov.

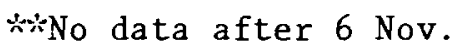

Thus, a power utility should consider installing a large WECS at the eastern location rather than the peak. The mean standard deviations of the wind speeds are nearly the same ( 9.5 vs $8.6 \mathrm{mph}$ ), which suggests no major differences in the gustiness, at least when averaged over six minutes.

A separate gustiness analysis is included in Appendix $\mathrm{F}$.

Figures 2 and 3 show that a predominately south-southwest wind would have speed enhancement as it came up the quasi-valley extending southward from a saddle between stations $A$ and $F$ (center and east). The wind at station $F$ was from the south or southwest $54 \%$ of the time during the 6 -month period. This is consistent with conclusions in Wegley's (1980) siting manual.

Reed's (1977, 1979) analyses of wind data for Clayton, NM, $64 \mathrm{~km}$ (40 miles) to the ESE indicate that the mean power density and mean wind speed during the months of June-Nov inclusive are 282 watts $/ \mathrm{m}^{2}$ and $14.3 \mathrm{mph}$ respectively. Similar observations from station $F$ at Sierra Grande are 542 and 18.8. The 
mean annual power density and mean annual wind speed at Clayton are 354 and 15.0. By comparison,

$$
\begin{aligned}
& \frac{282}{542}=\frac{354}{\mathrm{x}} ; \begin{array}{l}
\text { leads, to an estimated } 680 / \mathrm{m}^{2} \text { mean } \\
\text { annual power density at Sierra Grande, at } 10 \mathrm{~m}
\end{array} \\
& \frac{14.3}{15.0}=\frac{18.8}{\mathrm{x}} ; \begin{array}{l}
\text { leads to an estimated } 19.7 \mathrm{mph} \text { mean } \\
\text { annual wind speed at Sierra Grande, at } 10 \mathrm{~m}
\end{array}
\end{aligned}
$$

This is a very rough approximation taken from six months of data; for accurate yearly results at least one full year of observed data is needed at the site.

The exponents $\mathrm{k}$, for speed change with height, are shown relative to their frequency, speed, time of day and directions in Tables $\mathrm{C} 10, \mathrm{C} 11$ and $\mathrm{C} 12$ in Appendix $C ; k$ is derived from the two anemometers at the center, with $B$ at $10 \mathrm{~m}$ and $A$ at $20 \mathrm{~m}$. Speeds at $A$ of less than $14 \mathrm{mph}$ and greater than $45 \mathrm{mph}$ were excluded, to make them compatible with MOD-2 operations.

$$
v_{20}=v_{10}\left(\frac{20}{10}\right)^{k} ; \text { so } k=\frac{\log \left(\frac{V_{20}}{V_{10}}\right)}{\log \left(\frac{20}{10}\right)}
$$

The mean value of $k$ was +0.064 with a standard deviation of 0.16 for the 6month period and calculated every 6 minutes. The standard deviations were about three times the $\mathrm{k}$ values at $14 \mathrm{mph}$ and decreased to about $3 / 4 \mathrm{k}$ at $44 \mathrm{mph}$ with a generally linear change. The $\mathrm{k}$ values varied the least around midmorning and the greatest around sunset and sunrise with fairly large variations throughout the night. See Tables C16, C17, C18, and C19.

Because there were some time base errors between the $10-m$ and $20-m$ data loggers, these $k$ results are not completely reliable. One timing system should have operated both data loggers. This should be possible by disconnecting the timing system in one set and appropriately connecting the set with wires to the timing system in the other data logger. 
Considering these results with minimum wind speeds at midday, we hypothesize that during midday the warmer mountain creates a local mountain wind (anabatic flow) with an appreciable upward flow. This upward flow mixes air with lesser horizontal momentum with the free stream flow resulting in a well-mixed (small k) layer of air with lesser horizontal velocity (lower wind speed). At night the colder mountain causes stratified flow with larger $k$ variations and faster horizontal flow.

\section{ESTIMATE OF A LARGE WECS ENERGY OUTPUT ON SIERRA GRANDE}

The energy output of a MOD-2 WECS for the six-month period was estimated, using observed wind speed at site $A$ (20 m height at the top) and information provided by the Boeing Engineering and Construction Company (1979). The MOD-2 produces rated power of $2,500 \mathrm{~kW}$ in a wind speed of $27.5 \mathrm{mph}(12.3 \mathrm{~m} / \mathrm{s})$. Its cut-in wind speed is $14 \mathrm{mph}(6.3 \mathrm{~m} / \mathrm{s})$ and its cutout speed is $45 \mathrm{mph}(20.1 \mathrm{~m} / \mathrm{s})$. These speeds are for hub height and installation at sea level. The MOD-2 is the largest wECS yet built, with a 200 foot $(61-m)$ tower and two blades, $300 \mathrm{ft}(91.5-\mathrm{m})$ in diameter.

Appendix F explains how the accumulated energy from the MOD-2 was calculated.

Assuming $\mathrm{k}=1 / 7$ from $20 \mathrm{~m}$ to hub height we calculated a total of 4.5 million $\mathrm{kWh}$ should have been produced during the six months. If the $\mathrm{k}$ value from $20 \mathrm{~m}$ to hub height is the same as the instantaneous $\mathrm{k}$ value from $10 \mathrm{~m}$ to $20 \mathrm{~m}$, the calculations result in $3.7 \mathrm{million} \mathrm{kWh}$ for the same six months. This is an example of the uncertainties of extrapolating wind speeds to higher elevations.

Although long-term wind speed and power data have been observed at Clayton, 40 miles $(64 \mathrm{~km})$ away, we did not consider it appropriate to extrapolate the 6 months of MOD-2 calculations to a full year. It seems certain that the wind would be stronger at Sierra Grande during the other six months of the year, December through May, and that the MOD-2 would produce more power. However, it is inaccurate to use mean wind speeds for six months to estimate the wind energy accumulated during the same time. In addition, there will be an increase in the number of hours of wind above $45 \mathrm{mph}$, which introduces another 
uncertainty. Consequently, no estimate was made for the yearly output of a MOD-2 at Sierra Grande.

CONCLUSIONS

The major conclusions of the Sierra Grande experiment are:

1. The concept of direct measurements of winds at several points on a mountain is feasible and can depict variations in wind energy potential over distances of several hundred meters. Data loggers with timing capability are necessary to analyze the temporal flow over a mountain and to depict the diurnal flow.

2. Towers to hub height having wind velocity measured every 2 minutes with direction to the nearest $10^{\circ}$ appear necessary to accurately calculate the wind energy to be produced by a large WECS on a mountain. The cost of such tall towers and equipment will be high. Shorter towers require the extrapolation of wind speed with height which is uncertain in mountain areas. Ten-meter wooden poles installed by an electrical utility company truck were found to be the most practical method in this experiment. However, heavy trucks could not be used at all mountain sites.

3. This methodology, using battery power to record wind speed and direction observations on magnetic tape every six minutes (or even as frequently as every two minutes) and replacing the tapes monthly, should be good after several improvements are made:

a. A reliable, accurate tape reader must be provided which can read taped data directly into all standard computers; or a suitable alternative data reduction service should be made available.

b. A complete calibration of the entire system of six sets of sensors and six recorders is a sizeable undertaking, but is necessary before installation. 
c. The field calibration method, using a separate calibrated anemometer and the set of two test kits (field reader and sensor checker), appears to be a good procedure. The test kit should be used every time a tape is changed, and the separate anemometer every three or four months or if data look questionable.

d. The equipment needs to have stronger anemometer cups, stronger direction vanes and a direction vane that changes direction much more slowly.

e. The clock needs to be more stable to avoid resetting during the month of data collection. It is vital that two instruments for calculating $\mathrm{k}$ have their time constantly synchronized. It is important that all instruments operate on fairly closely synchronized time.

3. Estimated cost and manhours for a typical application of this concept and methodology for a year is estimated to be $\$ 63,035$ plus overhead in 1980 dollars.

4. Sierra Grande showed a wind speed and wind power minimum during midday.

5. The estimated energy from a MOD-2 situated at the peak was calculated to be 4.5 million $\mathrm{kWh}$ from June 6 to Dec 5 . This was based on wind speeds extrapolated from $20 \mathrm{~m}$ to hub height $61 \mathrm{~m}$ using the $1 / 7$ power law.

6. The mean wind speed and mean power density at $10 \mathrm{~m}$ and at the "best" location is $18.8 \mathrm{mph}$ and $542 \mathrm{~W} / \mathrm{m}^{2}$ for a six-month period (6 June - 5 December). Comparing these with similar data for Clayton, NM, this extrapolates to an estimated annual $19.7 \mathrm{mph}$ and $680 \mathrm{~W} / \mathrm{m}^{2}$, respectively, for Sierra Grande.

7. The mean exponent for wind speed changes from $10 \mathrm{~m}$ to $20 \mathrm{~m}$ was estimated to be +0.064 , somewhat less than the traditional to.14 value over flat land.

8. The location of the site near this peak could vary the yearly energy output by an estimated factor of 2.5 , by comparing the western with the eastern site.

9. Sierra Grande has some significant icing problems. 


\section{RECOMMENDATIONS:}

1. Wind measurements every two minutes with direction to the nearest 10 degrees are needed at hub height for a year to calculate an accurate estimate of the annual energy output to be expected from a large WECS in mountainous areas. These data are needed to calculate outages due to speed and direction variations. Ten-meter towers should be used to compare the wind power density at different locations.

2. The distance between the investigator and the site should be minimized as much as possible to decrease personnel scheduling problems and travel expenses.

3. The instrumentation should have a reader that will put data from the cassette tape directly into any standard computer; the anemometers need to be stronger; the wind vanes need to be stronger and with a much slower response time.

4. Exact synchronization of two or more observations on one tower should be mandatory so that calculations of $k$ are possible and realistic.

5. Sierra Grande should be seriously considered as a location for a large WECS. Some locations slightly further from the peak should be investigated.

6. A study to find less expensive ways to put up $30-\mathrm{m}$ or taller towers in remote areas is recommended.

7. It is recommended for any future operation that a dedicated minicomputer for field tests be mated to the reader if a simple reduction and associated program is needed. In the event that a more sophisticated program is desired, a reader mated to a Universal Asynchronous Receiver Transmitter (UART) would allow data from the RS 232 port to be fed into a large computer. 


\section{REFERENCES}

1. Baker, R. W. and John E. Wade, et al. 1978. "Wind Energy Prospecting." Wind Power Digest, No. 14.

2. Boeing Company Report. July 1979. MOD-Wind Turbine System Concept and Preliminary Design Report, Volume II, Detailed Report. NASA CR-159609. National Aeronautics and Space Administration, Washington, DC.

3. Hennessey, J. P. 1979. "Some Aspects of Wind Power Statistics." Journal of Applied Meteorology, 16:119-129.

4. Natural Power Company, New Boston, New Hampshire. Literature Concerning Their Cassette Data Logger Model.

5. Reed, J. 1977. "Wind Power Climatology of the United States.' SAND74-0348, Sandia Laboratories, Albuquerque, New Mexico.

6. Reed, J. W. 1979. "Wind Power Climatology of the United States Supplement." SAND78-1620, Sandia Laboratories, Albuquerque, New Mexico.

7. Wegley, H. L., et al. May 1978. A Siting Handbook for Small Wind Energy Conversion Systems. PNL-2521. Pacific Northwest Laboratory, Richland, Washington. 
APPENDIX A 
APPENDIX A

BUFFER INTERFACE

RELATED PROBLEMS

The wind data tapes are read on a Memodyne Reader Model 3122BV. Three types of output data are available from this reader:

\author{
1. Serial RS232 Data \\ 2. 8-bit Parallel Data \\ 3. 8-bit Parallel First-In-First-Out ( FIFO) Data.
}

These data outputs are in such a form that the data reduction is very cumbersome and needs a microcomputer-based interface to look at the data. A quick look at the data to verify the tapes also requires external equipment.

A printer was hooked up to the FIFO output with some success; however, the printout was not like the stated format.

The data just couldn't be connected to a computer or other devices as easily as the manual states. The manual for both the reader and the data logger are not written well and are confusing to the reader. The operation of both units is not explained well. The data outputs of the reader are not well defined and are confusing; therefore, it is hard to tell what outputs the reader has.

Data reduction of the wind data had to be done one of two ways:

1. A microcomputer-based interface had to be built to buffer the data between the reader and the university or PSL computer.

2. An interface had to be built for an existing PDP-11 computer. This computer will then format the data and put it on a 9-track computer tape. The tape could then be read by the university or PSL computer.

This last method was the one chosen. 
Figure $A-1$ is a logic diagram of a Memodyne $3122 /$ PDP-11 Buffer Interface. Figure A-2 is a circuit diagram of a Memodyne 3122/PDP-11 Buffer Interface.

MEMODYNE $3122 /$ PDP-11 INTERFACE

This interface was fabricated on a MDB Systems, Inc. MDM-1710 general purpose interface module. The $\mathrm{MDB}-1710$ consists of a single quad module containing the following:

1. Fixed logic to interface with a PDP-11 Unibus and with User's interface logic built on the module.

2. Circuit board facilities and wire-wrap posts to accommodate up to 40 integrated circuit devices.

The logic diagram of the MDB-1710 is shown on sheet 1 of 2 . Sheet 2 of 2 shows the added circuits to interface to the Memodyne Reader.

This interface is used to route the eight bits of First-In-First-Out (FIFO) data from the Memodyne Reader to the computer. $\overline{\text { FIFO READY }}$ is used to notify the computer that the data is available or ready. The computer will pulse shift out as it takes the data. Shift out will cause the FIFO to shift in the next data. This will cause $\overline{\text { FIFO READY }}$ to pulse and start the process again. This will continue until all 64 words are transferred out of the FIFO buffer. RUN/ $\overline{\text { HOLD }}$ will go to a logic zero prior to taking the first word. This was done so that the reader would stop reading after a read cycle, 64 words. The computer takes these 64 words and writes them on the 9 -track digital tape. The interface then starts the read process again after it completes writing to the 9 -track tape. 


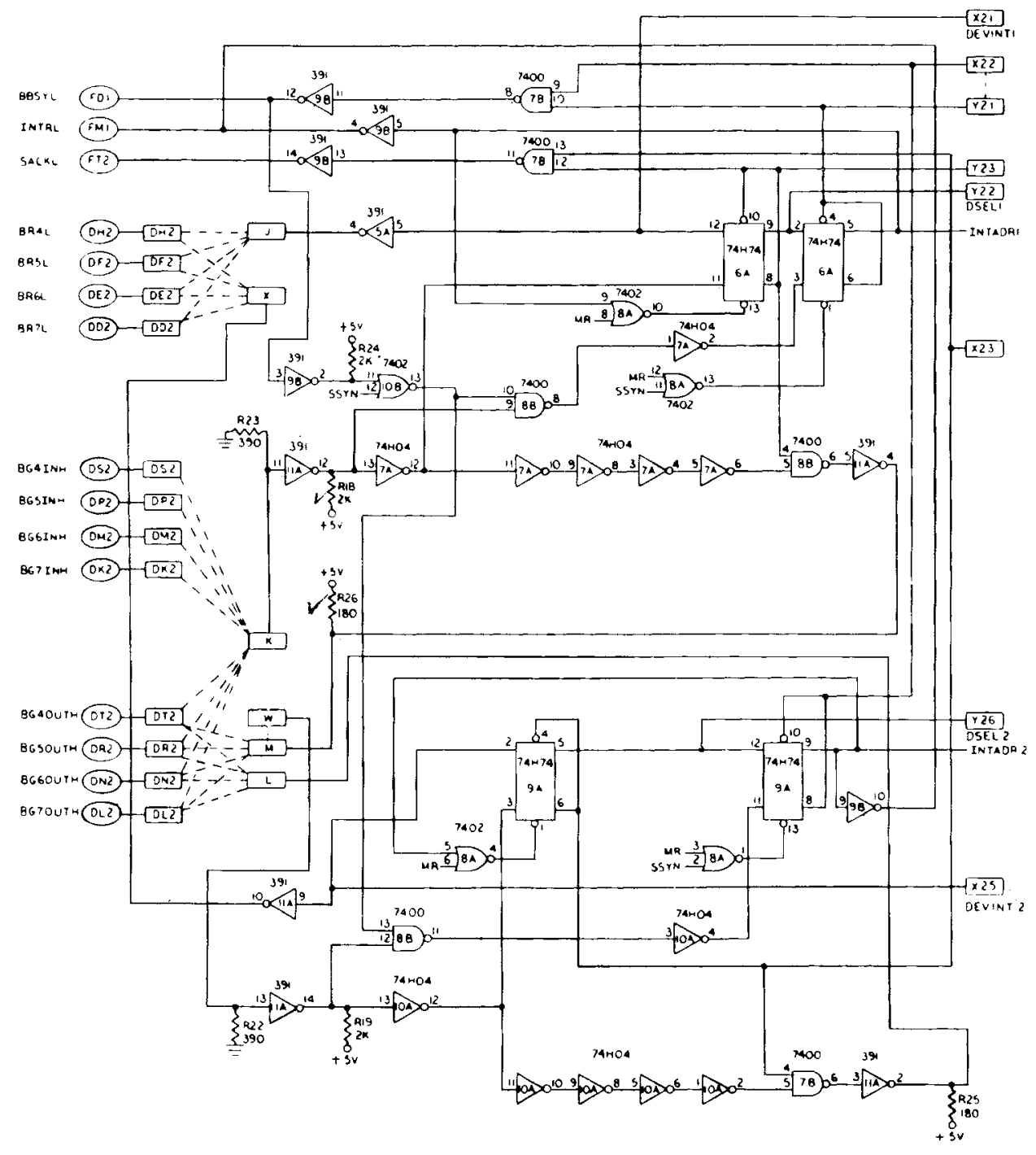

s.opass ano orcoos

ssime (E1) - $\frac{\sqrt{25}}{1}$

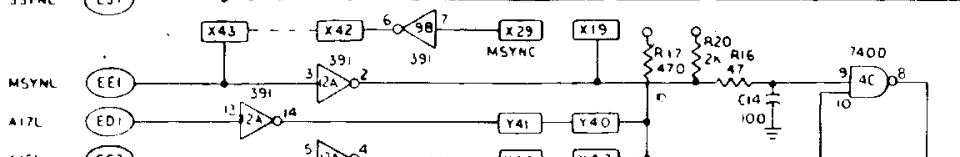

${ }_{1,51}$

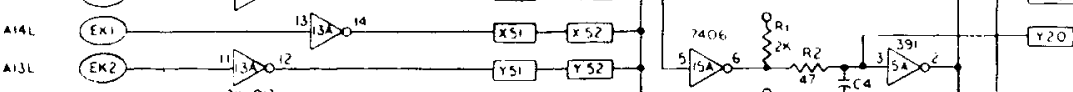

1.22 (6in)

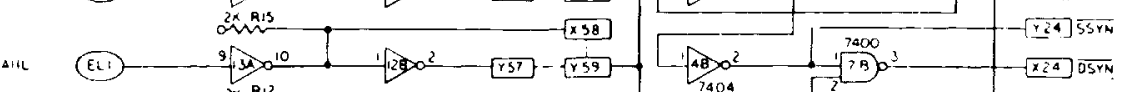

.1.0. (5i9) -

.020 (181)-

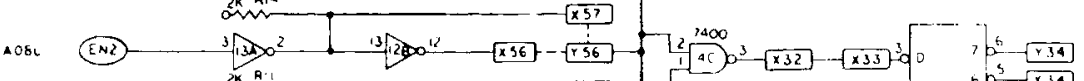

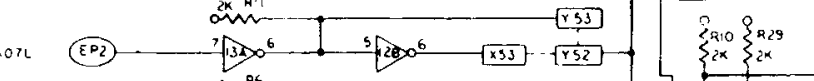

2.

(ob) (iil)

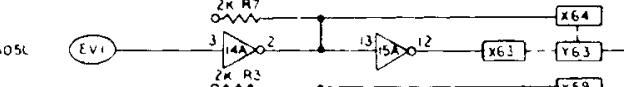

ara (602)-

(102)-

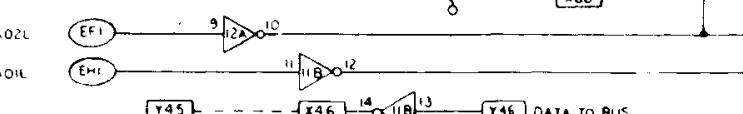

(1) (ifis)

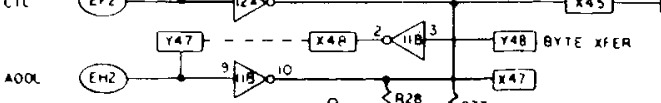

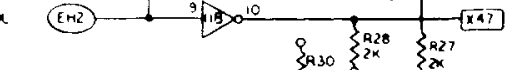

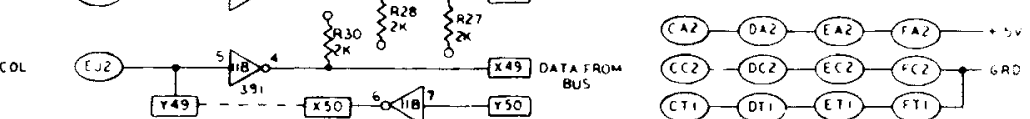
(iii)-(0ii) (iii)-iii] oxin 1/0 ous

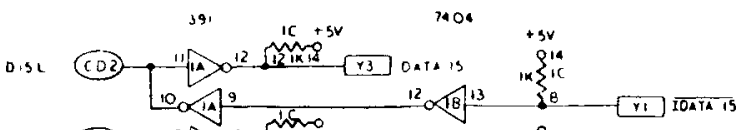

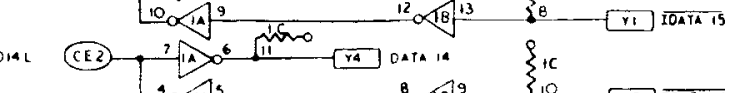

1.52 (다)

1.2. (142)

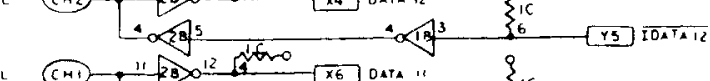

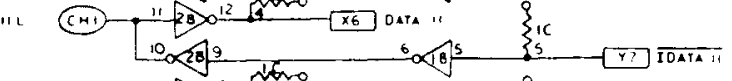

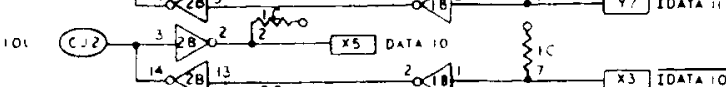

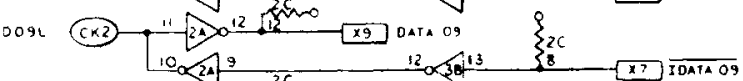

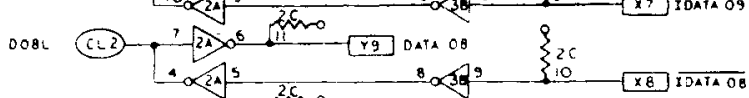

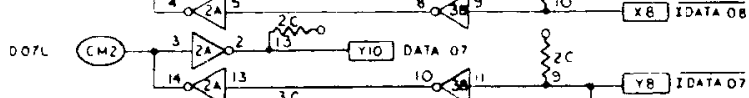

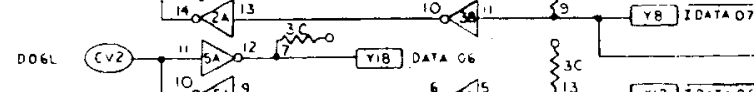

Dosi (192) ?

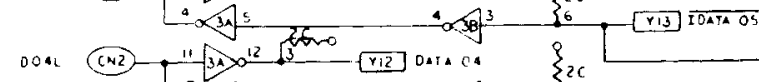

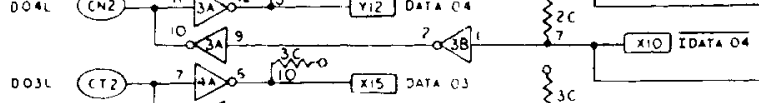

(19) -

Door (1002) [

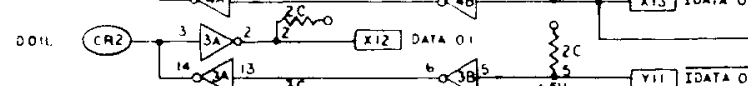

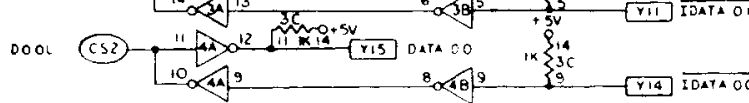

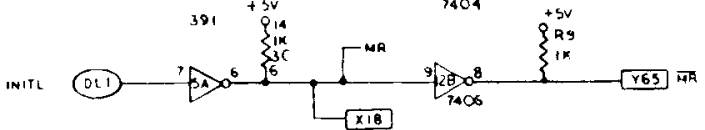

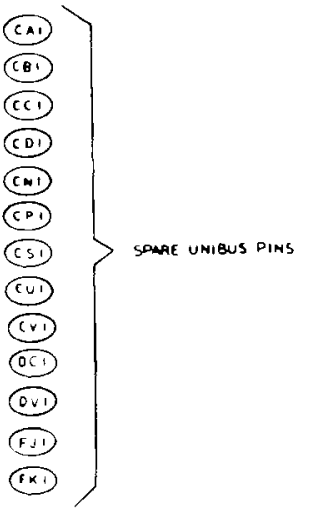

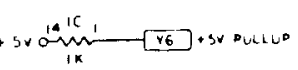

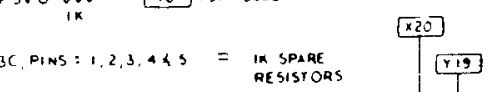

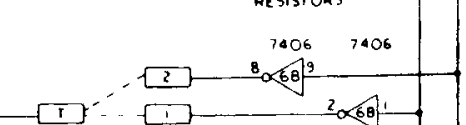

(7)-8 0

$[n]-$

잔.

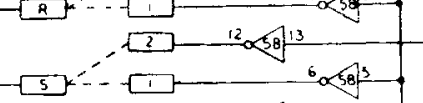

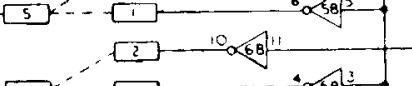

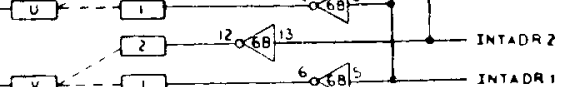

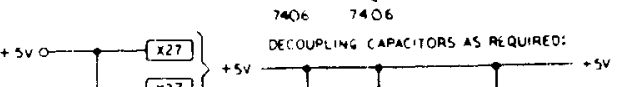

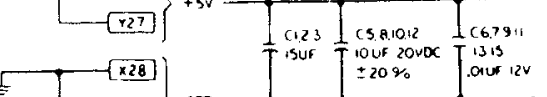

$\square$

LOGIC DIAGRAM, MDB-1710

Memodyne 3122/PDP-11 Interface Sheet 1 of 2 


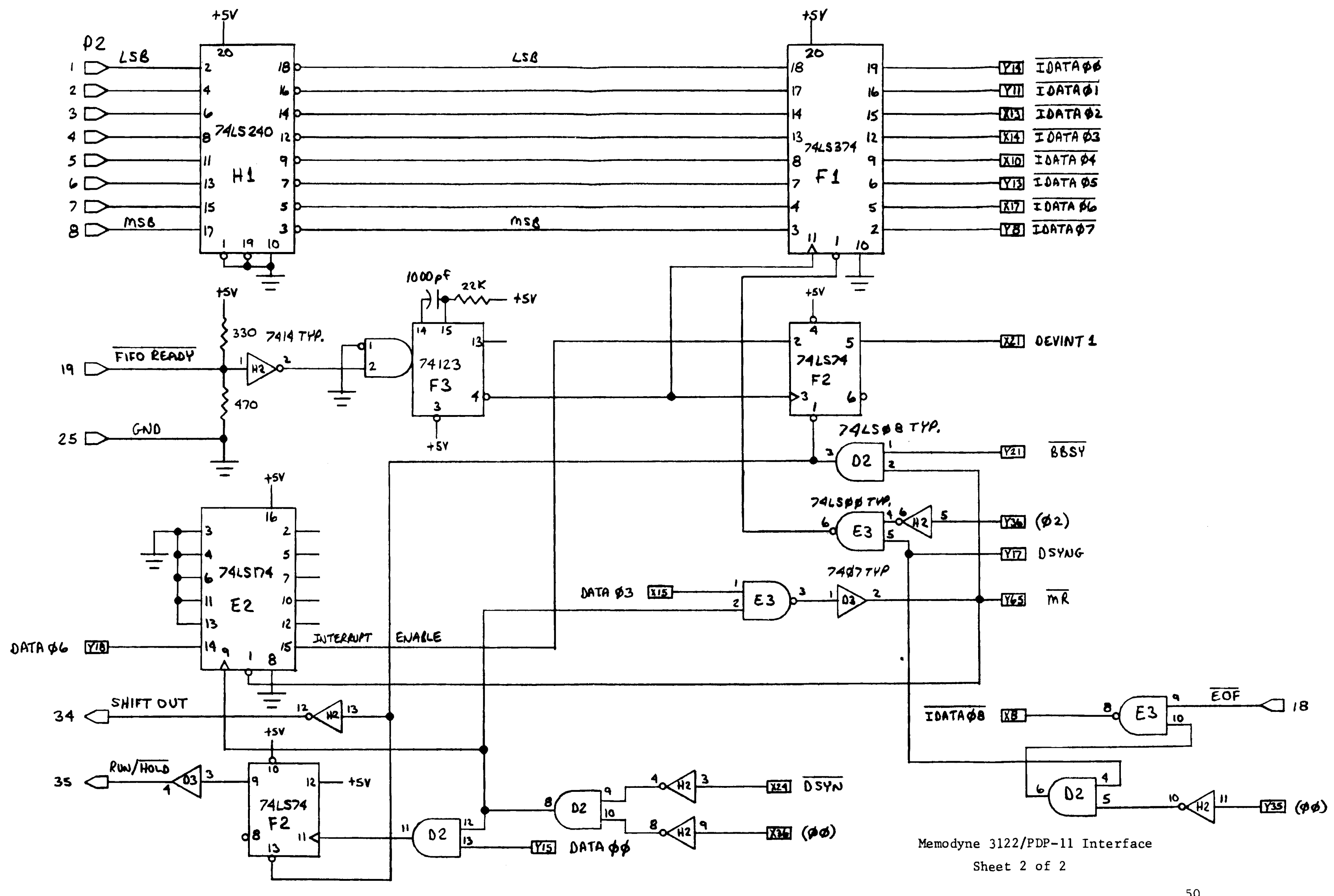


APPENDIX B 


\section{APPENDIX B}

Letter from Natural Power, Inc.

(Prepared in response to reading an earlier draft of this report.) 


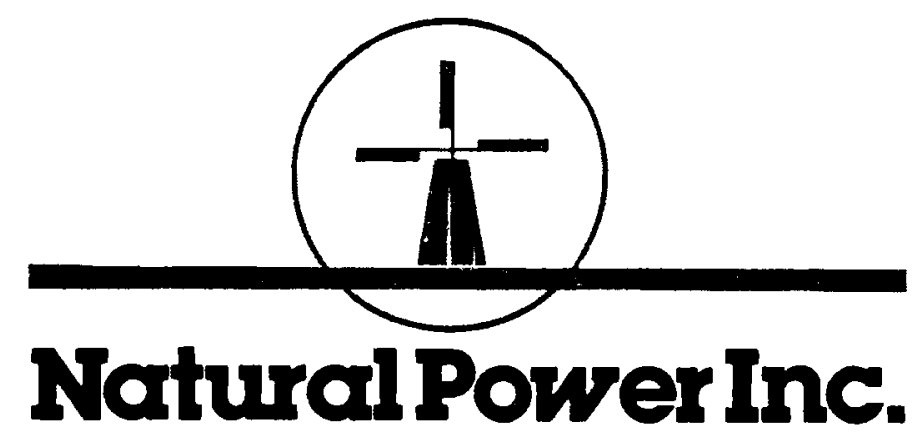

New Boston, New Hampshire $03070 \quad 603-487-5512$

Apri1 10, 1980

Kenneth M. Barnett

Physical Science Laboratory

New Mexico State University

Box 3 PSL

Las Cruces, NM 88003

Dear Mr. Barnett:

I have reviewed a draft copy of report \#PNL-3623 and submit the following observations:

The data collection system used in the study was new and had little operating time in an exposed environment. The system was tailored to your requirements, to the extent it was practical. It was constructed in a modular fashion using commercially available subsystems wherever possible.

The tape transport and control electronics, as well as the tape reader, are commercially available. The sensor amplifier, real time clock and timing electronics were designed and manufactured by Natural Power.

The enclosure was also designed by Natural Power.

The commercially available hardware, produced by Memodyne, was selected for many reasons, one of which was to minimize interface problems. The trouble you experienced in retrieving data from the cassettes was aggravated by Natural Power's lack of experience with the reader and Memodyne's poor documentation for that device. It was expected that there would be little trouble transmitting data from the Memodyne reader to the host computer as the reader was a standard product. There occurred a great many unanticipated problems with the reader which can be avoided in the future.

The reader returned to NPI was damaged in transit and was only received toward the end of March. This delayed evaluation of the Data Loggers returned to NPI. Incoming inspection revealed that all six Data Loggers were $100 \%$ electrically functional. Two questionable switches were detected, but did not seem to impair operation. A test was subsequently run with four of the units at our facility, outdoors, in sub-zero temperatures. All units performed perfectly. 
The climate in which you placed the Data Loggers was the most severe test of equipment which we have encountered. NPI has never observed fatique or destruction of anemometers or directions sensors of the type employed in your study under other circumstances. Our best estimate of the mechanical problems experienced is; they are the result of ice induced imbalance in high winds. You experienced electrical problems with the wind direction sensor resulting from units improperly assembled by a jobber. A star washer was inadvertantly substituted for a split washer inside the head. This problem has been corrected.

As a result of the Data Logger being custom tailored to your requirements, the sensor tester and field reader design lagged delivery of the Data Logger. The units employed for this study were hand-built models. Both units will shortly be standard NPI products.

The errors you observed, including multiple headers, real time clock jumps and short files can all be generated using the front panel controls. It has not been possible to recreate errors of the type you observed using external influences. It is hypothesized that the above are the result of high potential gradients between system components. The high potentials can be experienced in exposed terrain when highly charged clouds are overhead. A discharge in the form of lightning is not required. Natural Power feels that the addition of external lightning arrestors and lightning rods above the sensors would greatly reduce this source of malfunction. We are pleased that in every instance the Data Loggers seem to have resumed normal operation after the source of interference cleared. Some perturbation of recorded data is unavoidable. It is recognized that some means of accurately synchronizing the clocks is required. A remedy is to include a pyranometer in the system to record solar insolation. By comparing the times of sunset or sunrise, all instruments in the general area could be synchronized, even in the influence of disruptive interference. Such a scheme would also provide information on solar radiation, potentially valuable to WECS designers.

Natural Power has gained experience with the Memodyne tape reader and we stand ready to assist in retrieving cassette data via this device. Your recommendation of including one word of ones, instead of zeros in each sample is easily accomplished. If you feel it will assist you in unpacking cassette data, this modification can be completed on the present units.

We look forward to a fruitful relationship with you and your associates in the future.

Sincerely,

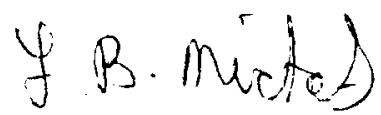

L. B. Nichols

Chief Engineer 
APPENDIX C 


\section{APPENDIX C}

\section{TABULATED RESULTS OF WIND MEASUREMENTS}

\section{TABLES}

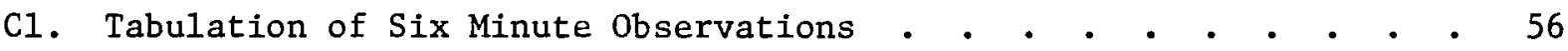

C2. Sumnary of Wind Data, Power and Energy Calculations. • • • • 57

C3. Wind Summary for Station A (Center, $20 \mathrm{~m}$ ) • . . . . . . . 60

C4. Wind Summary for Station B (Center, $10 \mathrm{~m}$ ) . . . . . . . . $\quad 61$

C5. Wind Summary for Station C (North, $10 \mathrm{~m})$. . . . . . . . . 62

C6. Wind Summary for Station D (West, $10 \mathrm{~m}$ ). . . . . . . . . . 63

C7. Wind Summary for Station E (South, $10 \mathrm{~m}$ ) . . . . . . . . 64

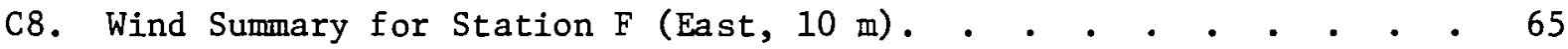

FIGURES

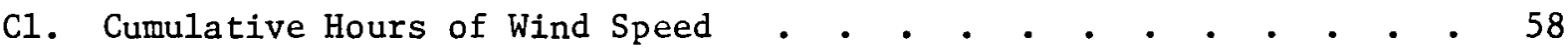

C2. Diurna1 Wind Speed Variations at Station A (Center, $20 \mathrm{~m}$ ). . . . 67

C3. Diurnal Wind Speed Variations at Station B (Center, $10 \mathrm{~m}$ ). . . 68

C4. Diurnal Wind Speed Variations at Station C (North, $10 \mathrm{~m}$ ) . . . 69

C5. Diurna1 Wind Speed Variations at Station D (West, $10 \mathrm{~m}$ ).$\quad$. 70

C6. Diurnal Wind Speed Variations at Station E (South, $10 \mathrm{~m}$ ) • • • 71

C7. Diurnal Wind Speed Variations at Station F (East, $10 \mathrm{~m}) \quad$. . . 72

C8. Frequency of Exponent k • • • • • • • • • • • • • •

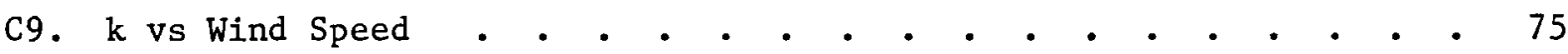

C10. k vs Time of Day . • • • • • • • • • • • • • • • . 76

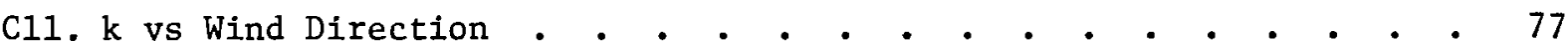


TIMF STATION A STATION B STATION C STATION D STATION E STATION F

DATE HH.MA SPEED DIR. SPEED DIR. SPEED DIR. STEED DIR. SPEED DIR. SPEED DIR. K(AB)

$\begin{array}{lllllllllllllll}08 / 12 / 79 & 17.48 & 32.5 & \text { W } & 27.5 & \mathrm{~S} & 26.0 & \mathrm{~W} & 22.5 & \mathrm{~W} & 24.0 & \mathrm{NW} & 29.5 & \mathrm{~S} & 0.241 \\ 08 / 12 / 79 & 17.54 & 32.5 & \mathrm{~W} & 28.0 & \mathrm{~S} & 25.5 & \mathrm{~W} & 21.5 & \mathrm{~W} & 23.0 & \mathrm{NW} & 28.0 & 5 & 0.215 \\ 08 / 12 / 79 & 18.00 & 33.0 & \mathrm{~W} & 28.0 & \mathrm{~S} & 25.5 & \mathrm{~W} & 21.5 & \mathrm{~W} & 23.5 & \mathrm{NW} & 30.0 & \mathrm{~S} & 0.237 \\ 08 / 12 / 79 & 18.06 & 35.0 & \mathrm{~W} & 26.5 & \mathrm{~S} & 24.0 & \mathrm{~W} & 20.5 & \mathrm{~W} & 22.5 & \mathrm{NW} & 31.0 & \mathrm{~S} & 0.401 \\ 08 / 12 / 79 & 18.12 & 34.5 & \mathrm{~W} & 26.5 & \mathrm{~S} & 24.5 & \mathrm{~W} & 20.0 & \mathrm{~W} & 20.5 & \mathrm{NW} & 29.5 & \mathrm{~S} & 0.381 \\ 08 / 12 / 79 & 18.18 & 36.0 & \mathrm{~W} & 24.0 & \mathrm{~S} & 24.5 & \mathrm{~W} & 20.5 & \mathrm{~W} & 20.0 & \mathrm{NW} & 27.5 & \mathrm{~S} & 0.585\end{array}$

TABLE C1 Sample Tabulation of Six-Minute Observations. This sample covers 30 minutes.

These Data are Available on Magnetic Tape and can be provided at cost of duplicating and mailing the tape. Contact the NMSU Physical Science Laboratory. 


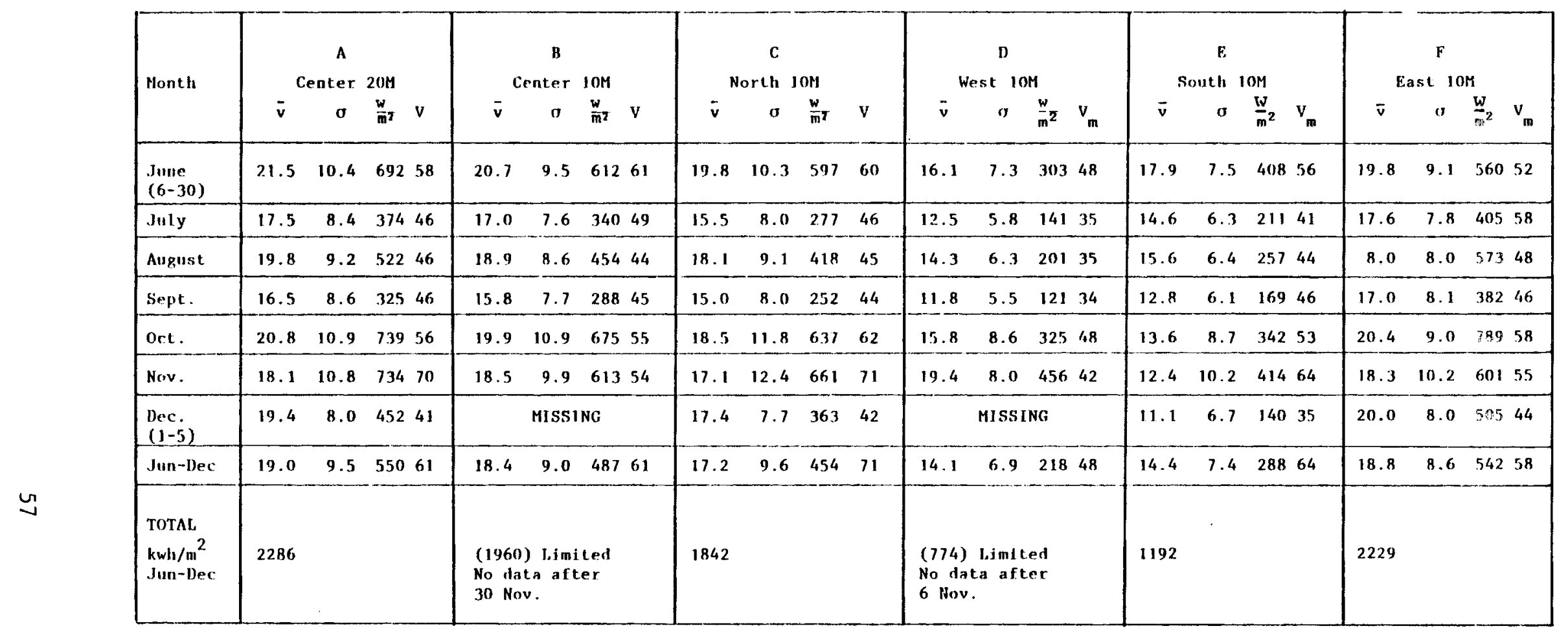

$\bar{v}=$ mean wind speed (mph)

${ }_{m^{2}}^{w}=$ inean power density

$v_{m}=$ maximum wind speed $(m p h)$

TABLE C2 Summary of Wind Data, Power and Energy Calculations. 


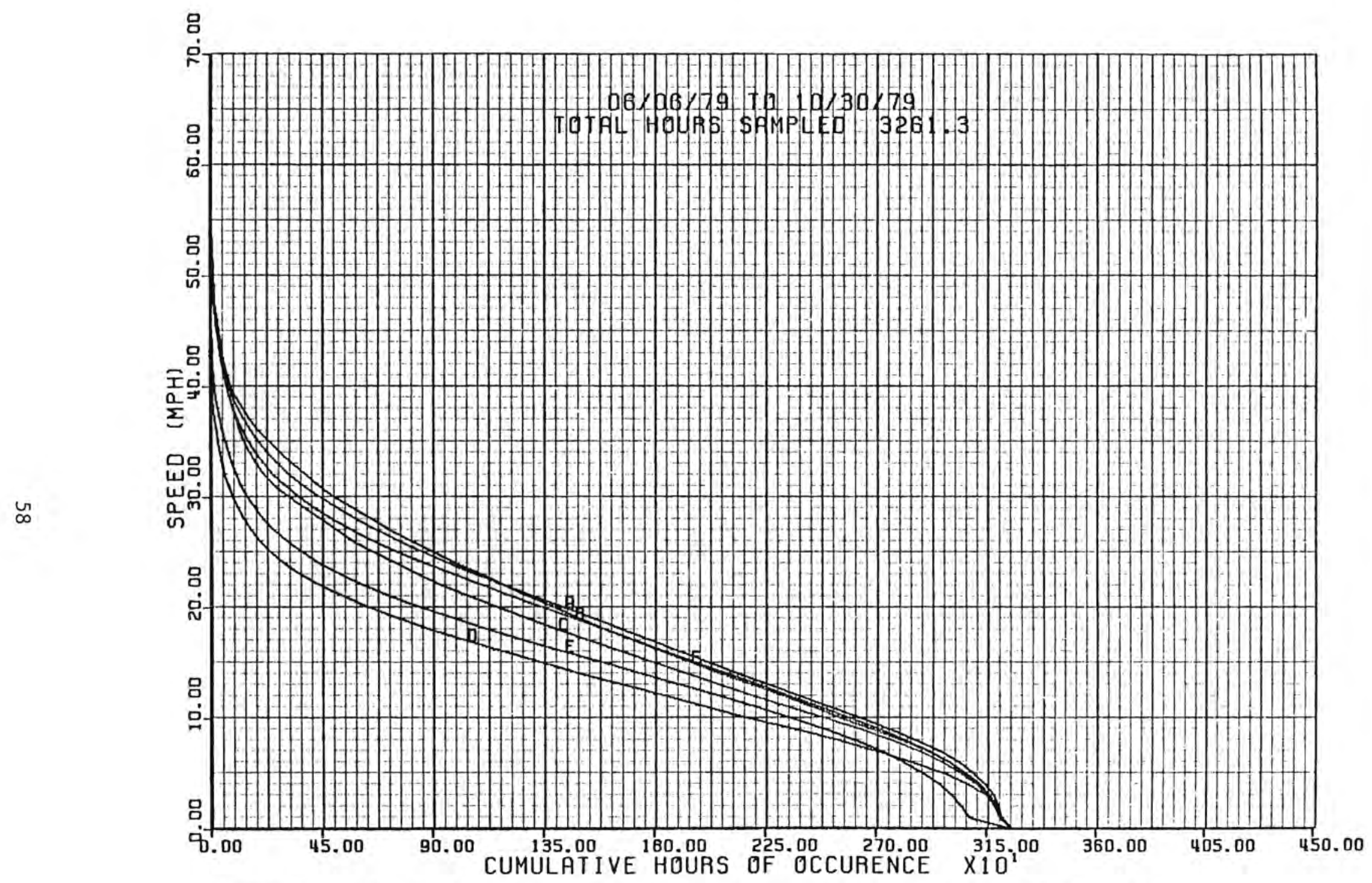

FIGURE C1 Cumulative Hours of Wind Speed, Sierra Grande during 3261 hours Between June and November 1977. 
COMMENTS CONCERNING WIND SUMMARIES FOR TOTAL SIX MONTHS, TABLES C3 to C8

Because of anemometers being stopped by icing or by physical damage, a large percentage of calm winds were originally recorded in late October and November. The data tapes were edited by comparison with daily synoptic weather maps. In those cases when calm winds were reported while the maps showed significant wind speeds, these individual, six-minute, wind speed observations were deleted from the data processing. We believe this resulted in more accurate calculations of mean wind speeds, mean wind power densities, and total wind energy densities. However, this did leave some discrepancies between the "\% of time in wind speed range" and "hours" in wind speed range. By completely reanalyzing all data, these discrepancies could have been avoided. This reanalysis was not done due to time limitations. We believe the speed, energy and power data are correct. This is partially confirmed by comparing the mean wind power densities for each month and six months at each station with the "expectation of the third moment", using mean wind speed, mean standard deviations and skewness, as explained by Hennessy (1977). A correlation coefficient of $0.99+$ was found between the calculations, involving 42 sets of data based on approximately 250,000 wind observations. 
STATION A

WIND SUMMARY FOR TIHE PERIOD

06/06/79 THRU 12/05/79

PERCENTACE FREQUENCY OF OCCURRENCE

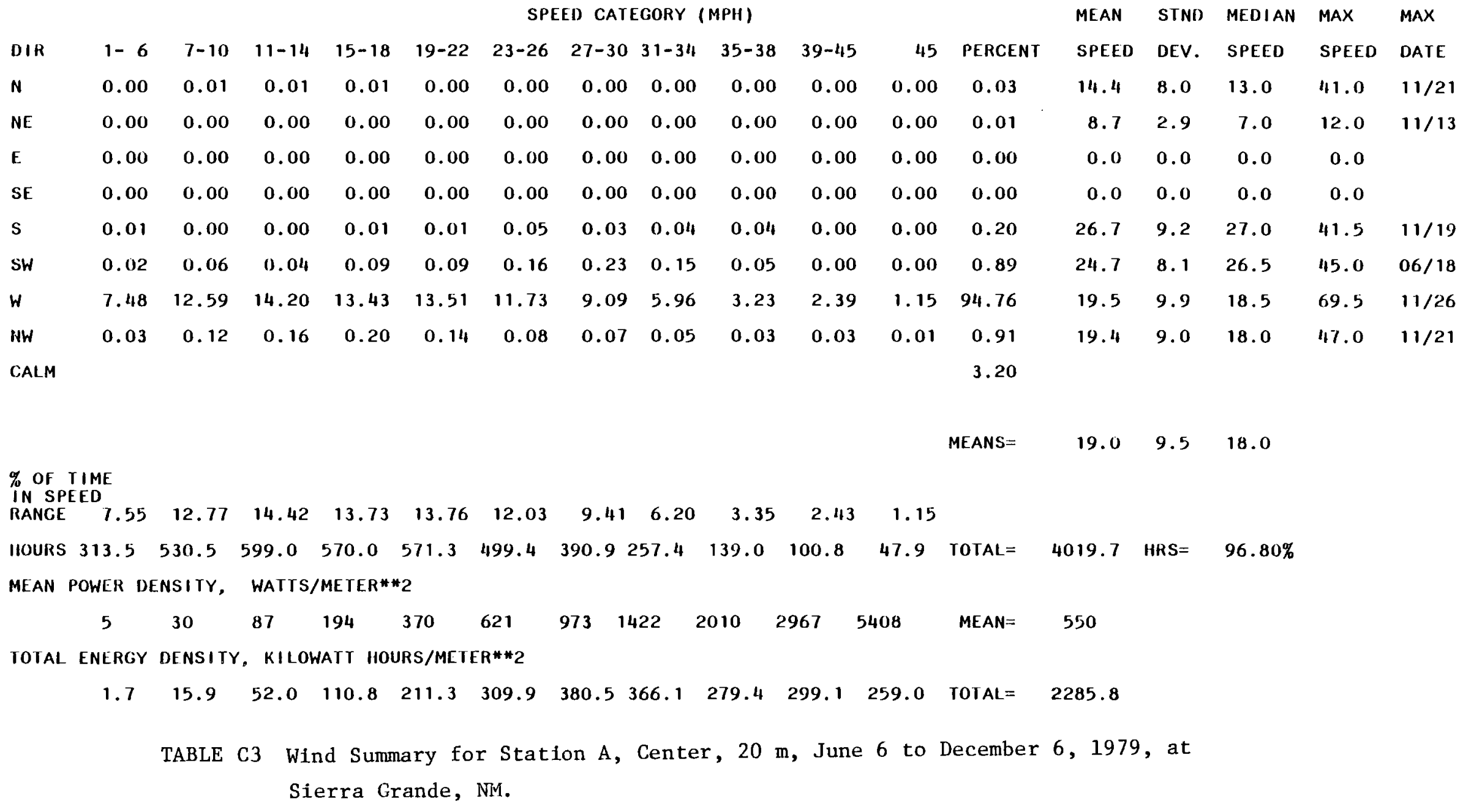


STATION B

WIND SUMMARY FOR THE PERIOD

06/06/79 THRU 11/25/79

PERCENTAGE FREQUENCY OF OCCURRENCE

SPEED CATEGORY (MPH)

DIR

N

NE

SE $\quad 0.03$

$\mathrm{s} \quad 0.68$

SW $\quad 1.55$

W 2.63

NW $\quad 3.14$

CALM $\begin{array}{llll}-26 & 27-30 & 31-34 & 35-38\end{array}$

0.010 .03

0.00

0.00

0.07

0.16

0.01

0.00

0.01

0.00

0.00

0.00

0.00

0.18

1.14

4.08

4.013 .73

$5.37 \quad 5.34$

1.08

3.86

3.41

5.85

$\begin{array}{lll}0.00 & 0.01 & 0.01\end{array}$

$0.00 \quad 0.00$

0.410 .28

2.811 .45

0.75

$2.91 \quad 2.76 \quad 1.55$

0.89

0.80

$3.33 \quad 1.99$

$39-45$
0.00
0.01
0.02
0.00
0.09
0.53
0.84
0.55

45

PERCENT

MEAN SIND MEDIAN MAX

MAX

0.00

0.07

SPEED

EV. SPEED SPEED

DATE

0.00

0.20

$17.7 \quad 11.3$

$15.5 \quad 11 / 14$

.00

0.41

$14.7 \quad 7.9 \quad 13.0$

47.0

$11 / 18$

0.00

0.12

$9.7 \quad 4.1 \quad 10.5$

$44.5 \quad 11 / 21$

0.01

7.07

17.5

$11 / 12$

25.64

19.7

48.0

$06 /: 8$

27.54

52.0

$10 / 20$

35.92

$18.7 \quad 8.8 \quad 18.5$

49.0

$06 / 19$

3.02

MEANS=

$18.4 \quad 9.0 \quad 18.5$

\% OF TIME

IN SPEED

$\begin{array}{llllllllllll}\text { IN SPNGE } & 8.09 & 12.67 & 14.91 & 14.67 & 14.21 & 12.45 & 9.34 & 5.30 & 2.63 & 2.04 & 0.67\end{array}$

$\begin{array}{lllllllllllll}\text { HOURS } 325.8 & 510.3 & 600.2 & 590.9 & 572.2 & 501.3 & 376.1 & 213.5 & 105.8 & 82.3 & 26.8 & \text { TOTAL= } & 3905.2\end{array}$ HRS $=\quad 96.86 \%$

MEAN POWER DENSITY, WATTS/METER*\#2

$\begin{array}{llllllllllll}5 & 30 & 88 & 195 & 368 & 616 & 965 & 1413 & 2000 & 3047 & 4815 & \text { MEAN= }\end{array}$

TOTAL ENERGY DENSITY, KILOWATT HOURS/METER\#\#2

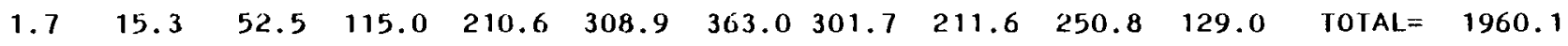

TABLE C4 Wind Summary for Station B, $10 \mathrm{~m}$, June 6 to November 25, 1979, at

Sierra Grande, NM. 
STATION C

WIND SUMMARY FOR THE PERIOD

06/06/79 THRU 12/05/79

PERCENTAGE FREQUENCY OF OCCURRENCE

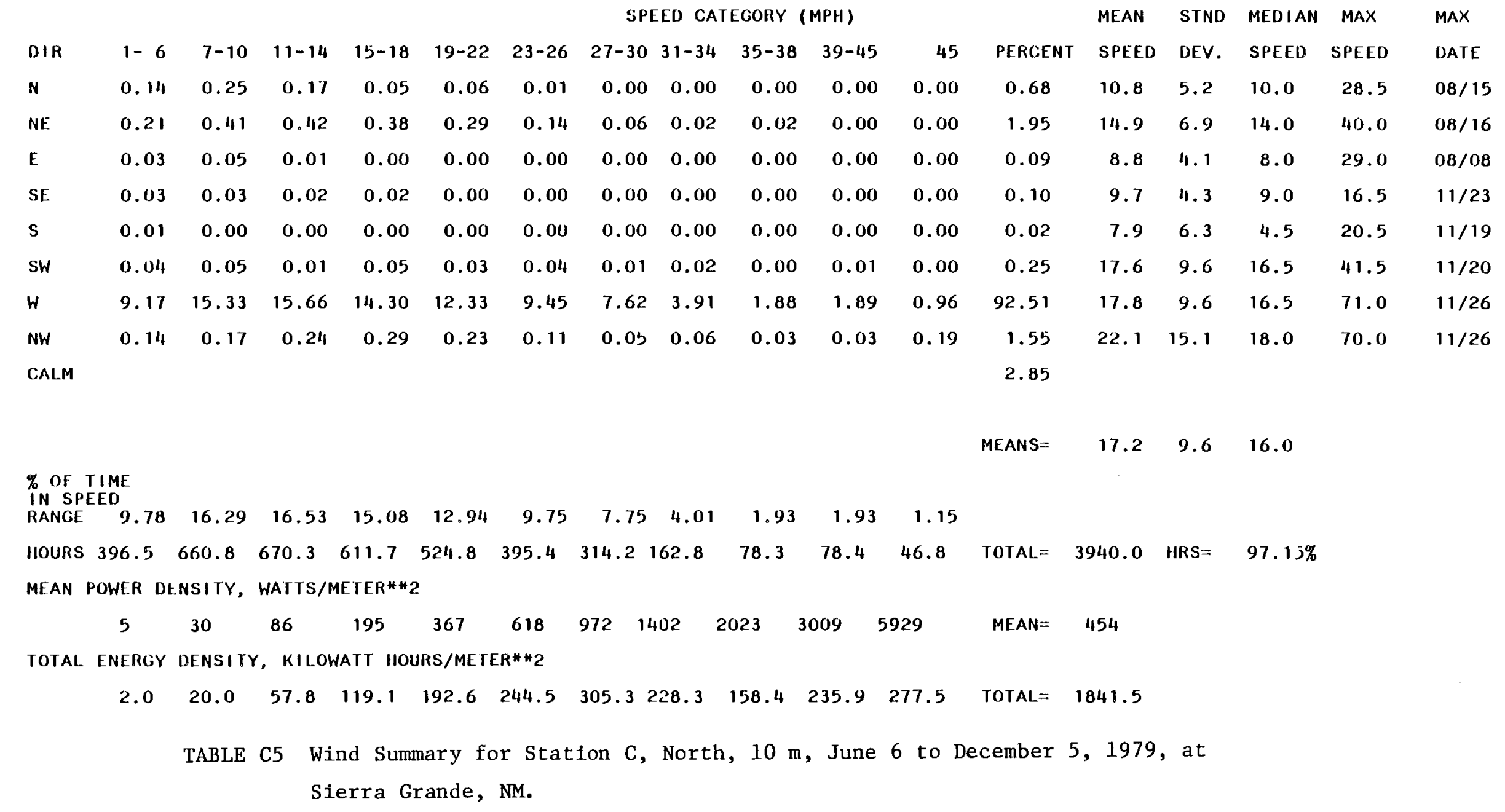


STATION D

WIND SUMMARY FOR THE PERIOD

06/06/79 THRU $11 / 06 / 79$

PERCENTAGE FREQUENCY OF OCCURRENCE

SPEED CATEGORY (MPII)

$\begin{array}{llllllllllll}N & 2.21 & 2.85 & 2.45 & 1.92 & 0.95 & 0.28 & 0.15 & 0.03 & 0.00 & 0.00 & 0.00\end{array}$

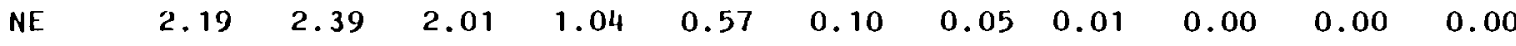

$\bar{c} \quad 0.00 \quad 0.00$

SE $\quad 0.00 \quad 0.00$

S $\quad 0.00 \quad 0.00$

SW $0.00 \quad 0.00$

W

NW

8. 32

2.05

11.16

3.78

2.01

0.00

0.00

0.01

0.10

0.00

0.00

0.00

$0.00 \quad 0.00$

0.00

0.00

$0.00 \quad 0.00$

0.00

0.00

0.00

0.00

0.00

$0.00 \quad 0.00$

0.00

0.00

0.00

0.010 .00

0.00

0.00

$0.00 \quad 0.00$

0.00

0.00

$2.59 \quad 1.17$

0.64

CALM

\begin{tabular}{rrrrrl} 
& MEAN & STND & MEDIAN & MAX & MAX \\
PERCENT & SPEED & DEV. & SPEED & SPEED & \multicolumn{1}{l}{ DATE } \\
10.82 & 11.9 & 5.9 & 11.0 & 33.0 & $07 / 30$ \\
8.35 & 10.7 & 5.3 & 10.0 & 32.5 & $07 / 30$ \\
0.01 & 14.7 & 2.5 & 15.0 & 17.0 & $10 / 16$ \\
0.00 & 0.0 & 0.0 & 0.0 & 0.0 & \\
0.00 & 0.0 & 0.0 & 0.0 & 0.0 & \\
0.01 & 10.5 & 1.3 & 11.0 & 11.5 & $07 / 16$ \\
64.93 & 15.4 & 7.5 & 15.0 & 48.5 & $10 / 20$ \\
14.50 & 13.2 & 6.5 & 12.5 & 48.5 & $06 / 19$ \\
1.38 & & & & &
\end{tabular}

MEANS $=\quad 14.1 \quad 6.9 \quad 13.6$

$\%$ OR TIME

$\begin{array}{llllllllllll}\text { IN SPEED } & & & & & & & & \\ \text { RANGE } & 14.77 & 20.18 & 20.25 & 18.36 & 12.76 & 6.97 & 3.01 & 1.30 & 0.70 & 0.32 & 0.01\end{array}$

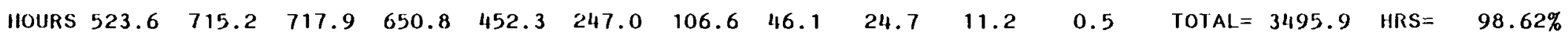

MEAN POWER DENSITY, WATTS/METER ${ }^{H 2}$

$$
\begin{array}{lllllllllllll}
5 & 29 & 87 & 193 & 361 & 605 & 951 & 1397 & 1973 & 288 & 4427 & \text { MEAN= } & 218
\end{array}
$$

TOTAL ENERGY DENSITY, KILOWATT HOURS/METER**2
$2.8 \quad 20.5$
$\begin{array}{llllll}62.2 & 125.6 & 163.2 & 149.6 & 101.4 & 64.4\end{array}$
$1,7.7 \quad 32.3$
2.2
TOTAL $=773.5$

TABLE C6 Wind Summary for Station D, West, $10 \mathrm{~m}$, June 6 to November 6 , 1979 at

Sierra Grande, NM. 
STATION E

WIND SUMMARY FOR THE PERIOD

06/06/79 THRU 12/05/79

PERCENTAGE FREQUENCY OF OCCURRENCE

SPEED CATEGORY (MPH)

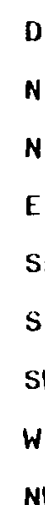

DIR $1-6$

0.12

0.12

0.06

0.12

0.04

0.66

6.49

3.77

4.85

CALM

\% OF TIME
IN SPEE.D

$\begin{array}{llllllllllll}\text { IN SPEED } & & & & & & & & & \end{array}$

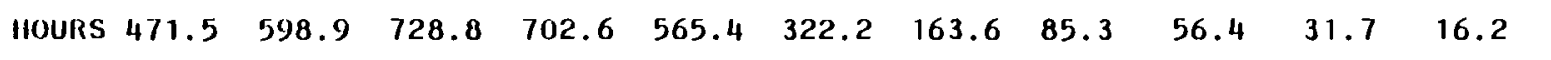
MEAN POWER DENSITY, WATTS/METER*\#2

$\begin{array}{lllllllllllll}5 & 30 & 87 & 193 & 362 & 611 & 955 & 1433 & 1997 & 2875 & 5441 & \text { MEAN }= & 288\end{array}$

TOTAL. ENERGY DENSITY, KILOWATT HOURS/METER**2

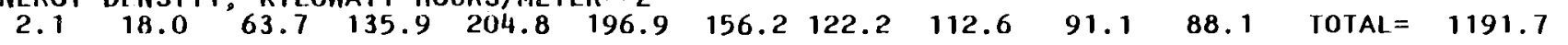

TABLE C7 Wind Summary for Station E, South, $10 \mathrm{~m}$, June 6 to December 5, 1979, at Sierra Grande, NM.

9.67

MEAN STIND MEDIAN MAX MAX

$\begin{array}{lllll}18.0 & 8.7 & 18.0 & 37.0 & 06 / 23\end{array}$

$\begin{array}{lllll}16.9 & 8.5 & 17.5 & 39.0 & 06 / 23\end{array}$

$\begin{array}{lllll}9.1 & 4.2 & 8.5 & 23.0 & 06 / 07\end{array}$

$\begin{array}{lllll}12.7 & 6.6 & 11.0 & 33.0 & 06 / 07\end{array}$

$\begin{array}{lllll}17.8 & 6.8 & 17.5 & 51.0 & 11 / 19\end{array}$

$\begin{array}{lllll}17.2 & 8.8 & 17.0 & 52.5 & 11 / 19\end{array}$

$\begin{array}{lllll}15.5 & 8.9 & 14.0 & 63.5 & 11 / 26\end{array}$

$\begin{array}{lllll}16.2 & 7.3 & 16.0 & 50.5 & 06 / 19\end{array}$

MEANS $=\begin{array}{lll}14.4 & 7.4 & 13.6\end{array}$

TOTAL $=3742.6 \quad$ IIRS $=90.33 \%$ 
STATION F

WIND SUMMARY FOR THE PERIOD

06/06/79 TIIRU 12/05/79

PERCENTAGE FREQUENCY OF OCCURRENCE

SPEED CATEGORY (MPH)

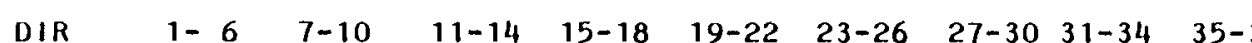

$\begin{array}{llllllllll}N & 1.18 & 1.35 & 1.64 & 1.59 & 1.51 & 1.43 & 1.36 & 0.91 & 0.72\end{array}$

$\begin{array}{llllllllll}N E & 1.77 & 2.05 & 1.45 & 1.02 & 0.57 & 0.36 & 0.26 & 0.13 & 0.03\end{array}$

E $\quad 1.48 \quad 1.23$

$S E$

S

SW

G $W$

NW

CALM

$\begin{array}{llllll}1.11 & 1.68 & 1.82 & 1.46 & 0.99 & 0.62\end{array}$

$0.85 \quad 1.93$

0.83

0.46

0.88

2.40

1.40

1.39

3.374 .45

$4.12 \quad 4.03$

1.20

1.17

5.375 .93

0.81

0.17

0.10

0.56

0.28
$0.00 \quad 0.00 \quad 0.00$

$\begin{array}{lll}0.32 & 0.20 \quad 0.12\end{array}$

$\begin{array}{lll}4.65 & 3.98 & 2.57\end{array}$

$2.09 \quad 1.24 \quad 0.72$

0.72
0.02

0.070 .02

0.02

0.170 .04

39-45 45

0.520 .39

$0.00 \quad 0.00$

$0.00 \quad 0.00$

0.110 .04

$1.49 \quad 0.42$

0.32

0.00

0.010 .00

0.08

0.00

0.00

MEANS

\section{MEAN STND MEDIAN MAX}

PERCENT

12.61

7.63

3.55

8.48

35.01

20.90

3.86

5.33

2.64
SPEED DEV SPEED SPEED DATE

$21.3 \quad 11.5-20.0$

$12.3-7.3-10.5$

$8.24 .5 \quad 7.5$

15.3

8.514 .0

$23.9 \quad 9.3 \quad 23.5$

$\begin{array}{lll}19.3 & 8.7 & 17.5\end{array}$

$\begin{array}{lll}11.8 & 5.5 & 11.0\end{array}$

$\begin{array}{lll}13.3 & 6.8 & 12.0\end{array}$

$49.507 / 17$

$31.0 \quad 12 / 05$

$54.0 \quad 11 / 21$

$57.010 / 20$

$57.5 \quad 10 / 20$

$41.0 \quad 10 / 20$

$40.5 \quad 10 / 05$

\% OF TIME

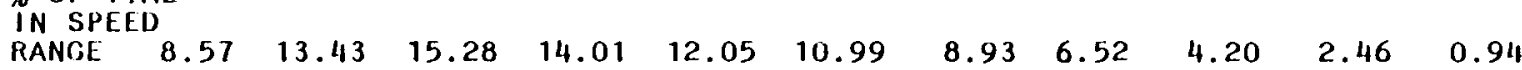

$\begin{array}{llllllllllll}\text { HOURS } & 352.0 & 551.6 & 627.7 & 575.8 & 495.2 & 451.5 & 366.8 & 267.7 & 172.5 & 100.9 & 38.5\end{array}$ MEAN POWER DENSITY, WATTS/METER*H2

$\begin{array}{llll}5 & 29 & 87 & 193\end{array}$

TOTAL ENERGY DENSITY, KILOWATT HOURS/METER\#\#2

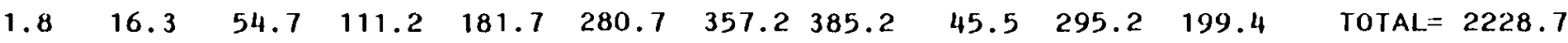

TABLE C8 Wind Summary for Station F, East, $10 \mathrm{~m}$, June 6 to December 5, 1979, at Sierra Grande, NM. 
COMMENTS ON FIGURES C2 to $\mathrm{C} 7$

The wind data analyzed here has a significant number of calm observations due to icing or damage to some anemometers. However, we do not believe this would significantly alter the diurnal speed variations shown for the six stations.

In Figure C5, one maximum speed is indicated to be $100 \mathrm{mph}$. We believe this is an error and should have been near $45 \mathrm{mph}$. 


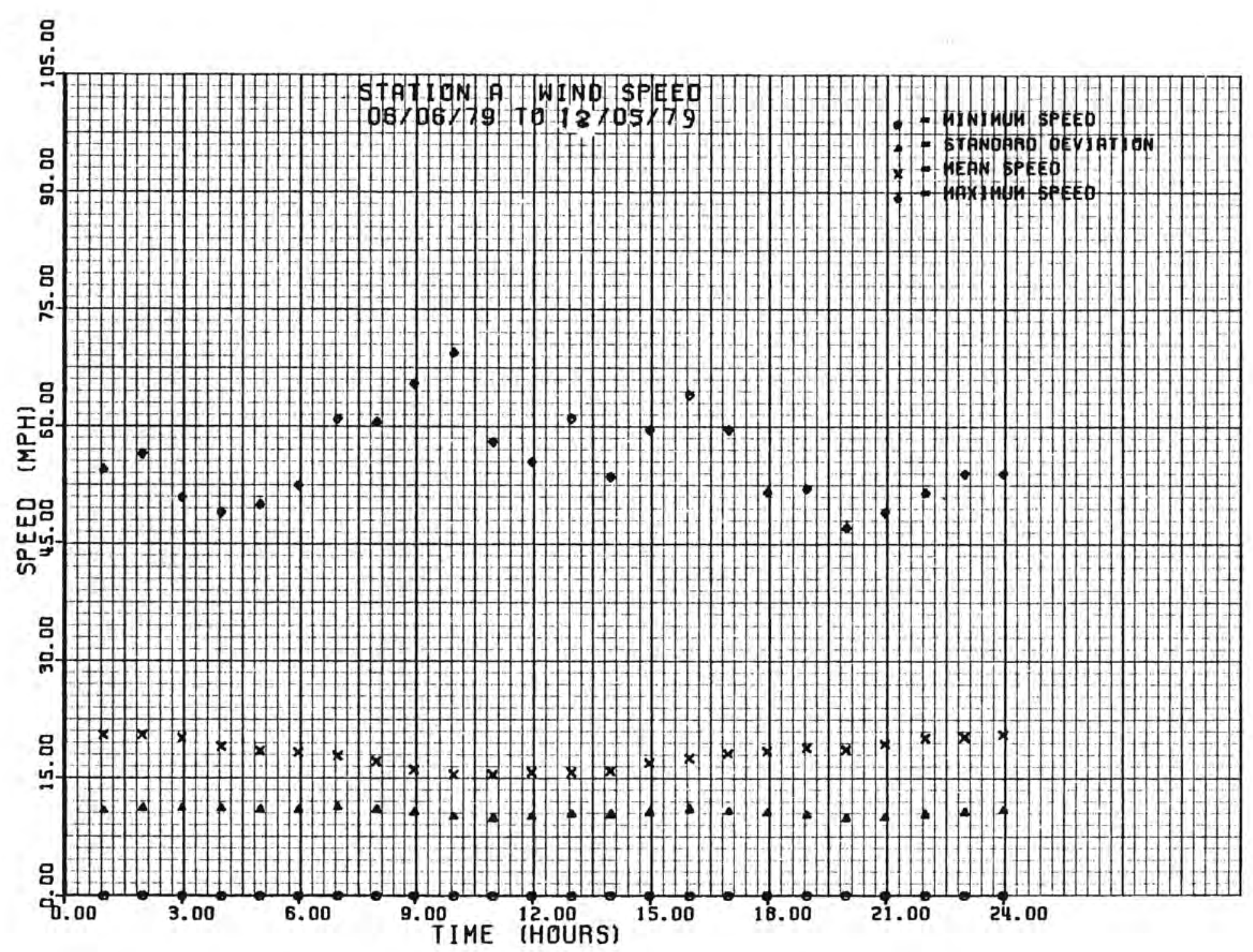

FIGURE C2 Diurna1 Wind Speed Variations at Station A (Center, 20-m). 


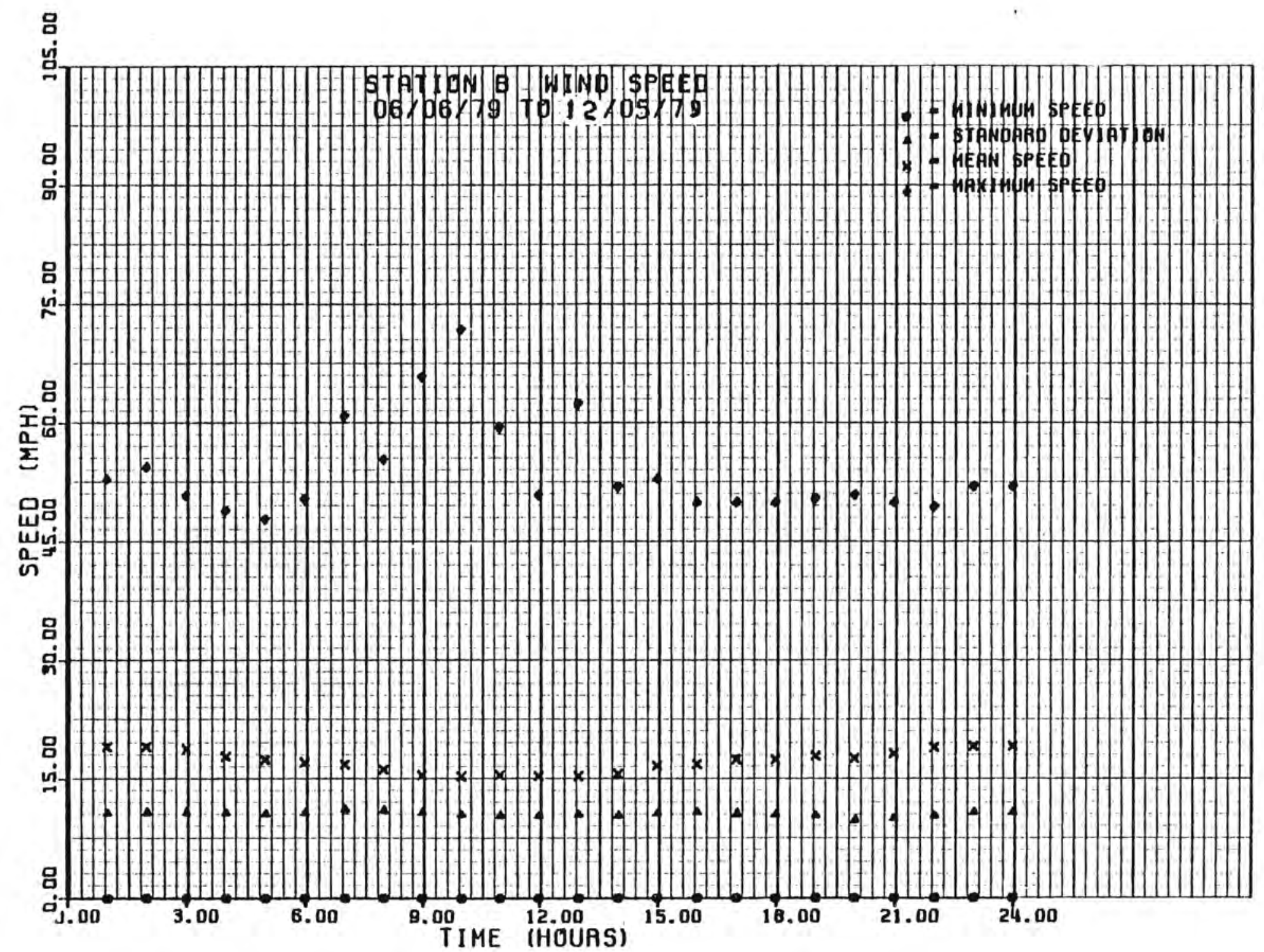

FIGURE C3 Diurna1 Wind Speed Variations at Station B (Center $10 \mathrm{~m}$ ). 


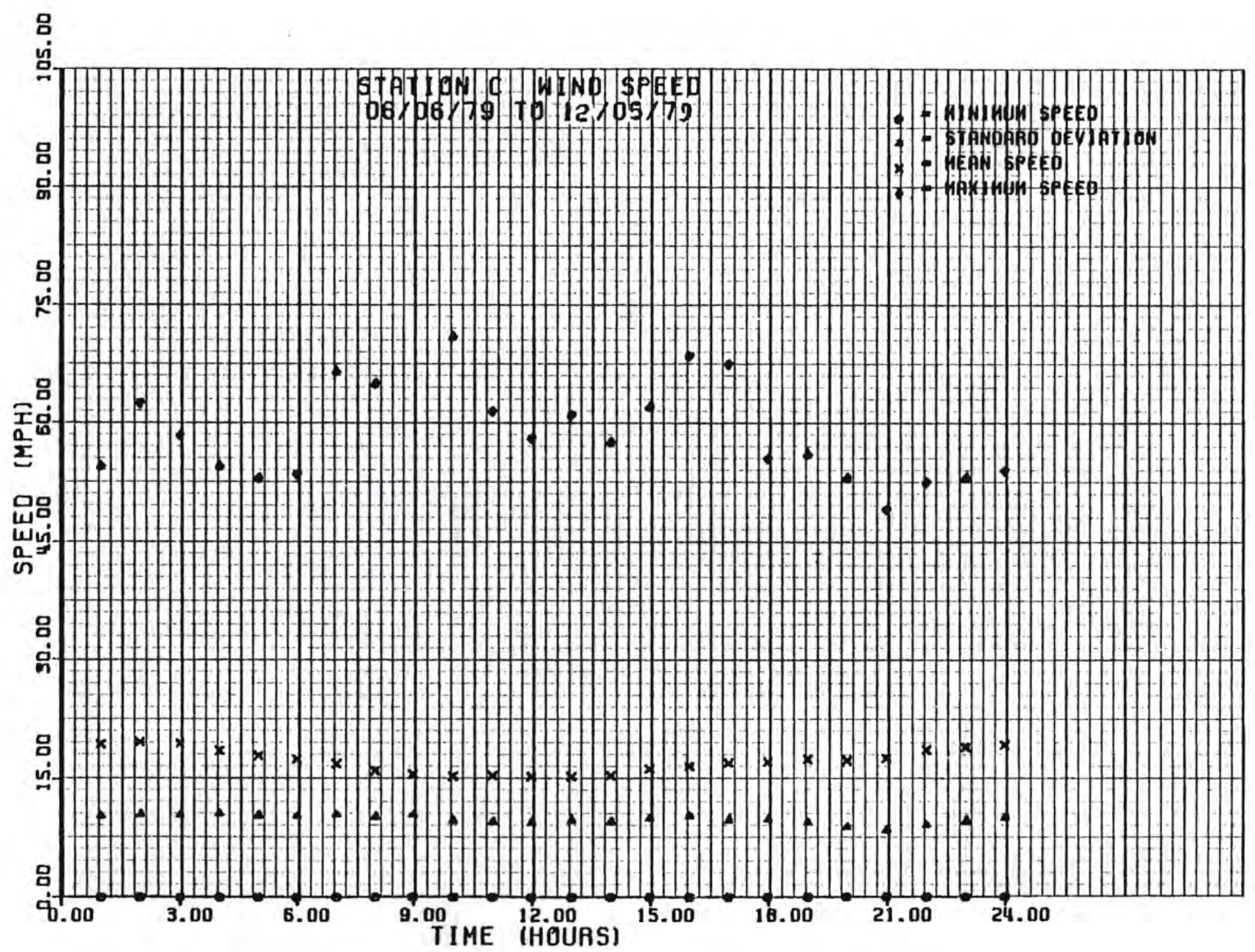

FIGURE C4 Diurnal Wind Speed Variations at Station C (North $10 \mathrm{~m}$ ). 


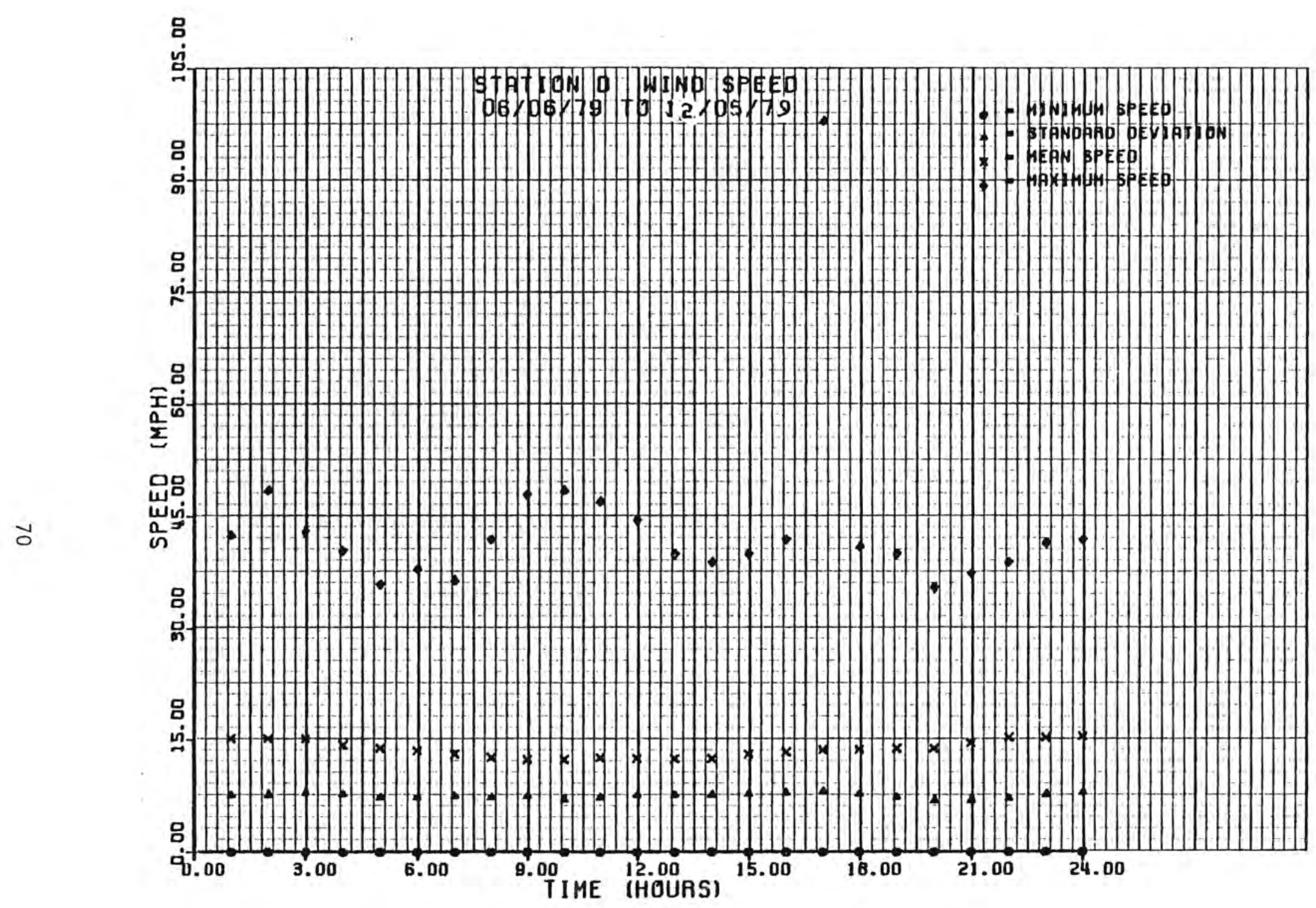

FIGURE C5 Diurnal Wind Speed Variations at Station D (West, $10 \mathrm{~m}$ ). 


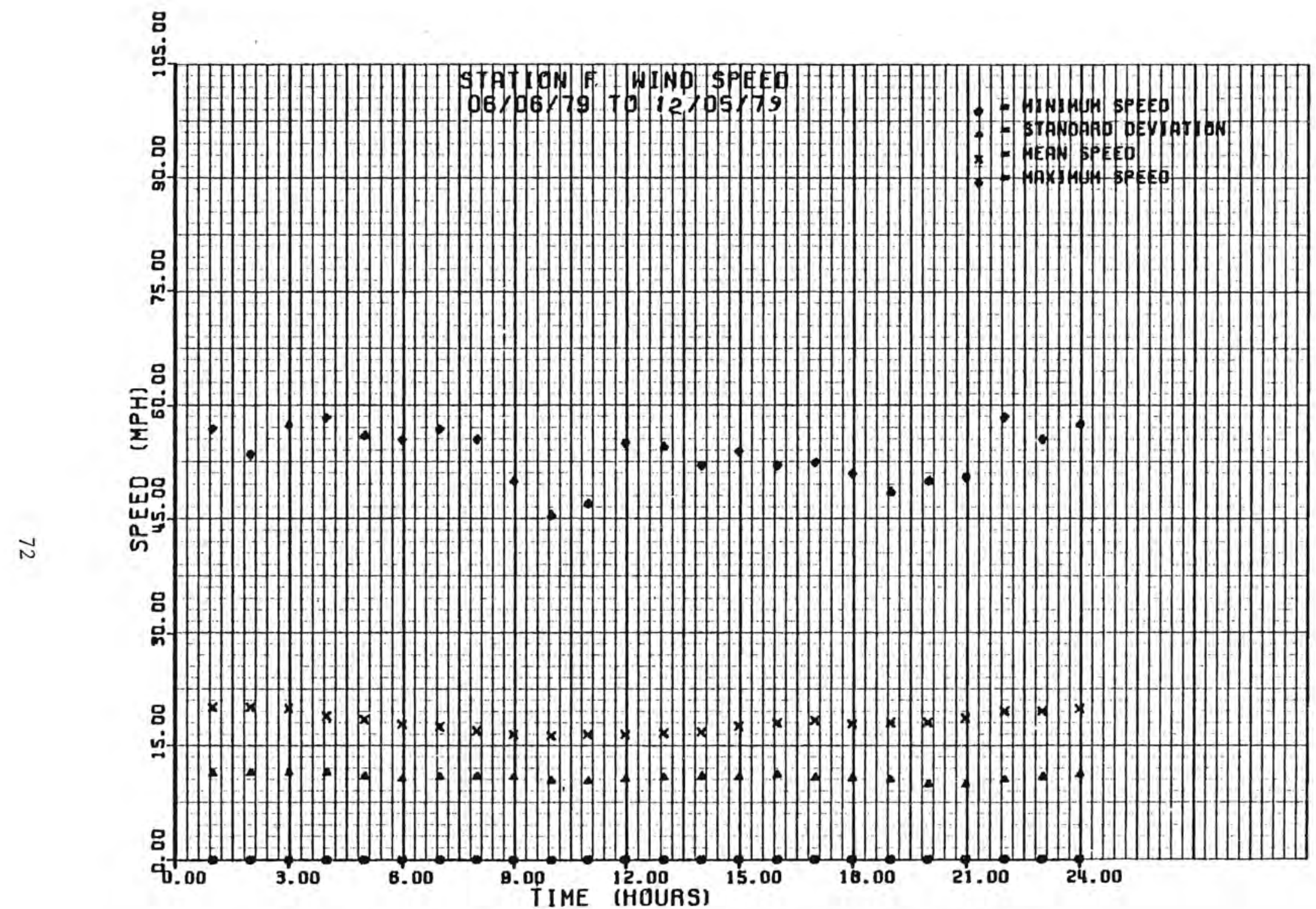

FIGURE C7 Diurnal Wind Speed Variations at Station F (East, $10 \mathrm{~m}$ ). 
COMMENTS ON CHARTS C16 through C19

These data were filtered to exclude wind speeds below $14 \mathrm{mph}$ and above $45 \mathrm{mph}$ so they would be applicable to the MOD-2 operations. Therefore, no calm wind data were applicable; however, there were some time discrepancies between the two recorders, one at $10 \mathrm{~m}$ and the other at $20 \mathrm{~m}$. Consequently, some errors are in these resulting $\mathrm{k}$ values. The data tapes were carefully edited to minimize these errors. 


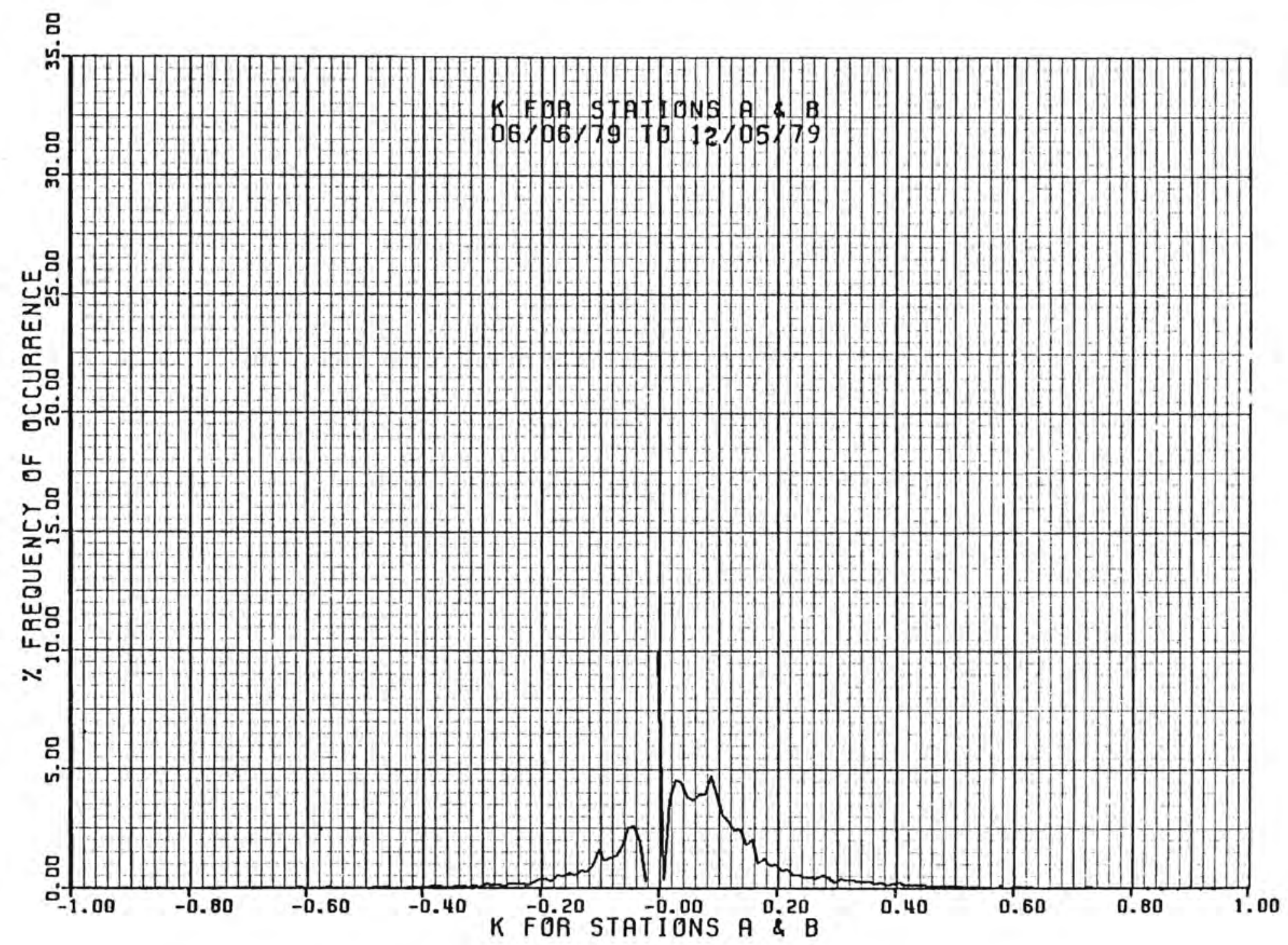

FIGURE C8 Frequency of exponent k, showing wind speed change with height. $\mathrm{V}_{20}=\mathrm{V}_{10}\left(\frac{20}{10}\right) \mathrm{k}$ from $10 \mathrm{~m}$ to $20 \mathrm{~m}$. 
COMMENTS ON CHARTS C16 through C19

These data were filtered to exclude wind speeds below $14 \mathrm{mph}$ and above $45 \mathrm{mph}$ so they would be applicable to the MOD-2 operations. Therefore, no calm wind data were applicable; however, there were some time discrepancies between the two recorders, one at $10 \mathrm{~m}$ and the other at $20 \mathrm{~m}$. Consequent1y, some errors are in these resulting $\mathrm{k}$ values. The data tapes were carefully edited to minimize these errors. 


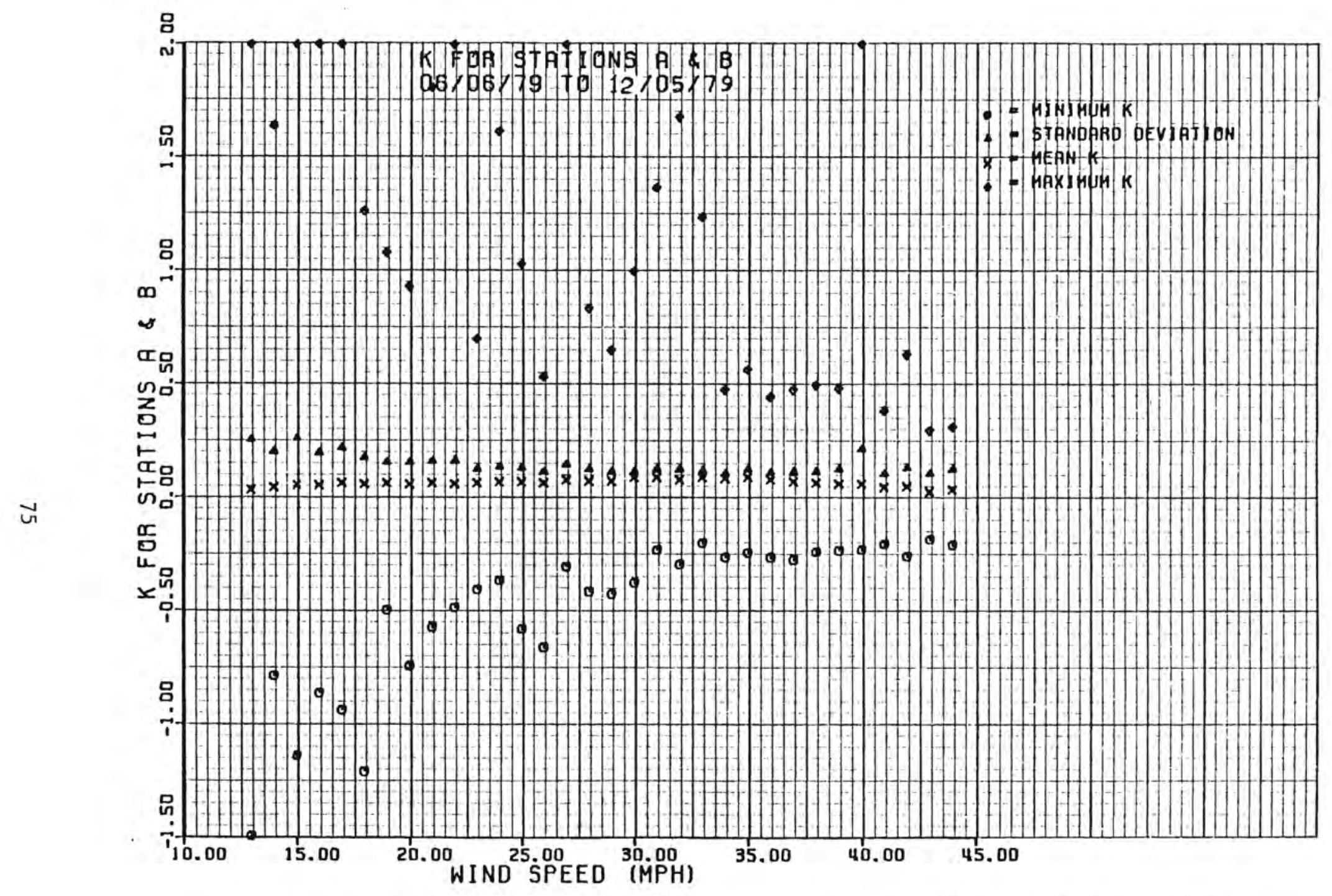

FIGURE C9 $\mathrm{k}$ vs Wind Speed at Station A $(20 \mathrm{~m}$.) Showing Wind Speed change with height $v_{20}=v_{10}\left(\frac{20}{10}\right) \mathrm{k}$ from $10 \mathrm{~m}$ to $20 \mathrm{~m}$. 


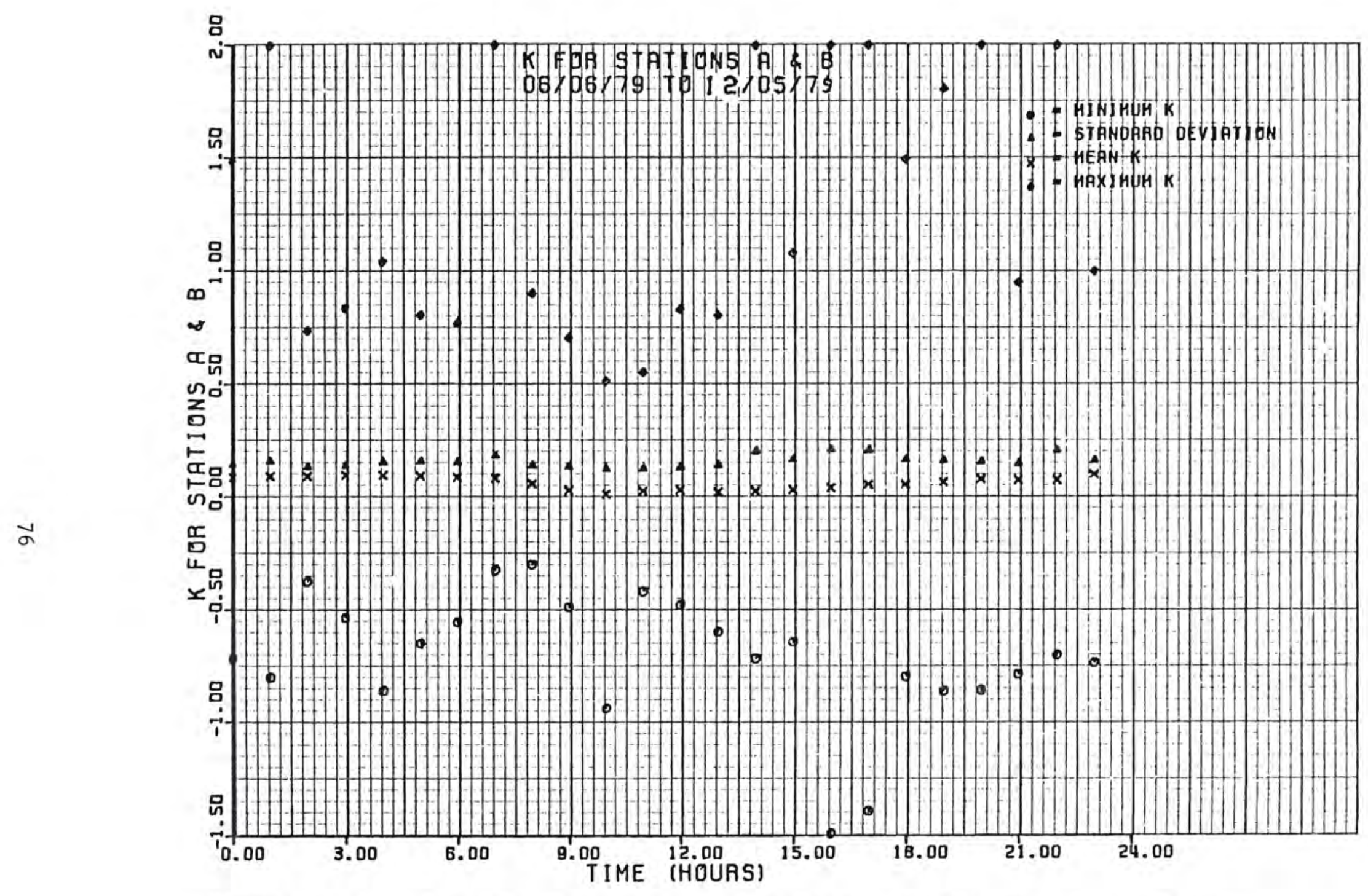

FIGURE C10 k vs Time of Day at Station A $(20 \mathrm{~m}$.$) Showing Wind Speed Change with$ height $v_{20}=v_{10}\left(\frac{20}{10}\right)^{k}$ from $10 \mathrm{~m}$ to $20 \mathrm{~m}$. 


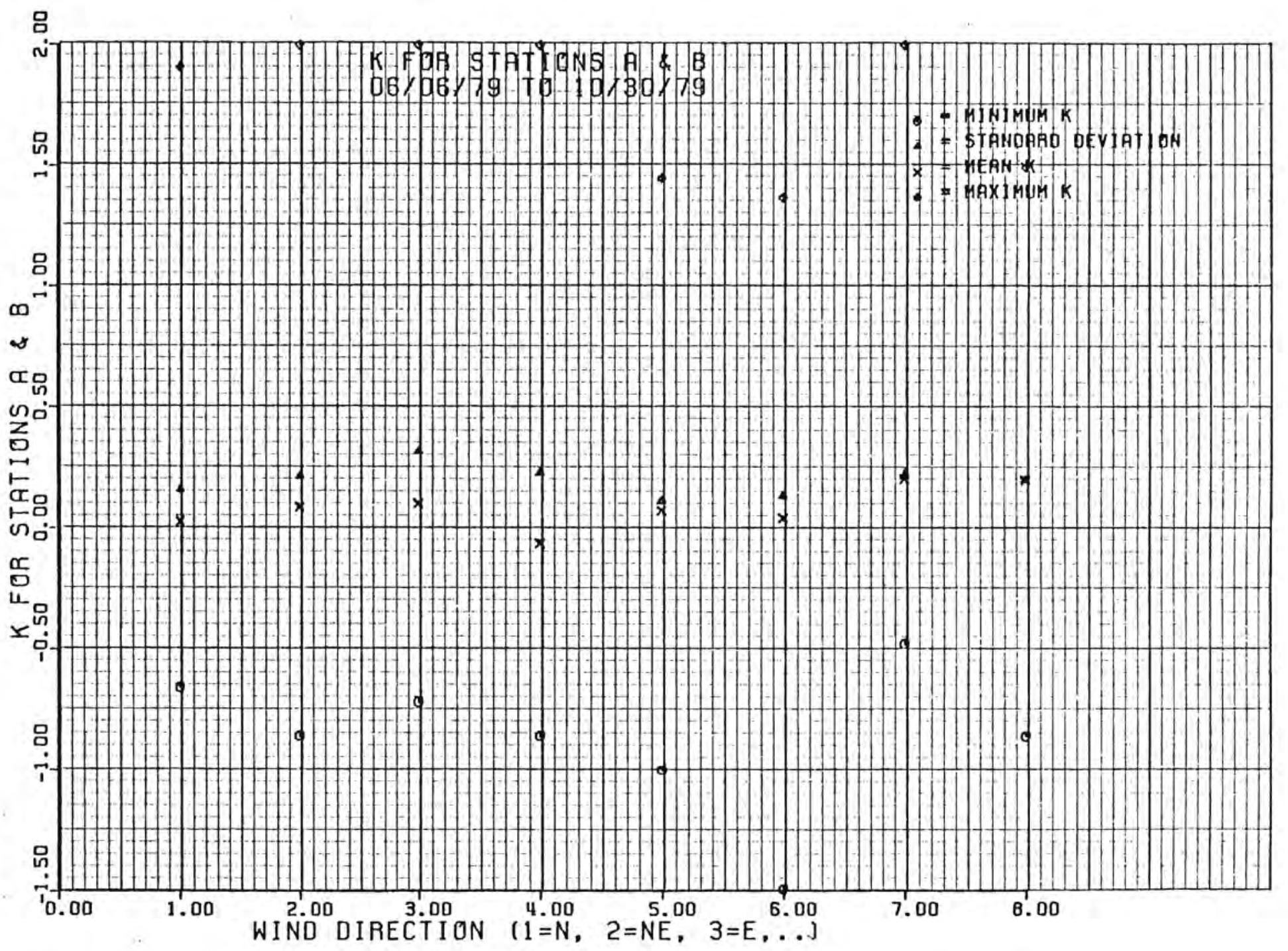

FIGURE C11 k vs Wind Direction at Station A $(20 \mathrm{~m}$.$) Showing Wind Speed Change with$ height $\mathrm{v}_{20}=\mathrm{v}_{10}\left(\frac{20}{10}\right)^{\mathrm{k}}$ from $10 \mathrm{~m}$ to $20 \mathrm{~m}$. 
APPENDIX D 


\section{APPENDIX D}

MODUPRINTER

A Practical Automation, Inc. (a) Mini-Moduprint series CMMP-6 printer was mated to the Memodyne Reader, Model 3122BV for a "quick look" end-to-end test of the Natural Power Data Logger system. After removing tapes from the Loggers, we "played" them through the above described system to determine if the Loggers were actually recording data (which we could not otherwise know until the tapes were processed at PSL). We also checked the data print-outs using a Texas Instruments (b) Programmer (hand-held calculator) to verify that the realtime clocks were functioning properly, and that the wind directions and speeds were correct. Our purpose was to maintain quality assurance and prevent loss of data, since we only serviced the sites once a month.

The reader was connected to the printer to print only three of the octal digits of the data on a line of the available 6 digits of the CMMP-6A. See Figure $D-1$.

The "Wiring List" is shown in Figure D-2. The wiring diagram for the Model 3122 is shown in Figure $\mathrm{D}-3$. The wiring list shows the connections between ready to start line. The one-shot was needed to stretch the FIFO ready line to beyond the minimum needed on the start line. A photograph of the Data Printer is shown in Figure 14.

(a) Practical Automation, Inc. Trap Falls Road, Shelton, CT 06484

(b) Texas Instruments, Inc. Mail Station 12-33, Attleboro, MA 02703 


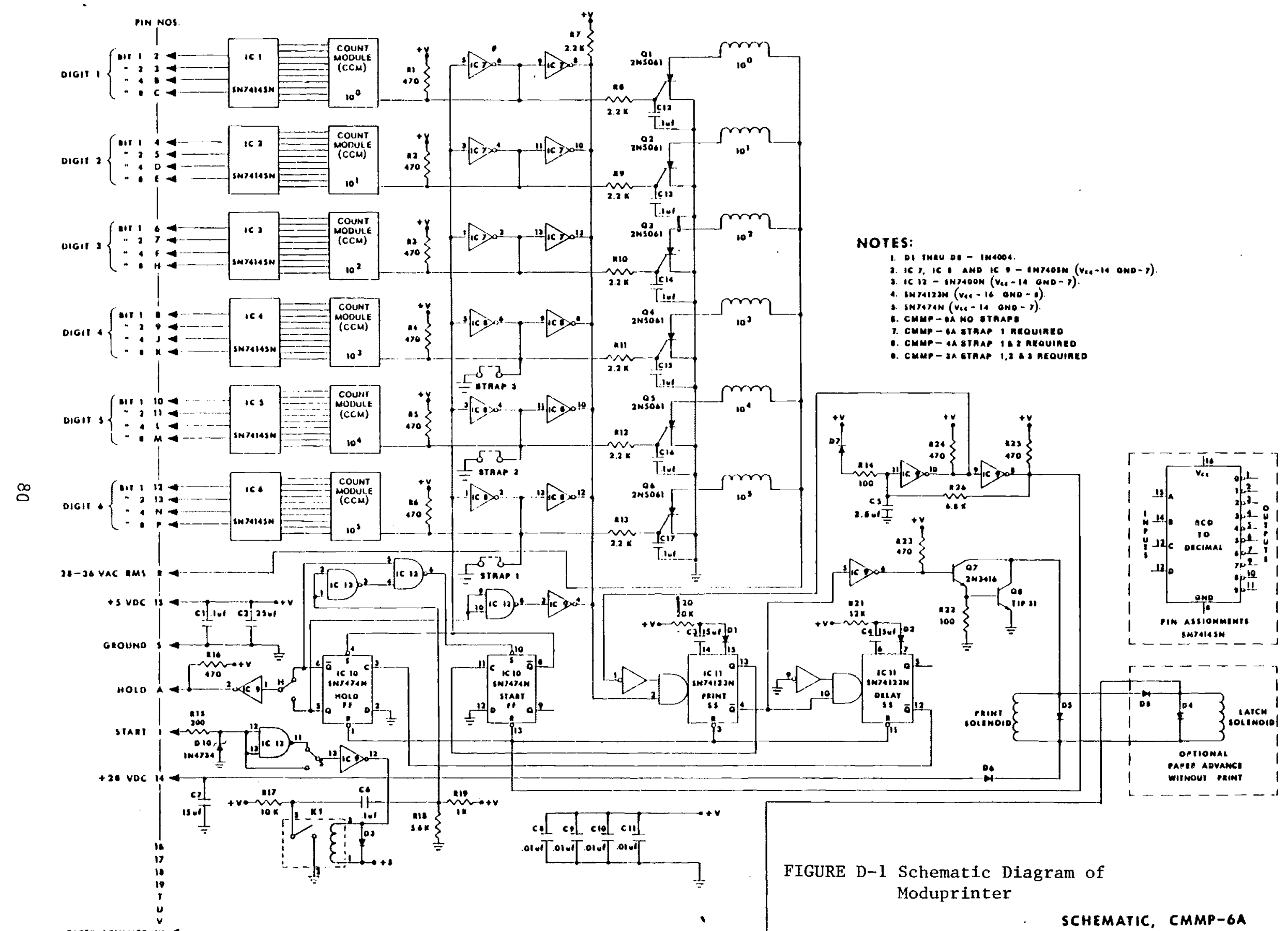


FIGURE D-2

WIRING LIST

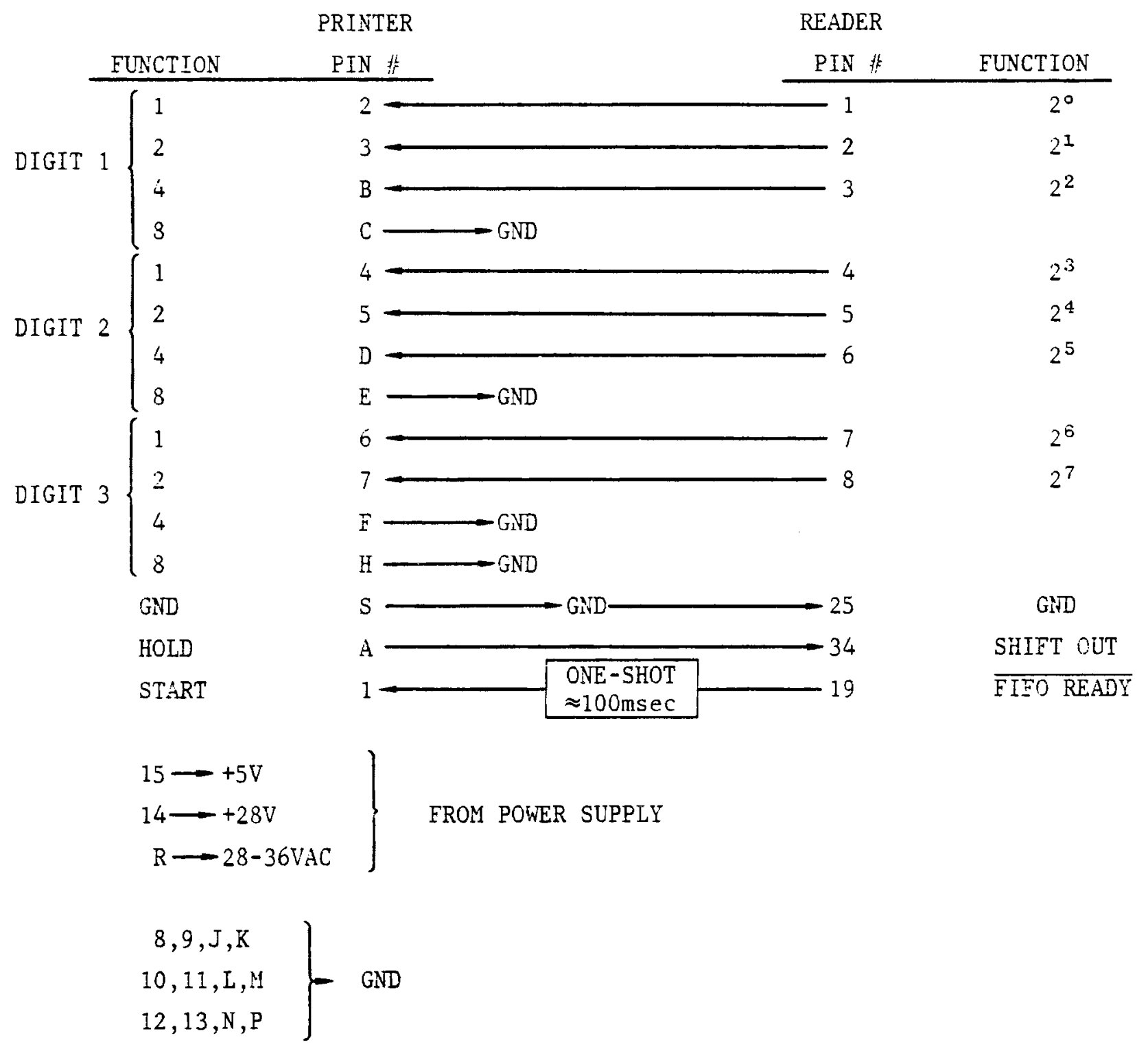


BAUD SWIICHES SK747-400

\begin{tabular}{|l|l|l|l|l|}
\hline 110 & 150 & 300 & 600 & 1200 \\
\hline
\end{tabular}

FUNCTION SWITCHI SK 747.483A

BAUD RATE CONN.

TOM ON CD

MODEL 15

VIA RIBBON

CABLE
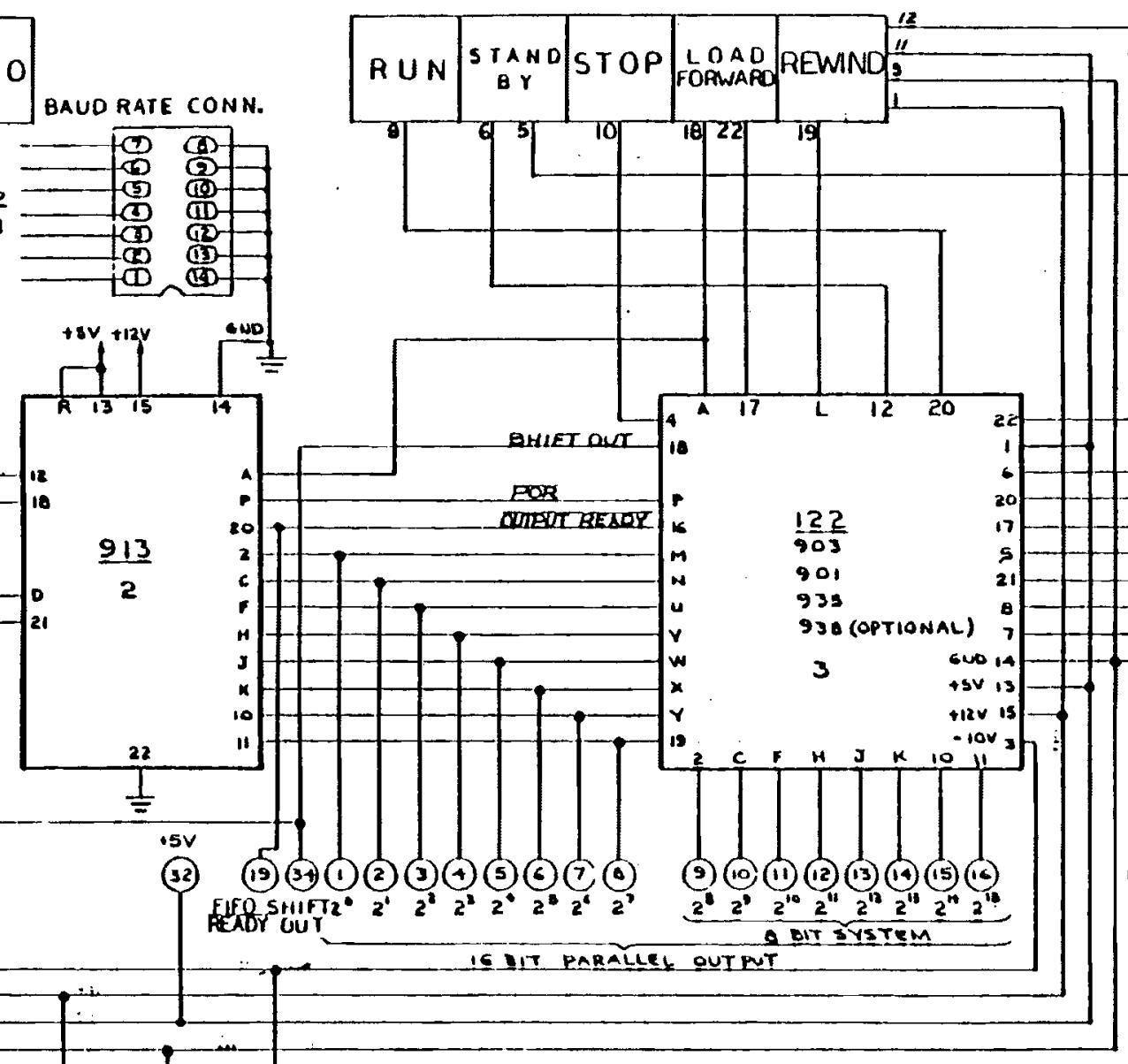

NOTES:

) FOR O BIT OUTPUTS REMOVE ICT48 OF THE 935 MOARD

OR IF 930 FIFO IS USED REMOYE IC 748 OF THE 935 BOARD.

e) EJ OUTPLT SUCKET AMPHENOL 57-40360

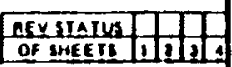

\begin{tabular}{|c|c|c|c|}
\hline 等, & \&3 & $\frac{1}{a-1,20}$ & 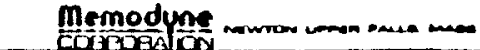 \\
\hline 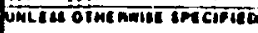 & $\ldots$ & $\ldots$ & WIRIVIG DIAGRAM \\
\hline 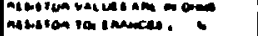 & {$[\cdots$} & $\ldots$ & MODEL 3122 \\
\hline 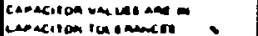 & $\cdots$ & 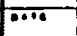 & UNIVERSAL READER \\
\hline 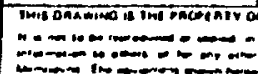 & minoments & $=$ & $c]$ \\
\hline
\end{tabular}

FIGURE D-3. Wiring Diagram of Moduprinter

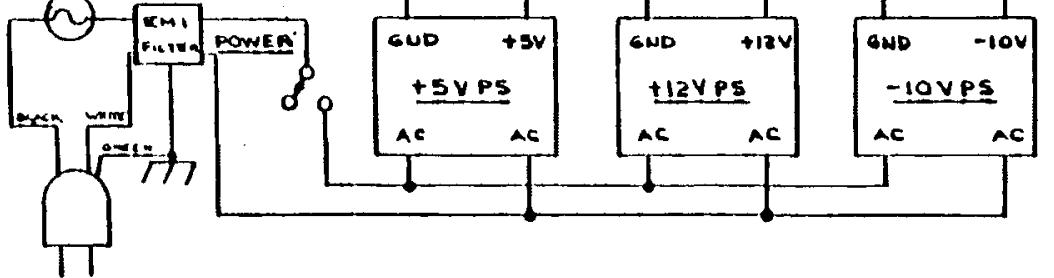


APPENDIX E 


\section{APPENDIX E}

\section{ERROR ANALYSIS OF NATURAL POWER DATA LOGGER}

Table E-1 shows the listing of the major problems with each of the six data loggers per data set. The time of each set varies somewhat; their exact dates are shown in the table.

The "Header Character Strings" (HCS) are where the logger for some unknown reason puts in a series of its hexidecimal header identification. The logger is supposed to record its hexidecimal header each six minute time interval when it records a sample of data - but it will often record a series of header information with no other valid data.

The "NO GO $\emptyset "$ is where the real-time clock (RTC) reset button is pushed to reset the RTC to zero time, but the RTC shows some other time at inception. It is possible that one or two of these failures could have been caused by personnel not resetting the RTC; however, a checklist was faithfully followed to minimize this problem.

The "TIME JUMP" is where the RTC for some unknown reason resets itself, but not always to zero. Usually it is some random number, necessitating the computer analyst to work extra to sort out the proper time parity. Logger $C$ on tape $\mathrm{C}-2$, reset itself as follows:

\begin{tabular}{crr} 
Sample number & \multicolumn{1}{c}{ From } & To \\
11 & 1027423550 & 1085 \\
2935 & 1065245 & 391 \\
4593 & 165112 & 418
\end{tabular}

Logger E with 9 time jumps in 1-1/3 month is the worst example of this problem. It is known that a direct cloud-to-ground lightning strike hit the tower of $A$ and $B$ during set 1 and reset the clocks. Lightning may have caused the 9 time jumps at E-1, but there was no lightning during data sets 5 and 6 . 
Logger $C$ had the worst case of data loss with a total of 11 days dropped out of 189 or $6 \%$ loss. The average loss of data per logger for the entire project was 3.67 days or a $2 \%$ loss.

An average of $2 \%$ data loss for the Natural Power Data Logger is considered good when compared to a recent Request for Proposal from the Department of Energy where they set a guideline of no more than $10 \%$ data loss from unattended data loggers. 


\begin{tabular}{|c|c|c|c|c|c|c|}
\hline SET' & A & B & c & D & $E$ & F \\
\hline 1 & $\begin{array}{l}\text { On } 17 \text { May } \\
1 \text { time jump }\end{array}$ & $\begin{array}{l}\text { On } 17 \text { May } \\
1 \text { time jump }\end{array}$ & $\begin{array}{l}\text { On } 30 \text { May } \\
\text { HCS } \\
\text { Bits } 17,24 \\
\text { Dropped } \\
1 \text { time jump }\end{array}$ & $\begin{array}{l}\text { On } 6 \text { June } \\
\text { HCS } \\
\text { First } 18 \\
\text { Samples no } \\
\text { good - I time } \\
\text { jump }\end{array}$ & $\begin{array}{l}\text { On } 29 \text { May } \\
\text { HCS } \\
9 \text { time junup }\end{array}$ & $\begin{array}{l}\text { On } 29 \text { May } \\
\text { HCS } \\
\text { No header } \\
\text { dst } 24 \\
1 \text { time jump } \\
\text { No to }\end{array}$ \\
\hline $\begin{array}{l}2 \\
\text { on } 10 \mathrm{July} \\
\text { off } 7 \text { Aug. } \\
(x \in p \quad A \& B)\end{array}$ & $\begin{array}{l}\text { HCS } \\
\text { No Go } q^{2} \\
\text { on } 6 \text { June }\end{array}$ & $\begin{array}{l}\text { No } 60 \emptyset \\
\text { on } 6 \text { June }\end{array}$ & $\begin{array}{l}\text { HCS } \\
3-t \text { ine jumps }\end{array}$ & HCS & HCS & OK \\
\hline 3 & $\begin{array}{l}\text { HCS } \\
\text { on } 10 \text { July } \\
\text { of } 7 \text { Aug. }\end{array}$ & $\begin{array}{l}\text { OK } \\
\text { on } 10 \text { July } \\
\text { of } 7 \text { Aug. }\end{array}$ & (THHSE & FOUR SETS ARE & UDED IN SETS AB & \\
\hline $\begin{array}{l}4 \\
\text { on } 7 \text { Aug. } \\
\text { of } f 13 \text { Sep. }\end{array}$ & $\begin{array}{l}\text { HCS } \\
6 \text { hrs } 16 \text { min } \\
\text { missing-start }\end{array}$ & $\begin{array}{l}\text { HCS } \\
\text { Time off }\end{array}$ & $\begin{array}{l}\text { IICS } \\
2 \text { time jumps }\end{array}$ & HCS & OK & $\begin{array}{l}\text { HCS } \\
\text { Numerous } \\
\text { ti.ne jumps }\end{array}$ \\
\hline $\begin{array}{l}5 \\
\text { on } 13 \text { Sep. } \\
\text { on } 6 \text { Nov. }\end{array}$ & $\begin{array}{l}\text { one time jump } \\
\text { time off }\end{array}$ & $\begin{array}{l}\text { bytes dropped } \\
\text { time of } \\
1 \text { time jump }\end{array}$ & $\begin{array}{l}11 \text { days missing } \\
1 \text { time jump }\end{array}$ & 1 time jump & $\begin{array}{l}7.87 \text { days msg } \\
\text { HiCS } \\
1 \text { time jump }\end{array}$ & $\begin{array}{l}\text { HCS (bad) } \\
5 \text { time jumps }\end{array}$ \\
\hline $\begin{array}{l}6 \\
\text { on } 6 \text { Nov. } \\
\text { off } 5 \text { Dec. }\end{array}$ & $\begin{array}{l}\text { No GO } \\
2 \text { time jumps }\end{array}$ & $\begin{array}{l}\text { bytes dropped } \\
\text { first } 26 \text { samples } \\
2 \text { time junps }\end{array}$ & 1 time jump & $\begin{array}{l}\text { no data } \\
\text { power not } \\
\text { turned on }\end{array}$ & $\begin{array}{l}\text { HCS (worst) } \\
\text { bytes dropped } \\
3 \text { time jumps } \\
27.35 \text { hrs ms }\end{array}$ & $\begin{array}{l}\text { HCS } \\
\text { NO GO } \emptyset \\
1 \text { time jump }\end{array}$ \\
\hline $\begin{array}{l}\text { IICS } \\
\text { NO GO } \\
\text { time jumps } \\
\text { missing data }\end{array}$ & $\begin{array}{l}3 \\
2 \\
4 \\
6 \mathrm{hrs} 16 \mathrm{~min}\end{array}$ & $\begin{array}{c}1 \\
1 \\
26 \text { samples }\end{array}$ & $\begin{array}{c}3 \\
0 \\
7 \\
11 \text { days }\end{array}$ & $\begin{array}{r}3 \\
0 \\
2 \\
-\end{array}$ & $\begin{array}{l}4 \\
0 \\
13 \\
\sim 9 \text { days }\end{array}$ & $\begin{array}{r}4 \\
2 \\
\sim 12 \\
\sim 1 \text { day }\end{array}$ \\
\hline
\end{tabular}

1. HCS: Header Character Strings

2. No 60 : Timer does nol go to when reset.

3. Time Jump: Timer resets itself for no known reason. 
APPENDIX $\mathrm{F}$ 


\section{APPENDIX F}

\section{CALCULATION OF MOD-2 ENERGY OUTPUT ON SIERRA GRANDE}

The sea-level performance of the MOD-2 wind turbine is summarized by Figure F-1, which was provided by the Boeing Engineering and Construction Company. The MOD-2 is rated at $2500 \mathrm{kw}$. Power is first produced when the wind speed at the hub increases to $14.0 \mathrm{mph}$, its cut-in speed. At this speed, the power is

$$
\begin{aligned}
& P=\frac{1}{2} \rho V^{3} A C \\
& P= \text { atmospheric density }=1.24 \mathrm{~kg} \mathrm{~m}^{-2}(\text { standard sea level }) \\
& \mathrm{V}^{3}=(14.0 \mathrm{mph})^{3}=\left(6.26 \mathrm{~ms}^{-1}\right)^{3}=122.7(\mathrm{~m} / \mathrm{s})^{3} \\
& \mathrm{~A}=\pi(150 \mathrm{x} .3048)^{2}=6567 \mathrm{~m}^{2} \\
& C_{\mathrm{p}}=\text { power coefficient }=0.126 \text { from Figure } \mathrm{F}-1
\end{aligned}
$$

Power is 62947 watts $=62.9 \mathrm{kw}$ (at $14.0 \mathrm{mph}$ ). (Compensation has to be made for start up time, as discussed later).

As the wind speed increases from $14.0 \mathrm{mph}$ to $27.5 \mathrm{mph}$, the $\mathrm{C}_{\mathrm{p}}$ changes as shown in Figure F-1. The rated speed is $27.5 \mathrm{mph}$ and the output is $2500 \mathrm{~kW}$. The output stays at $2500 \mathrm{~kW}$ until the cut out speed of $45.0 \mathrm{mph}$. At speeds stronger than $45 \mathrm{mph}$, the blades are feathered and stopped.

To calculate the output of a Mod-2 on Sierra Grande, two corrections must be made to Figure $F-1$. The mean air density is considerably less at the hub height of $8920 \mathrm{ft} \mathrm{msl}$, and the wind speed data available were observed at $20 \mathrm{~m}$ (66 ft) above the surface but have to be applied to the hub height of $61 \mathrm{~m}(200 \mathrm{ft})$ above the surface. Figure F-2 is applicable to Sierra Grande and was provided by the Boeing Engineering and Construction Company.

In addition, reference was made to report DOE/NASA CR-159609 "MOD-2 Wind Turbine System Concept and Preliminary Design Report, Volume II Detailed Report" prepared by the Boeing Engineering and Construction Co., July 1979.

The correction for a lower density requires that the cut-in, rated and cutout 


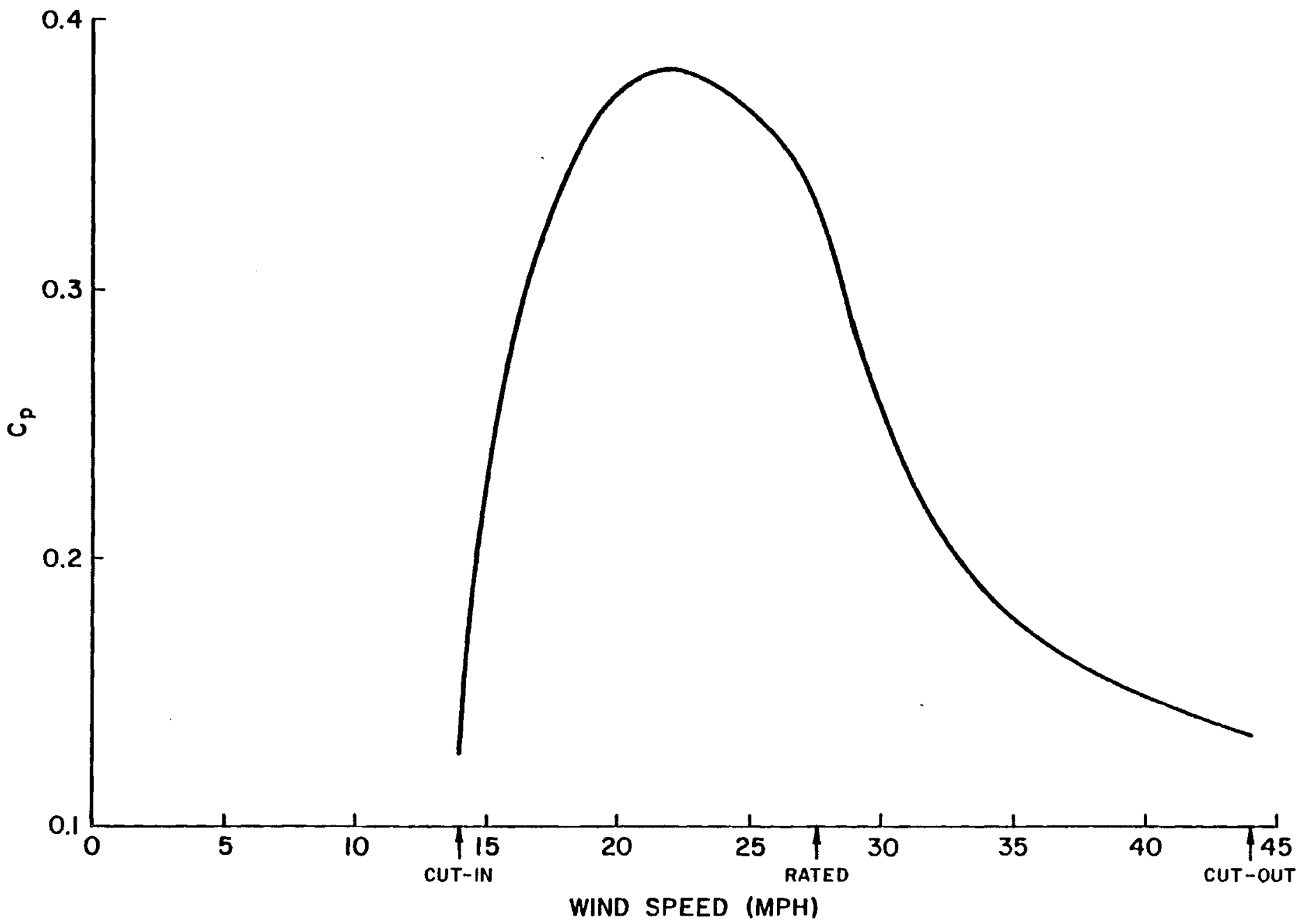

FIGURE Fl $C_{p}$ vs Wind Speed for the MOD-2 Wind Turbine at Sea Level Atmospheric Conditions. Provided by the Boeing Engineering and Construction Company. 


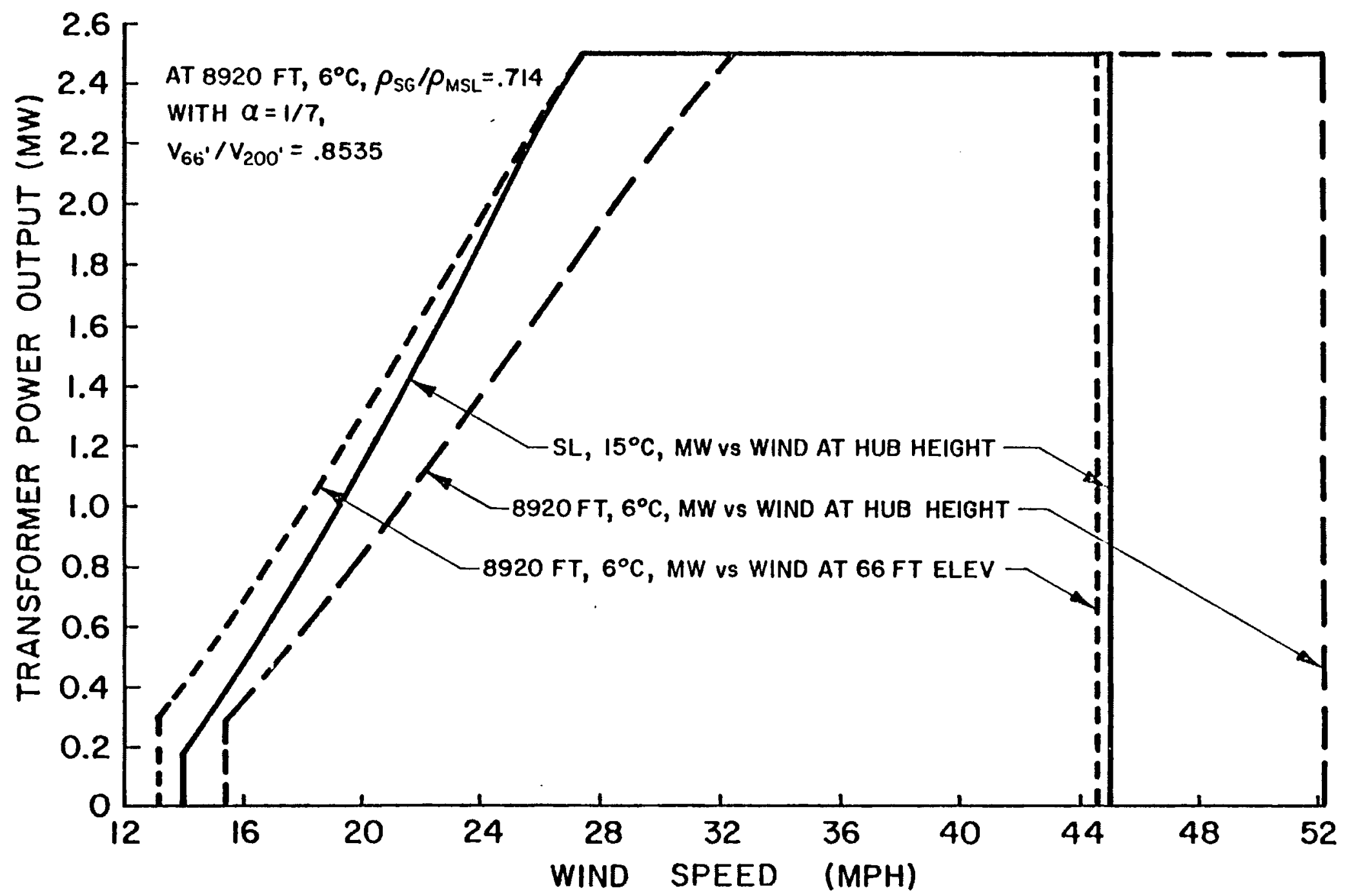

FIGURE F2 Power Output vs Wind for the MOD-2 Wind Turbine at Sierra Grande Atmospheric Conditions. Provided by the Boeing Engineering and Construction Company. 
speeds be stronger. The mean air density at Sierra Grande was assumed to be $74 \%$ of the standard sea level value, or $0.918 \mathrm{~kg} \mathrm{~m}^{-3}$.

The correction for using wind measured at $20 \mathrm{~m}$ and extrapolated to $61 \mathrm{~m}$ decreases the value of the wind speed needed at $20 \mathrm{~m}$ representative of the speed at hub heights.

The expected output of a MOD-2 on top of Sierra Grande was calculated two different ways. The first way extrapolated the wind speed from Station $A$, at $20 \mathrm{~m}$, to hub height, at $61 \mathrm{~m}$, using a $1 / 7$ exponent for wind speed increase with height. The second way was to extrapolate the same wind speed using an exponent that is determined by the observed wind speed change from $10 \mathrm{~m}$ to $20 \mathrm{~m}$. In the first case, the shorter dashed line curve on Figure C-2 was used; in the second case, the solid curve indicated by $" 8920 \mathrm{ft} 6^{\circ} \mathrm{C}$, MW vs WIND AT HUB HEIGHT" was used.

Example $1 \mathrm{~V}_{\text {hub }}=\mathrm{v}_{20}\left(\frac{61}{20}\right)^{1 / 7}$

In Figure $\mathrm{F}-2$, the cut in speed, as measured at $20 \mathrm{~m}$ above the ground at Sierra Grande is $6.03 \mathrm{~ms}^{-1}(13.5 \mathrm{mph})$. At this speed the power output of the MOD-2 is $0.32 \mathrm{MW}$ and, for a time period of 6 minutes, the energy output is 32 $\mathrm{kWh}$. At the speed of $12.3 \mathrm{~ms}^{-1}(27.5 \mathrm{mph})$, the power is $2.5 \mathrm{MW}$ and the energy output during six minutes is $250 \mathrm{kWh}$. This relationship can be closely approximated by

$$
E_{i}=\text { Energy }(\mathrm{kWh})=-174.1+15.34 \mathrm{~V}_{\mathrm{i}}(\mathrm{mph} \text { at } 20 \mathrm{~m})
$$

Equation 2 is valid for $13.5 \leq \mathrm{V}_{i} \leq 27.5$ (mph at $20 \mathrm{~m}$ ).

For $27.5<v_{i} \leq 44.5 ; E_{i}=250 \mathrm{kWh}$

For

$$
\mathrm{V}_{i}<13.5 ; \mathrm{E}_{i}=0
$$

For $\quad v_{i}>44.5 ; E_{i}=0$

The accumulated energy $\mathrm{E}$ is given by

$$
E=\sum_{i=1}^{n} E_{i}
$$


where $E_{i}$ is used as defined in Equations 2 to 5

$i$ refers to each mean wind observed during six minutes

$\mathrm{n}$ is the total number of six minute observations used.

Example 2 $\quad \mathrm{V}_{\text {hub }}=\mathrm{V}_{20}\left(\frac{61}{20}\right)^{\mathrm{k}}$

where

$$
\mathrm{k}=\frac{\log \left(\frac{V_{20}}{V_{10}}\right)}{\log \left(\frac{20}{10}\right)} \text { as measured simultaneously. }
$$

A different curve is used from Figure F-2, the one designated by "8920 FT $6^{\circ} \mathrm{C}$ MW vs WIND AT HUB HEIGHT." The calculation of energy is similar to that in Example 1 but with slightly different criteria:

$$
\begin{aligned}
& E_{i}=0 ; \text { if } V_{h u b}<15.5 \\
& E_{i}=-167.2+12.94 V_{h u b} ; \text { if } 15.5 \leqq V_{h u b} \leqq 27.5 \\
& E_{i}=250 \mathrm{kWh} ; \text { if } 27.5<V_{h u b}<52.2 \\
& E_{i}=0 ; \text { if } V_{h u b}>27.5
\end{aligned}
$$

where $\mathrm{E}_{i}$ is in $\mathrm{kWh}$

$V_{\text {hub }}$ is in mph

The accumulated energy is calculated similarly:

$$
E=\sum_{i=1}^{n} E_{i}
$$

where $E_{i}$ is used as defined in Equations 7-10

$i$ refers to each mean wind speed observed during six minutes

$\mathrm{n}$ is the total number of six-minute observations used. 
Using $E_{i}$ is used as defined in Equations 7 to 10

$i$ refers to each mean wind speed observed during six minutes

$\mathbf{n}$ is the total number of six-minute observations used.

Using the value of $1 / 7$ for $k$, we calculated that 4.5 million $k$ Wh would have been produced during the six-month period and for a $k$ value measured between $A$ and $B, 3.7$ million $\mathrm{kWh}$ would have resulted.

A start-up time correction must be considered. As stated in section 5.2.4.2 of the referenced Boeing report, if the machine is stopped due to low wind speed and the wind increases to $14 \mathrm{mph}$, approximately 10 minutes are required to accelerate the rotor from zero to $8 \mathrm{rpm}$. Synchronous speed $(17.5 \mathrm{rpm})$ is first reached after 13 minutes. In the opposite case, if the machine is stopped because of strong winds and the wind speed dropped to $45 \mathrm{mph}$, one minute is required to go from zero to $8 \mathrm{rpm}$ and an additional minute is then needed to reach $17.5 \mathrm{rpm}$. These time lags were included in our computer analysis.

An additional correction should have been made for sudden changes in wind direction. The Boeing Report in Section 3.2.3 states that if the yaw error (difference between machine heading and wind direction measured by an anemometer above the nacelle) exceeds 20 degrees when averaged over a 2 -minute period, the machine is automatically shut down. We did not have the wind direction data needed for this. Consequently no account was taken of any yaw error.

We considered using wind speed and power from Clayton to help estimate the annual energy to be expected by a MOD-2. However, mean wind power does not correlate accurately with mean wind speed. Also, there may be a large number hours in the winter when the speed would have exceeded $45 \mathrm{mph}$. Consequently we felt an extrapolation contained too many uncertainties.

However, we feel certain that the MOD-2 would generate more electrical energy during the more windy six months from December to June than it did during the less windy six months of June to November. 


\section{Sample of Calculations}

Power Density

$$
\begin{aligned}
\frac{\text { Power }}{\text { Area }} & =\frac{\text { Watts }}{\mathrm{m}^{2}}=\frac{\mathrm{Nm} / \mathrm{s}}{\mathrm{m}^{2}}=\frac{\frac{1}{2} \rho \mathrm{F}^{3} \mathrm{~A}}{\mathrm{~m}^{2}}=\frac{1}{2} \rho \mathrm{V}^{3} \\
\text { use } \rho & =.918 \mathrm{~kg} / \mathrm{m}^{3} \\
V & =[.447 \mathrm{~V}(\mathrm{mph})] \mathrm{m} / \mathrm{s}
\end{aligned}
$$

Then

$$
\begin{aligned}
\frac{\text { Watts }}{\mathrm{m}^{2}} & =.5 \times .918 \times(.447 \mathrm{v})^{3}\left[\frac{\mathrm{kg}}{\mathrm{m}^{3}} \frac{\mathrm{m}^{3}}{\mathrm{~s}^{3}}\right] \\
\mathrm{kg} & =\mathrm{Ns}^{2} / \mathrm{m} \\
\frac{\text { Watts }}{\mathrm{m}^{2}} & =4.099 \times 10^{-3} \mathrm{v}^{3}(\mathrm{v} \text { is in } \mathrm{mph})
\end{aligned}
$$

\section{Energy Density}

$$
\begin{aligned}
& \frac{\text { Energy }}{\text { Area }}=\frac{\text { Power } \times \text { Time }}{\text { Area }}=\frac{\text { Watt sec }}{\mathrm{m}^{2}} \\
& \frac{\text { Watt sec }}{\mathrm{m}^{2}}=.5 \times .918 \times .0893 \mathrm{v}^{3} \times \text { time }(6 \mathrm{~min}) \\
& \frac{\mathrm{kwh}}{\mathrm{m}^{2}}=4.099 \times 10^{-6} \mathrm{v}^{3}(\mathrm{mph}) \times \text { Number of } 6 \mathrm{~min} \text { obs }
\end{aligned}
$$


APPENDIX G 


\section{APPENDIX G \\ ANALYSIS OF SELECTED WIND CONDITIONS}

\section{ANALYSIS OF SIERRA GRANDE WIND SUMMARIES}

Site A was located at $20 \mathrm{~m}$ on the peak of Sierra Grande. The direction data were no good until 6 November 1979, when a new vane was installed; even then the direction data is suspect; no east of southeast winds were recorded. The summary for the month of June shows $0.58 \%$ calm. Maximum for the month was $58.5 \mathrm{mph}$ on 19 June. July, August and September wind summaries all show less than $1 \%$ calm. Anemometer head blown off $10 / 30 / 79$, replaced $11 / 6 / 79$. Maximum wind recorded in a 6 -month period was $69.5 \mathrm{mph}$ on $11 / 26 / 79$. Anemometers at all sites iced up $10 / 30 / 79$ until $11 / 2 / 79$.

Site $B$ was located at $10 \mathrm{~m}$ on the peak of Sierra Grande. The directional data were no good until 6 November 1979, when a new vane was installed. The anemometer cups were blown off in the $11 / 26 / 79$ storm after a six minute average wind speed of $72 \mathrm{mph}$. The wind vane had blown off prior to $11 / 6 / 79$ probably during the $10 / 30 / 79$ storm. Maximum wind recorded was $72 \mathrm{mph}$ on $11 / 26 / 79$.

Site $C$ was located on $10-\mathrm{m}$ pole at the north position. The direction data were no good until 11/6/79. Maximum wind recorded was $72 \mathrm{mph}$ on 11/26/79.

Site $D$ was to the west side of the peak. The direction data were no good for the period of the test. We missed the last 30 days because of power not being turned on.

Site $E$ was the southern pole. The wind direction data were good for the first 3 weeks of June and then were bad throughout the rest of the test period. Maximum wind was $63.5 \mathrm{mph}$ on $11 / 26 / 79$. Anemometer blown off $10 / 30 / 79$, replaced $11 / 6 / 79$.

Site $F$ was the eastern location with as much wind speed average at its 10-m height as Site $\mathrm{A}$ with $20-\mathrm{m}$ height. It was the only site to have good wind direction data for the entire test period. Maximum wind recorded at Site $F$ was $58.5 \mathrm{mph}$ in July. During the $11 / 26 / 79$ storm the max wind was $\mathrm{SW} 44.5 \mathrm{mph}$. Anemometer head blown off $10 / 29 / 79$, replaced $11 / 6 / 79$. 
ANALYSIS OF WIND SPEED PERSISTENCE AND WIND GUST FACTOR

The wind gust factor is a measure of the intensity of gusts; it is given by the ratio of the total range of wind speed between gusts and the intermediate periods of lighter wind to the mean wind speed, averaged over both gusts and lulls.

Persistence in general is the tendency for the occurrence of a specific event to be more probable, at a given time, if the same event has occurred in the immediately preceding time period. In this presentation, $x(t)$ denotes the present value, and the value of persistence is $x(t-1)$. The wind direction data were not good enough in this test to present persistence as is often done as the ratio of the magnitude of the mean wind vector to the average speed of the wind without regard to direction.

The wind persistence data for the speed range 0-3 should be disregarded for October, November and December. The loss of anemometer cups and freeze-up of the cups biased the data. The usual persistence of 0.25 for all stations in the above months is assumed to be correct.

The wind gust factors show a diurnal trend in the summer months, particularly $A$ and $B$. After 1 oct. the diurnal trend is not evident.

A comparison of the gust factor of $A$ and $B$ shows that the gust factor is usually greater for $A$ at $20 \mathrm{~m}$ than for $B$ at $10 \mathrm{~m}$ for June; July is mixed but in August and September the gust factor is usually higher at the lower level. In October, Station B had the highest gust factor between 0-15 hours and then Station A from 16-23 hours. In November, the gusts were strongest at A.

Analysis of these and other wind data show that Station $F$ at the east site is an interesting case. For the period of test it had as high wind speed average at $10 \mathrm{~m}$ as Station $\mathrm{A}$ did at $20 \mathrm{~m}$. It was the only site with consistently good wind direction data, but the wind directions were highly variable even in strong wind conditions, showing the effects of turbulence of the wind deflected by the peak. Even with the variability of wind direction, it was not the gustiest site; Station $E$ at the south site had the highest gust factor for 
August through November with the max. gust factor of 1.519 recorded in October and 1.089 in November.

\section{ANALYSIS OF WIND FLOW OVER AN ISOLATED MOUNTAIN PEAK}

To investigate Wegley's hypothesis that maximum winds should be below a mountain peak tangent to the wind direction, fourteen cases of wind flow over Sierra Grande were analyzed.

These cases were chosen for interesting synoptic cases from June through November. Various wind directions were chosen to see the results of the flow patterns. The 0500 hours surface wind direction was used from Station $F$ even though in certain cases there was some deflection experienced from topographic effects (no deflections were noticed for a south wind). The 0500 MDT $500 \mathrm{mb}$. gradient flow was estimated from the Daily Weather Maps from the National Oceanic and Atmospheric Administration. The surface wind velocities analyzed were from 0500 daily. Sierra Grande has a nocturnal wind maximum between sunset and sunrise so the winds at 0500 were usually substantial. Even though various directions were chosen, the sample is biased by nine south flow cases.

Station $F$ on the east side was in a saddle below a minor peak 200 meters to the east of it. The 10-m pole was essentially even with the highest point of the eastern peak. Site F's mean wind speed at $10 \mathrm{~m}$ for the period of the test was the same as that of site $A$ at $20 \mathrm{~m}$. This venturi effect increased the wind flow at Site $F$ and masked the effects expected on a symmetrical mountain. If it is assumed that the wind speed at Site $F$ is essentially the same as Site $D$ (west) and Site $E$ (south) under most conditions, (it was a large majority of the time for $D$ and $E$ ) then the following typical pattern emerged: 
FIGURE G1

Typical Composite Wind Pattern

Site C

$35 \mathrm{mph}$

Site A

Site D

$23 \mathrm{mph}$

$35.5 \mathrm{mph}$

Site B

$32.5 \mathrm{mph}$

Site E

$23 \mathrm{mph}$

$\uparrow$

WIND DIRECTION
Site F

$23 \mathrm{mph}$

The results tend to show that the maximum extends from the peak down to the downwind site, not tangential to the flow.

Of the fourteen cases used, two cases showed the maximum at the peak only; one showed the maximum skewed to the left of the wind but from the peak down wind; one showed the maximum upwind of the peak, it was triangular with two lower sites and the peak showing the same velocities; ten cases showed the maximum from the peak to the downwind site. 


\section{DISTRIBUTION}

No. of

Copies

OFFSITE

A. A. Churm

DOE Chicago Patent Group

$9800 \mathrm{~S}$. Cass Avenue

Argonne, IL 60439

5 D. F. Ancona/C. I. Aspliden

Department of Energy

600 E. Street, N.W.

Washington, DC 20545

5 G. P. Tennyson

Department of Energy

Albuquerque Operations office 4501 Indian School Road N.E.

Suite 151

Albuquerque, NM 87110

F. R. Summers, P.E.

U.S. Department of Energy

Alaska Power Administration

P.0. Box 50

Juneau, AK 99802

27 DOE Technical Information Center

Peter Lissaman

Aerovironment, Inc.

145 Vista Avenue

Pasadena, CA 91107

W. A. Vachon

Arthur D. Little, Inc.

20 Acorn Park

Cambridge, MA 02140

Peter Smeallie

AWEA Windletter

1609 Connecticut Avenue N.W.

Washington, DC 20008

American Wind Energy Association

1621 Connecticut Avenue, N.W.

Fifth Floor

Washington, DC 20009
No. of

Copies
Richard Katzenberg

American Wind Energy Association

Natural Power, Inc.

New Boston, NH 03070

Nicholas Butler

Bonneville Power Administration

P.0. Box 3261-EIC

Portland, OR 97208

M. Ginosar/J. Lerner

California Solar Energy Commission

Energy Resources, Conservation and Development Commission

1111 Howe Avenue, Mai1 Stop 15

Sacramento, CA 95825

R. N. Meroney

Department of Civil Engineering

Colorado State University

Fort Collins, CO 80523

E. H. Gilmore

Department of Agriculture

Agriculture Research Service

Bushland, TX 79012

L. A. Liljedah1

Department. of Agriculture

Agriculture Wind Energy Program

Building 001 , Room 126 BARC-West

Beltsville, MD 20705

Jay Tappan

Department of Energy

State of Oregon

Labor and Industries Building

Room 111

Salem, OR 98310

4 Frank Goodman, Jr.

Electric Power Research Institute

P.0. Box 10412

Palo Alto, CA 94025 
No. of

Copies

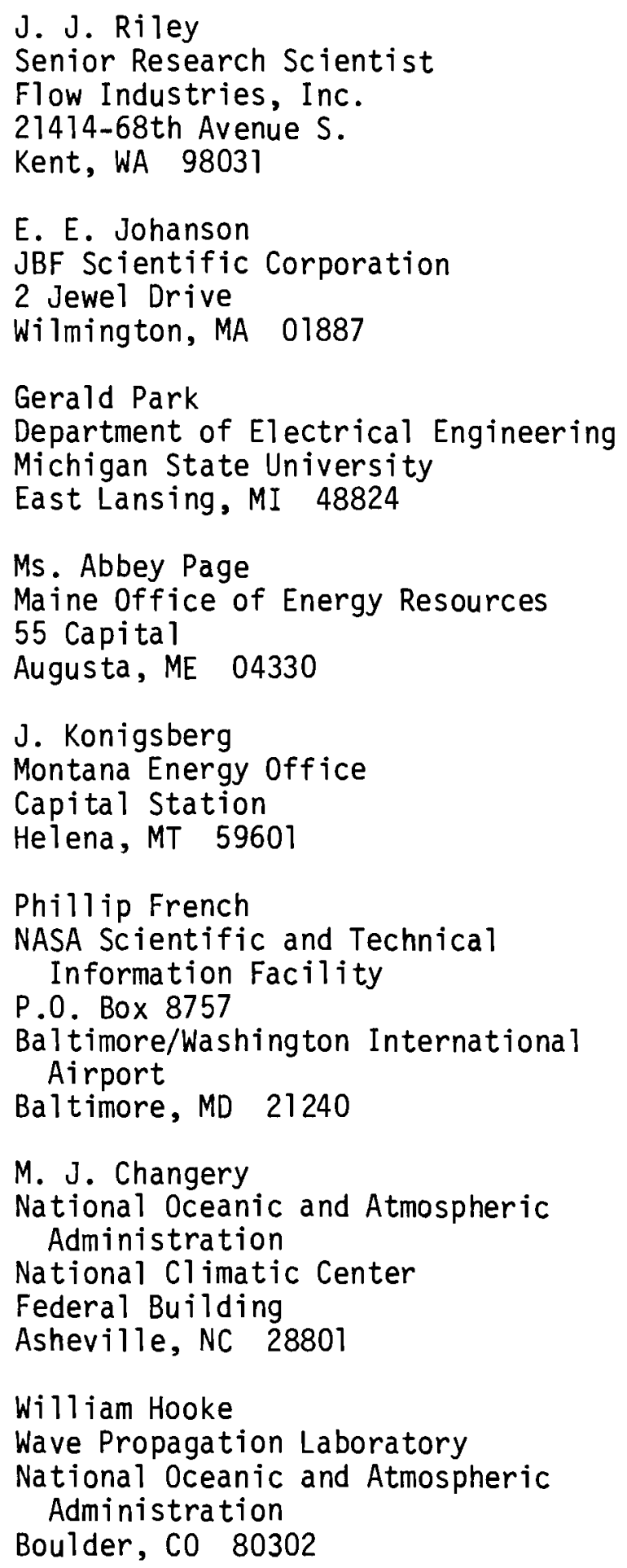

No. of

Copies

E. W. Hewson/J. E. Wade Oregon State University Corvallis, OR 97331

2 R. L. Simon

Pacific Gas and Electric 215 Market Street

San Francisco, CA 94106

E. L. Luther PRC Eng. Analysis Co. 0ld Springhouse Road McLean, VA 22102

Terry J. Hea ly/C. Hansen Rockwell International Rocky Flats Plant P.0. Box 464 Golden, CO 80401

E. Kadlec Sandia Laboratories Division 5443

P. 0. Box 5800

Aibuquerque, NM 87115

R. M. Traci

Science Applications, Inc. 1200 Prospect Street

P.0. Box 2351

La Jolla, CA 92038

I. Vas

Solar Energy Research Institute 1536 Cole Blvd. Golden, C0 80401

C. M. Bhumralkar SRI International 333 Ravenswood Avenue Menlo Park, CA 94205

\section{W. Owens}

Tennessee Valley Authority 426 United Bank Building Chattanooga, TN 37401 
No. of

Copies

Thomas A. Schroeder University of Hawai at Monoa 2525 Correa Road Honolulu, HI 96822

R. A. Pielke University of Virginia Department of Environmental Sciences Clark Hall

Charlottesville, VA 22903

Ms. Susan Hosch Washington State Energy Office 400 E. Union Avenue, ist Floor 01 ympia, WA 98504

L. L. Nelson

U.S. Water \& Power Resource Service Denver Federal Center, Bldg. 20

Denver, CO 80225

G. D. Thomann

Wichita State University

P.0. Box 44

Wichita, KS 67208

Farrell Smith Seiler

Wind Energy Report

Box 14 - 104 X. Village Avenue

Rockville Centre, NY 11571

R. W. Marrs

University of Wyoming

Department of Geology

Laramie, WY 82071
No. of

Copies

ONSITE

1 DOE Richland Operations Office P.0. Box 550

Richland, WA 99352

H. E. Ransom

44 Pacific Northwest Laboratory

Battelle BouTevard

Richland, WA 99352

W. R. Barchet

J. C. Barnard

J. W. Buck

J. R. Connell

J. C. Doran

K. Drumheller

C. E. Elderkin

D. L. Elliott

R. L. George

D. L. Hadley

T. R. Hiester

V. K. Hopkins (15)

A. H. Miller

E. L. Owzarski

W. T. Pennell

D. C. Powell

J. V. Ramsdell

D. S. Renne

H. L. Wegley

L. L. Wendel 1

R. K. Woodruff

R. Zengerle

Technical Information - Library (5)

Publishing Coordination (2) 


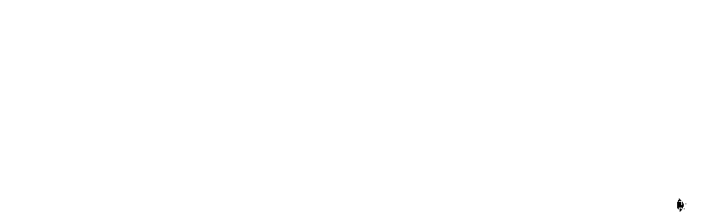

